Cesium Sorption and Desorption on

Selected Los Alamos Soils

K. Stephen Kung

Joe Chan

Pat Longmire

Malcolm Fowler

DSTRBDION OF THS DOCUENT IS UNMITED 


\section{DISCLAIMER}

This report was prepared as an account of work sponsored by an agency of the United States Government. Neither the United States Government nor any agency thereof, nor any of their employees, make any warranty, express or implied, or assumes any legal liability or responsibility for the accuracy, completeness, or usefulness of any information, apparatus, product, or process disclosed, or represents that its use would not infringe privately owned rights. Reference herein to any specific commercial product, process, or service by trade name, trademark, manufacturer, or otherwise does not necessarily constitute or imply its endorsement, recommendation, or favoring by the United States Government or any agency thereof. The views and opinions of authors expressed herein do not necessarily state or reflect those of the United States Government or any agency thereof. 


\section{DISCLAIMER}

Portions of this document may be illegible in electronic image products. Images are produced from the best available original document. 


\section{Table of Contents}

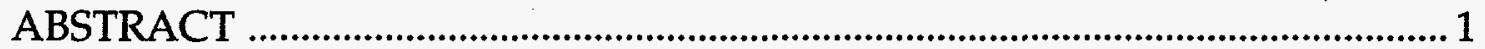

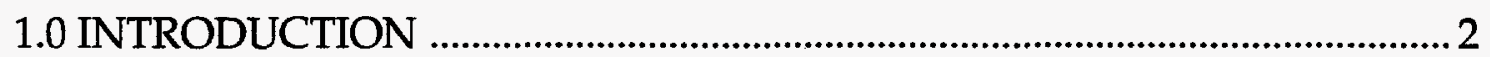

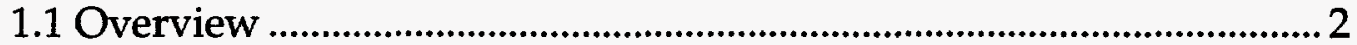

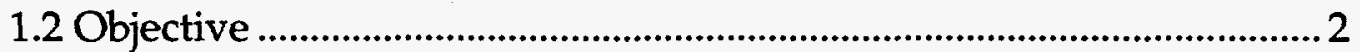

2.0 EXPERIMENTAL DESIGN AND PROCEDURES ......................................... 2

2.1 Soil Sample Sites and Soil Characterization ............................................. 2

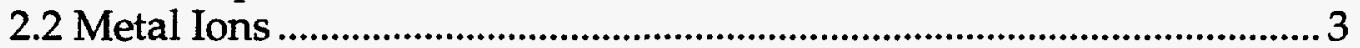

2.3 General Procedure .....................................................................................

2.4 Detailed Experimental Procedures .................................................................. 3

2.5 Chemical Analysis Method........................................................................... 4

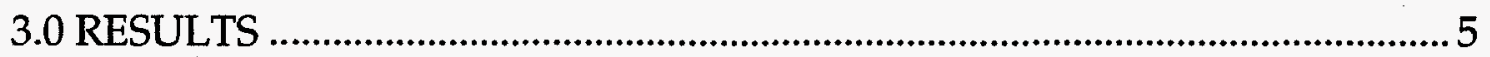

3.1 Cesium sorption by Los Alamos Soils...................................................... 5

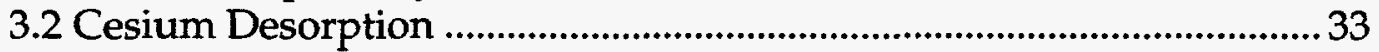

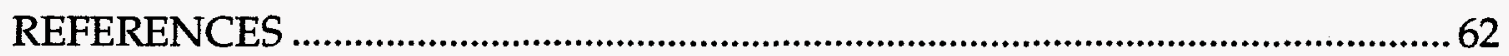

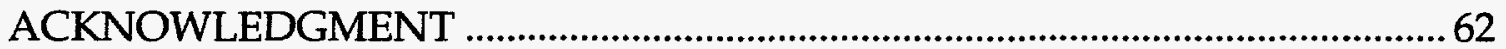




\title{
CESIUM SORPTION AND DESORPTION ON SELECTED LOS ALAMOS SOILS
}

by

K. Stephen Kung, Joe Chan, Pat Longmire, and Malcolm Fowler

\begin{abstract}
Laboratory experiments were conducted to evaluate the sorptivity of cesium onto Los Alamos soils under controlled experimental conditions. Four soil profiles were collected and each soil profile which is broken into layers according to previously identified soil horizons were studied. Batch sorption isotherms were studied to quantify the chemical reactivity of each soil horizon toward cesium ion. Radioactive cesium-137 was used as sorbent and gamma counting was used to quantify the amount of sorption. Desorption experiments were conducted after the sorption experiments. Batch desorption isotherms were studied to quantify the desorption of presorbed cesium from these Los Alamos soils.

Results suggest that cesium sorbs strongly on all soil samples. On a weight basis, Ancho Canyon soil profile was the most sorptive soil sample, whereas lower Los Alamos Canyon soil profile was the least sorptive soil material. For a given soil profile, B horizons have a higher sorptivity than those of A horizons. For Ancho Canyon soil profile, the sorption of $\mathrm{Cs}$ follows the order: $\mathrm{Bt}$ $(13-20) \geq B t k b(44-54) \geq B w k b(20-44)>A(0-13)$, where the sampling depth, in $\mathrm{cm}$, are indicated in parentheses. For EG\&G soil profile, the sorption of Cs follows the order: Bwb (180-250) > Bw $(42-70) \geq \mathrm{Bt}(15-42) \geq \mathrm{CB}(70-120) \geq \mathrm{A}(0-15)$. For upper Los Alamos Canyon valley site, cesium sorption follows: Buried A layer $>$ colluvium layer $>$ A layer. For road site of upper Los Alamos Canyon soils, all three layers have similar Cs sorptivity. For lower Los Alamos Canyon soils, cesium sorption follows: C (10-25) > A $(0-10)>$ valley washout. From sorption isotherm, the cesium sorption $\mathrm{Kd}$ for each soil sample was calculated.

For the desorption experiments, less than $1 \%$ of the presorbed cesium was desorbed from Ancho Canyon soils and most EG\&G soils. About 1-3\% of cesium was found desorbed from upper Los Alamos Canyon soils and about $3-6 \%$ of cesium was found desorbed from lower Los Alamos Canyon soils. Desorption isotherms for all soil samples are also presented in this report.

This study suggests cesium may sorb strongly and irreversibly on most Los Alamos soils. The amount of cesium sorption and desorption is possibly related to the clay content of the soil sample since subsurface sample has a higher clay content than that of surface sample.
\end{abstract}




\subsection{INTRODUCTION}

\subsection{Overview}

Cesium-137 is a nuclear fission product. Its presence in soil is due to nuclear testing such as aboveground thermonuclear tests, nuclear accidents (such as Chernobyl), and leaks from cooling water of nuclear reactors at nuclear power plants. The migration of Cs-137 in surface soil is important to environmental assessment since surface soils have a close relation to human life. In order to conduct a risk assessment and remediation strategy, the distribution coefficient must be measured.

Cesium is very soluble in water. However, its mobility in natural environments is believed to be retarded by its strong interaction with soil minerals. Although sorption of cesium on soil materials has been studied, the desorption process is seldom studied. Also, the sorption process is usually studied using the whole soil and relatively high dissolved cesium concentration.

The goal of this work is to develop specific laboratory experiments to characterize the cesium sorptivity for Los Alamos soils. This study will emphasize on the quantification of the reactivity of Los Alamos soils under controlled laboratory conditions. Batch sorption and desorption isotherms were used to quantify the amount of cesium that was retained onto the soils. Since cesium-137 emits a strong gamma ray, relatively low cesium equilibrium concentrations $\left(10^{-10} \mathrm{M}\right)$ were studied.

\subsection{Objective}

The objective of this laboratory experiment is to quantify the cesium sorptivity of Los Alamos soils under a controlled environment in the laboratory. The purposes of this work are to determine Cs sorption coefficient for Los Alamos Soils and to evaluate the potential transport of cesium. Based on this information, a risk assessment and remediation strategy can be developed.

\subsection{EXPERIMENTAL DESIGN AND PROCEDURES}

\subsection{Soil Sample Sites and Soil Characterization}

Soil samples were collected during summer of 1994. Soil profiles from four different locations (upper Los Alamos Canyon site, lower Los Alamos Canyon site, EG\&G site, and Ancho Canyon site) were collected. All surface and subsurface soils were sampled. Each soil profile has been broken into layers according to identified soil horizons. These soils have been considered as background soil of Los Alamos area; a detailed information of these soils was reported in Longmire et al. $(1993,1994)$. Soil samples were collected at the same profiles or close to the soil profiles that were described in the background soil report. Collected soil samples were air-dried in the laboratory and stored after passing through a $2 \mathrm{~mm}$ sieve.

Upper Los Alamos Canyon Sites. Upper Los Alamos Canyon sites are located on both sides of Los Alamos Reservoir Road, approximately 200 feet west of West Road. Two soil sample sites, road site and valley site, were collected in this area. The road site is near the cliff south of Reservoir Road, and the valley site is in the valley floor north of the stream. Three distinct soil layers were sampled for each 
site. For road site, A horizon $(0-22 \mathrm{~cm}), B A$ horizon $(22-60 \mathrm{~cm})$, and $B w$ horizon $(60-80 \mathrm{~cm})$, were collected. For valley site, $A$ horizon, colluvium horizon, and buried A horizon, were collected.

EGEG Site. EG\&G site is located in the south gully of State Road 502, across from EG\& $G$ buildings. Five horizons, A horizon $(0-15 \mathrm{~cm})$, Bt horizon (15-42 $\mathrm{cm}), B w$ horizon $(42-70 \mathrm{~cm}), C B$ horizon $(70-120 \mathrm{~cm})$, and $B w b$ horizon (180-250 $\mathrm{cm})$, were collected.

Lower Los Alamos Canyon Sites. Lower Los Alamos Canyon sites are located west of State Road 4, near Tsankawi ruins. Two soil sample sites, stream washout site and gully site, were collected in this area. Two horizons, A horizon (0-10 $\mathrm{cm}$ ), and C horizon (10-25 cm), were collected in gully site. Surface soil at the stream washout of the valley floor was also collected.

Ancho Canyon Site. Ancho Canyon site is located at the Ancho Canyon Mesas, on the west side of State Road 4. Four horizons, A horizon $(0-13 \mathrm{~cm}), \mathrm{Bt}$ horizon $(13-20 \mathrm{~cm})$, Bwkb horizon $(20-44 \mathrm{~cm})$, and Btkb horizon $(44-54 \mathrm{~cm})$, were collected. A whole soil sample at a nearby profile from $0-40 \mathrm{~cm}$ was also collected.

\subsection{Metal Ions}

Cesium. Radioisotope cesium-137 obtained from DuPont was used as sorbent in the sorption experiments. This material was used with no further purification. According to the manufacturer, it does not contain any nonradioactive Cs as carrier. Desired concentration of the material was diluted and prepared in $0.01 \mathrm{M}$ $\mathrm{KCl}$ solution.

\subsection{General Procedure}

Batch sorption isotherm was used to quantify the chemical reactivity of Los Alamos soil samples to cesium under controlled experimental conditions. Batch sorption experiments involve selecting a soil sample, adding a solution containing known cesium concentration, mixing the solution and the soil in a container, separating the soil form the suspension, and determining the amount of cesium in the solution phase. At least four initial solution concentrations, 5.2, $8.3,25.6$, and $42.5 \times 10^{-10} \mathrm{M}$, were used to generate a sorption isotherm. Cesium137 solution was used as tracer. For all the solutions, $0.01 \mathrm{M} \mathrm{KCl}$ was used as a background electrolyte to remain an essentially constant ionic strength.

\subsection{Detailed Experimental Procedures \\ Batch Sorption Experiment.}

1. Determine the weight of clean centrifuge tube.

2. Weigh two grams of the dried soil sample into a clean centrifuge tube.

3. Weigh the tube with soil sample.

4. Add $20 \mathrm{ml}$ of solution which contains a known concentration of Cs-137 ions.

5. Weigh the tube after addition of the solution.

6. Seal the tube and mix the phases on a shaker for at least 72 hours. 
7. Centrifuge the mixture for 10 minutes at speed of $5,000 \mathrm{rpm}$. Swirl the tube at upright position to remove solid from the tube side walls. Centrifuge again for 30 minutes at speed of $10,000 \mathrm{rpm}$. Swirl the tube again. Centrifuge the final suspension for 60 minutes at a minimum speed of $12,000 \mathrm{rpm}$.

8. Separate the phases by carefully pouring all the solution out to a clean tube.

9. Centrifuge again for 60 minutes at a minimum speed of $12,000 \mathrm{rpm}$. Separate the phases by carefully pouring the all solution out to a clean tube.

10. Centrifuge again for 60 minutes at a minimum speed of $12,000 \mathrm{rpm}$. Pipette at least $10 \mathrm{ml}$ of the supernatant to a clean tube. Centrifuge again for 60 minutes at a minimum speed of $12,000 \mathrm{rpm}$.

11. Transfer $5 \mathrm{ml}$ to analyze the Cs concentration left in the supernatant solution by gamma spectrometry.

12. Determine the amount of sorption by subtracting the final solution concentration out of the initial concentration.

13. Plot the sorption isotherms.

14. Determine the sorption coefficient.

Batch Desorption Experiment.

1. Add $20 \mathrm{ml}$ of $0.01 \mathrm{M} \mathrm{KCl}$ solution into centrifuge tube left from step 9 , the second run of separation, in sorption experiment.

2. Swirl the tube and carefully pour all solution out to the centrifuge tube left from step 7, the first run, in sorption experiment.

3. Seal the tube and mix the phases on a shaker for at least 72 hours.

4. Centrifuge the mixture for 10 minutes at speed of 5,000 rpm. Swirl the tube at upright position to remove solid from the tube side walls. Centrifuge again for 30 minutes at speed of 10,000 rpm. Swirl the tube again. Centrifuge the final suspension for 60 minutes at a minimum speed of 12,000 rpm. .

5. Separate the phases by carefully pouring all the solution out to a clean tube.

6. Centrifuge again for 60 minutes at a minimum speed of $12,000 \mathrm{rpm}$. Separate the phases by carefully pouring the all solution out to a clean tube.

7. Centrifuge again for 60 minutes at a minimum speed of $12,000 \mathrm{rpm}$. Pipette at least $10 \mathrm{ml}$ of the supernatant to a clean tube. Centrifuge again for 60 minutes at a minimum speed of $12,000 \mathrm{rpm}$.

8. Transfer $5 \mathrm{ml}$ to analyze the Cs concentration left in the supernatants by gamma spectrometry.

9. Determine the amount of desorption from the final solution concentration.

10. Plot the sorption isotherms.

11. Determine the sorption coefficient.

\subsection{Chemical Analysis Method}

Cesium. Radioisotope cesium-137 was analyzed by gamma spectrometry at the counting room of the nuclear chemistry facility (TA-48, RC-1) with sodium iodide and/or germanium detector using $661 \mathrm{keV}$ energy. 


\subsection{RESULTS}

\subsection{Cesium sorption by Los Alamos Soils}

The sorption isotherms of Cs-137 by different soil profile were studied.

Results were plotted for each horizon of the soil profile. In these figures, the amount of cesium sorption (in mole per gram of soil) onto a given soil sample is plotted as a function of the equilibrium cesium concentration (in mole per liter) of the cesium solution. The slope of the isotherm is the sorption coefficient (in liter per gram) of cesium in the soil sample.

Sorption results suggest that cesium sorbs strongly on all soil samples. On a weight basis, the Ancho Canyon soil profile was the most sorptive soil sample, whereas lower Los Alamos Canyon soil profile was the least sorptive soil material. For a given soil profile, B horizons have higher sorptivity than those of A horizons. For Ancho Canyon soil profile, the sorption of $\mathrm{Cs}$ follows the order: Bt (13-20) $\geq$ Btkb (44-54) $\geq$ Bwkb (20-44) > A (0-13), where the sampling depth, in $\mathrm{cm}$, are indicated in parentheses. For EG\&G soil profile, the sorption of Cs follows the order: Bwb (180-250) > Bw (42-70) $\geq \mathrm{Bt}(15-42) \geq \mathrm{CB}(70-120) \geq \mathrm{A}(0-$ 15). For upper Los Alamos Canyon valley site, cesium sorption follows: Buried $A$ layer $>$ colluvium layer $>$ A layer. For road site of upper Los Alamos Canyon soils, all three layers have similar Cs sorptivity. For lower Los Alamos Canyon soils, cesium sorption follows: $C(10-25)>A(0-10)>$ valley washout. From sorption isotherm, the cesium sorption $\mathrm{Kd}$ for each soil sample was calculated. Each soil sample was plotted in the following figures. 
Upper Los Alamos Canyon. Sorption isotherm of Cs on A Layer soil sample of upper Los Alamos Canyon Site. Cesium sorption coefficient is calculated as 65.7 (in $\mathrm{ml}$ per $\mathrm{g}$ ) for this soil sample.

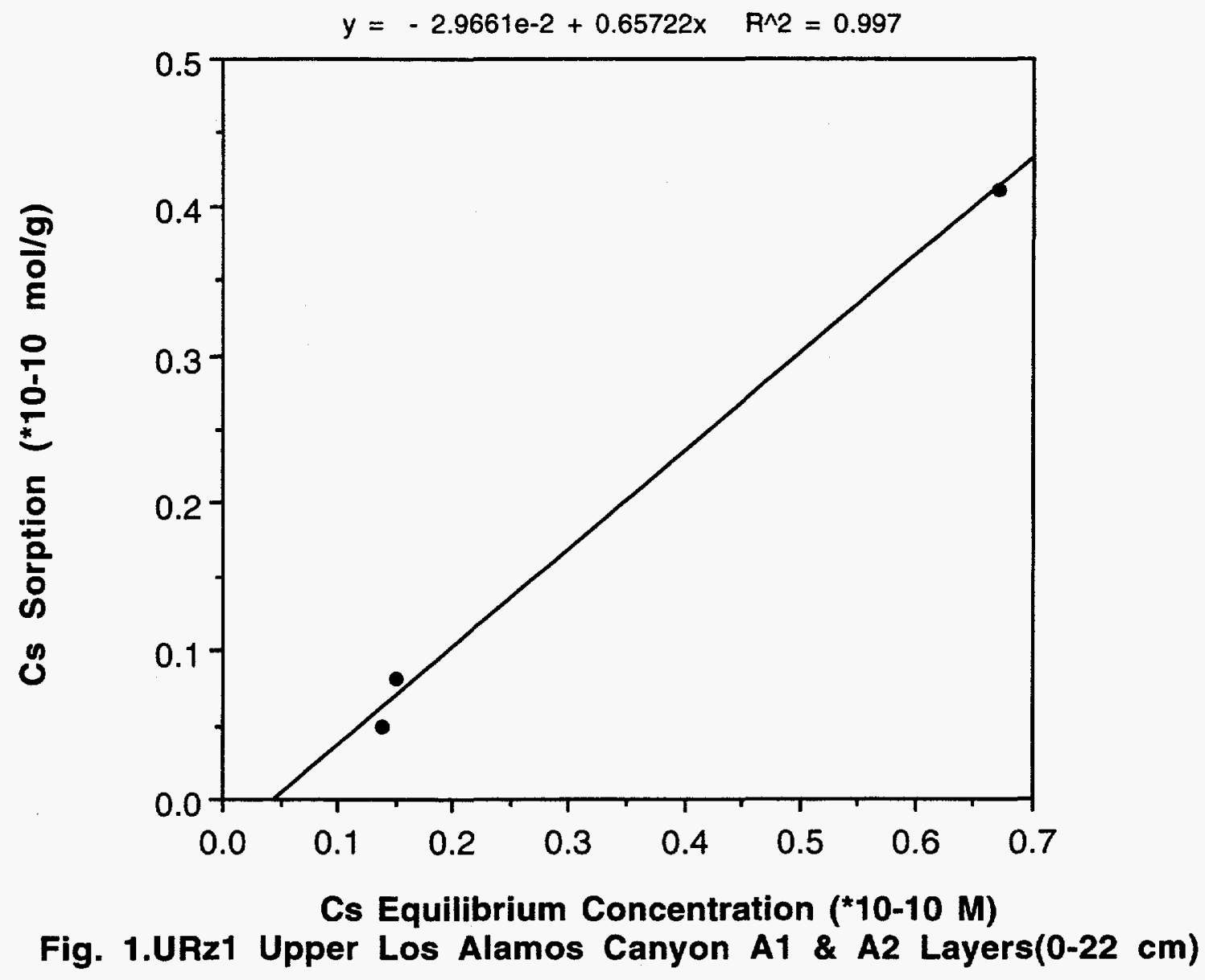


Sorption isotherm of Cs on BA Layer soil sample of upper Los Alamos Canyon Site. Cesium sorption coefficient is calculated as 77.4 (in $\mathrm{ml} \mathrm{per} \mathrm{g}$ ) for this soil sample.

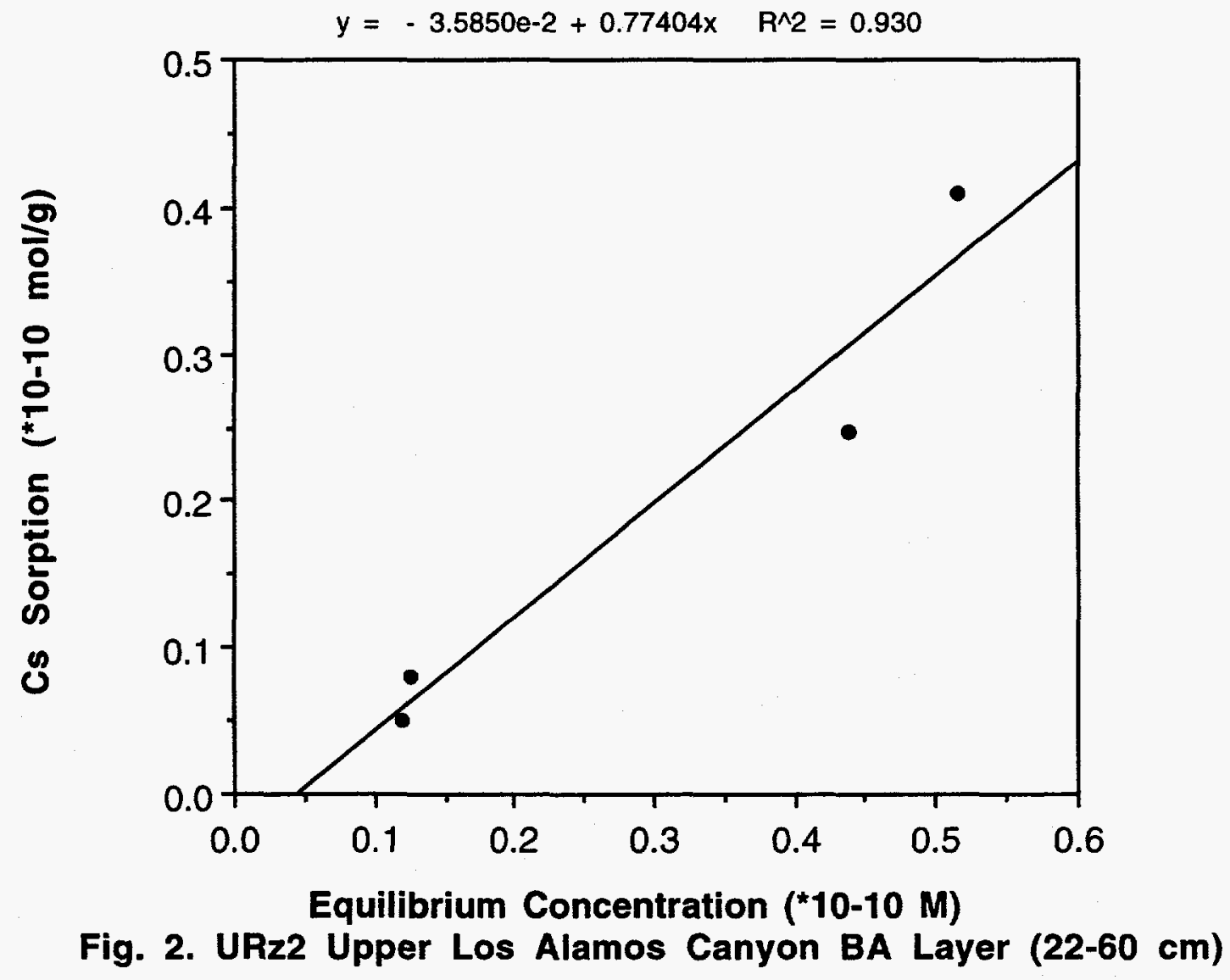


Sorption isotherm of Cs on Bw Layer soil sample of upper Los Alamos Canyon Site. Cesium sorption coefficient is calculated as 71.6 (in $\mathrm{ml} \mathrm{per} \mathrm{g}$ ) for this soil sample.

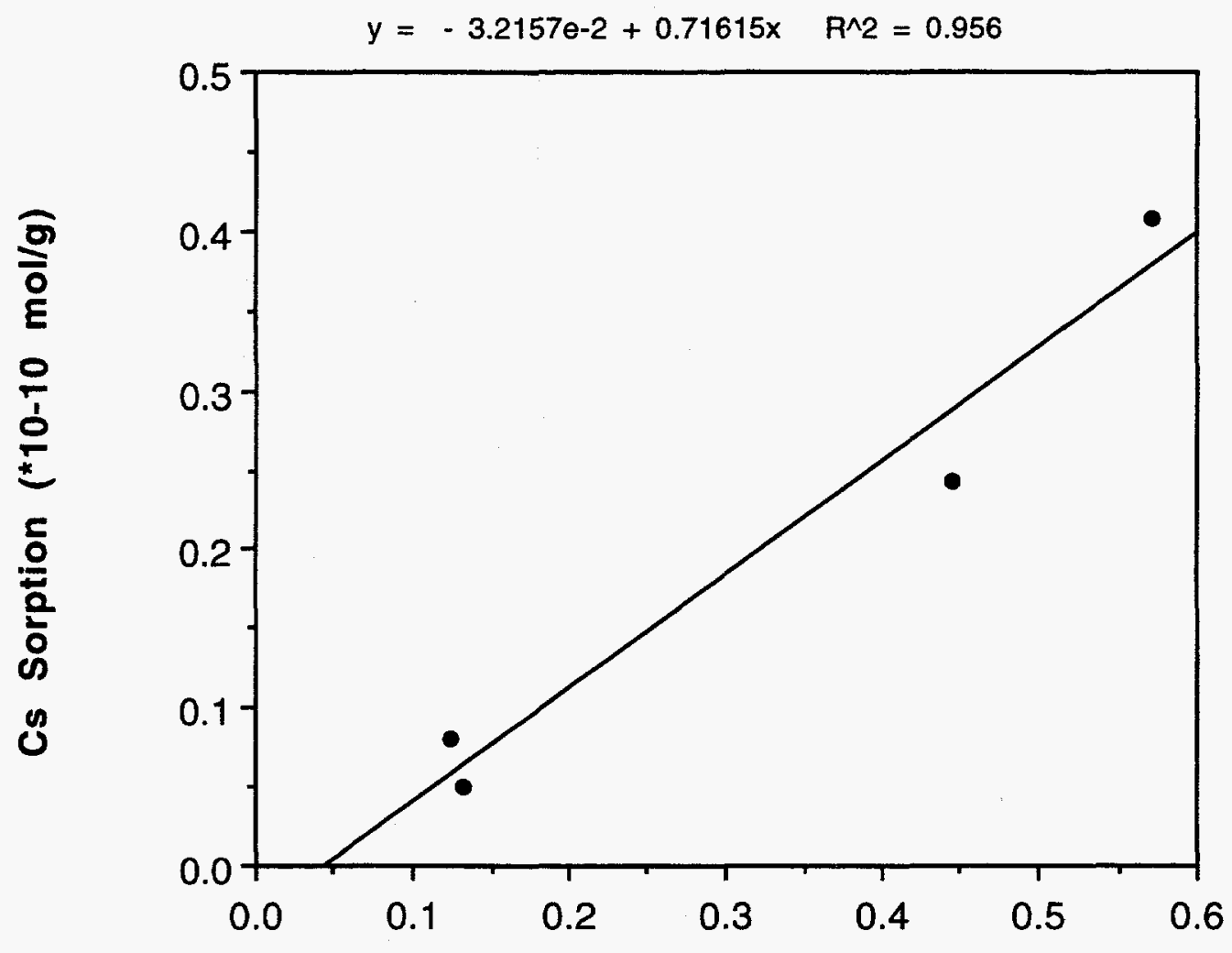

Equilibrium Concentration $\left({ }^{*} 10-10 \mathrm{M}\right)$

Fig. 3. URz3 Upper Los Alamos Canyon Bw Layer $(60-80 \mathrm{~cm})$ 
Site.

Sorption isotherms of Cs on soil samples of upper Los Alamos Canyon

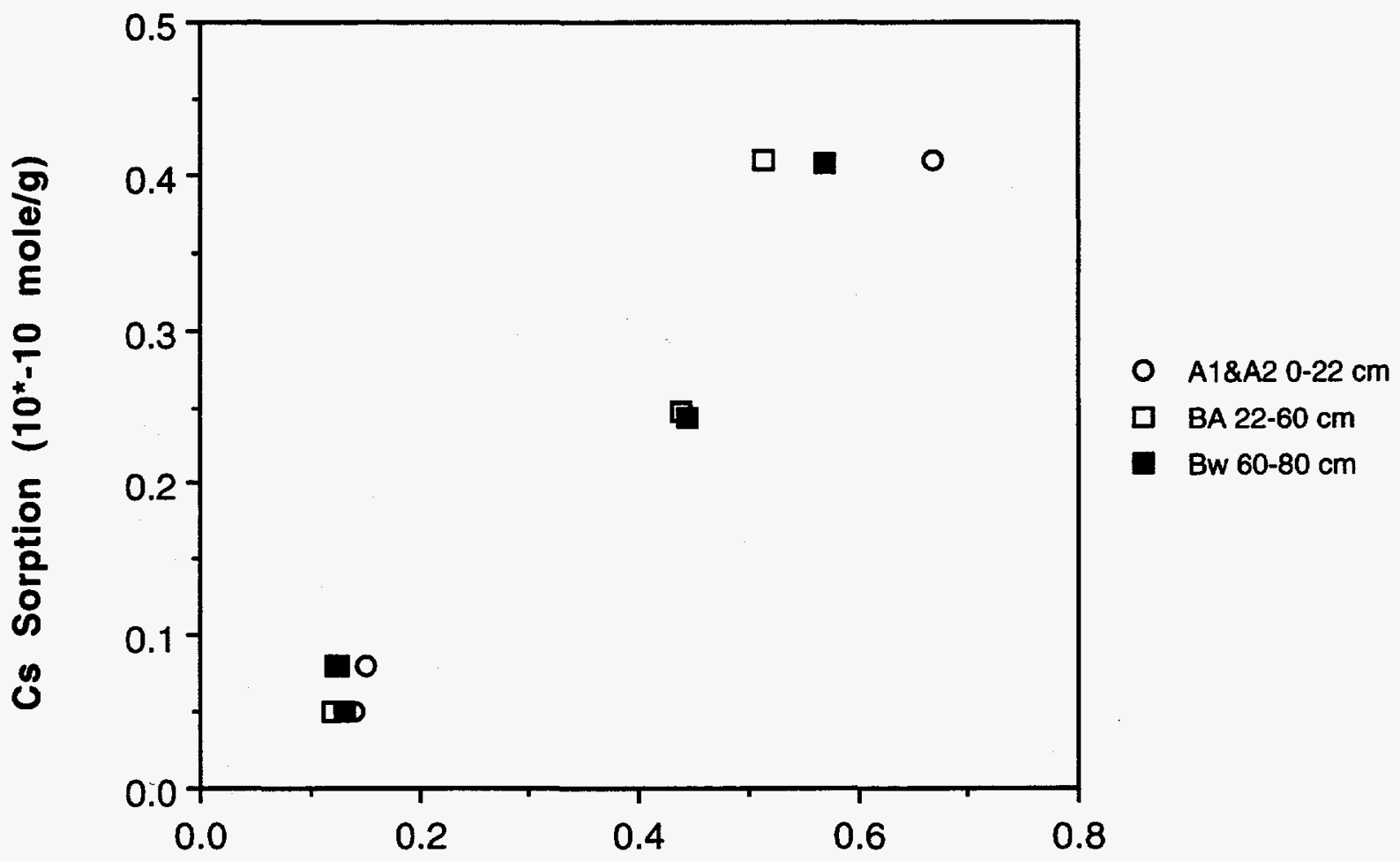

Equilibrium Concentration ( $\left.{ }^{*} 10-10 \mathrm{M}\right)$

Fig. 4. Upper Los Alamos Canyon Site Soil Layers 
Sorption isotherm of $\mathrm{Cs}$ on valley A Layer soil sample of upper Los Alamos Canyon Site. Cesium sorption coefficient is calculated as 32.3 (in $\mathrm{ml}$ per g) for this soil sample.

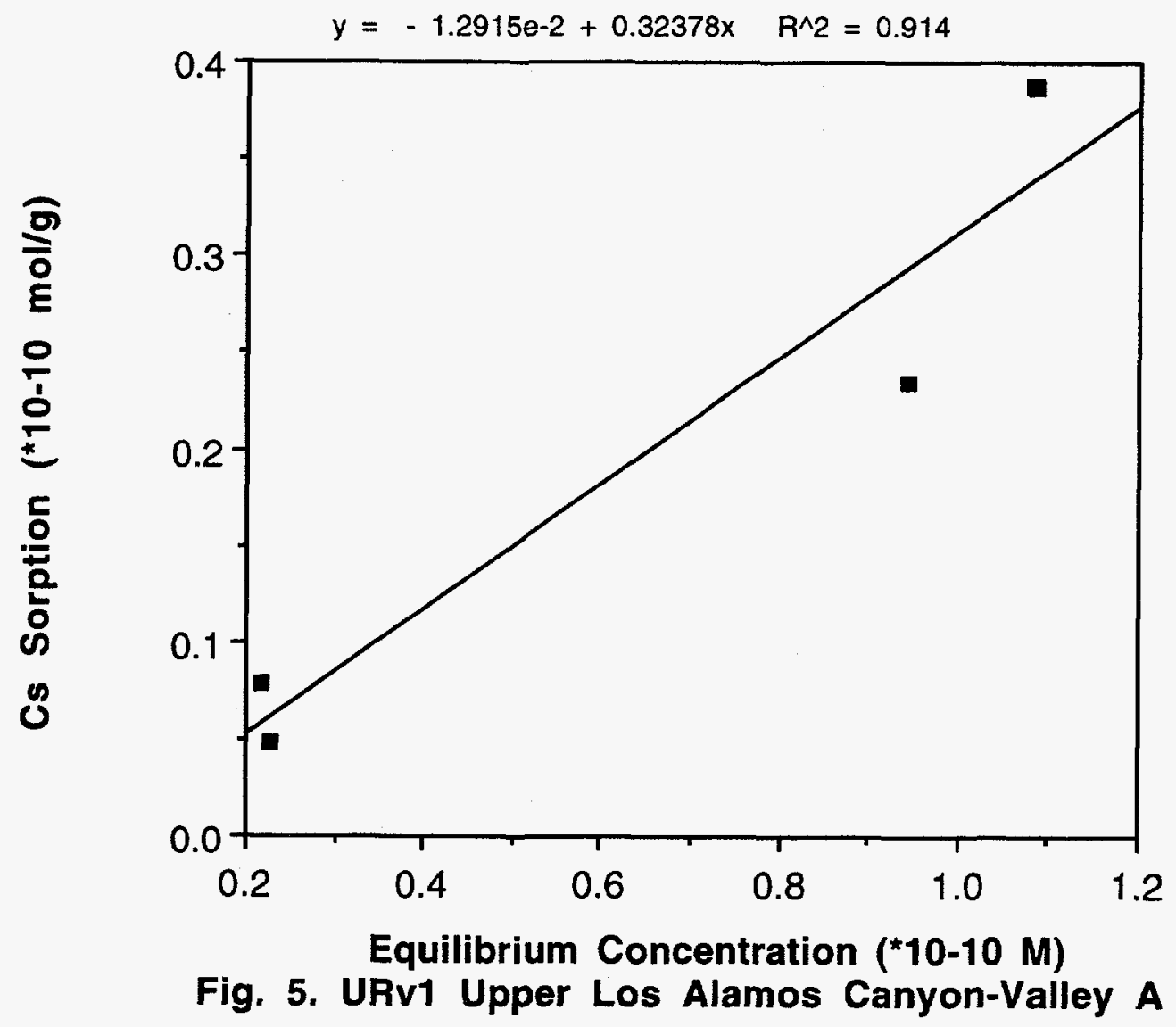


Sorption isotherm of Cs on valley colluvium Layer soil sample of upper Los Alamos Canyon Site. Cesium sorption coefficient is calculated as 47.1 (in $\mathrm{ml}$ per $\mathrm{g}$ ) for this soil sample.

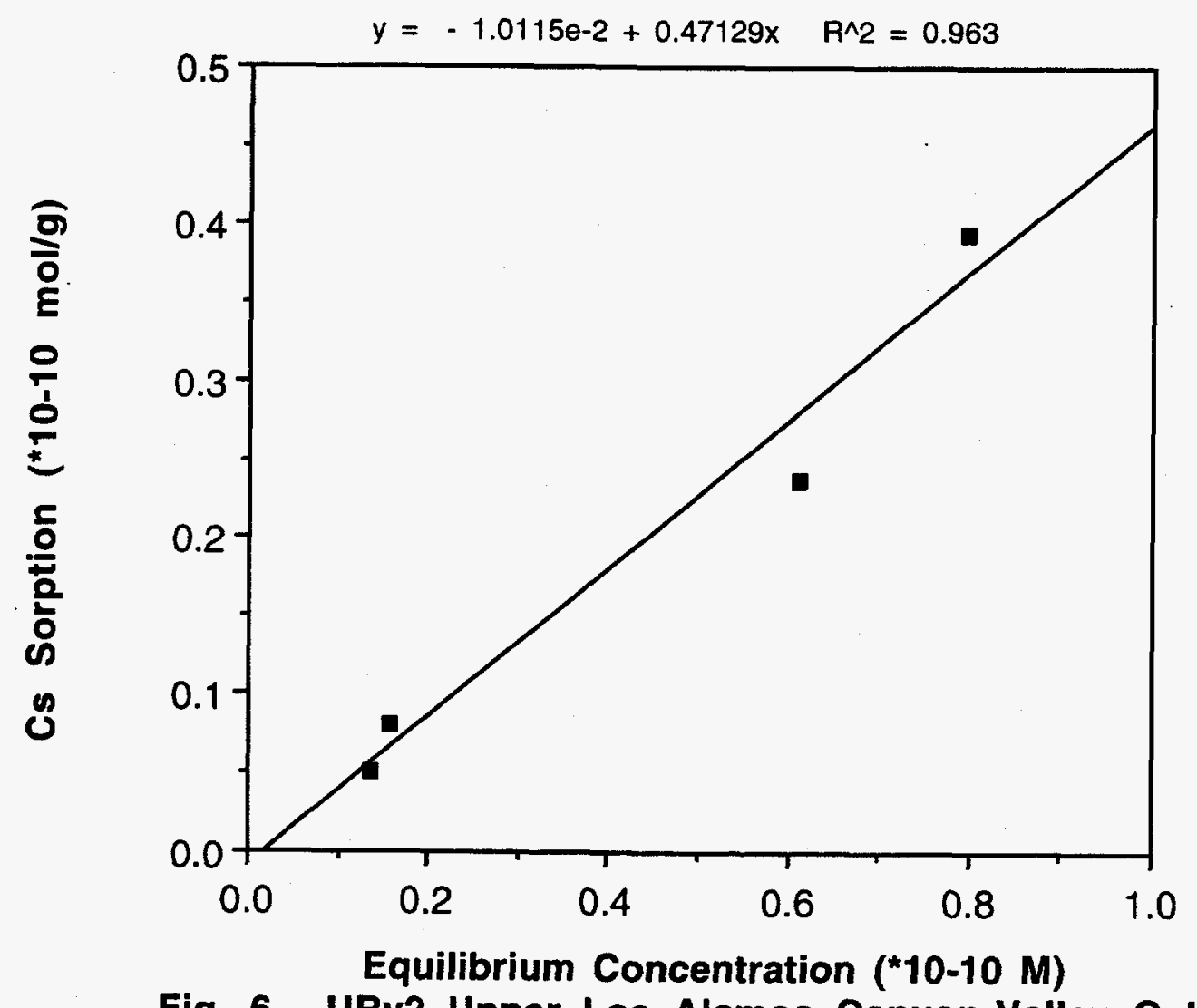

Fig. 6. URv2 Upper Los Alamos Canyon-Valley Colluvium 
Sorption isotherm of Cs on valley buried A Layer soil sample of upper Los Alamos Canyon Site. Cesium sorption coefficient is calculated as 76.9 (in ml per g) for this soil sample.

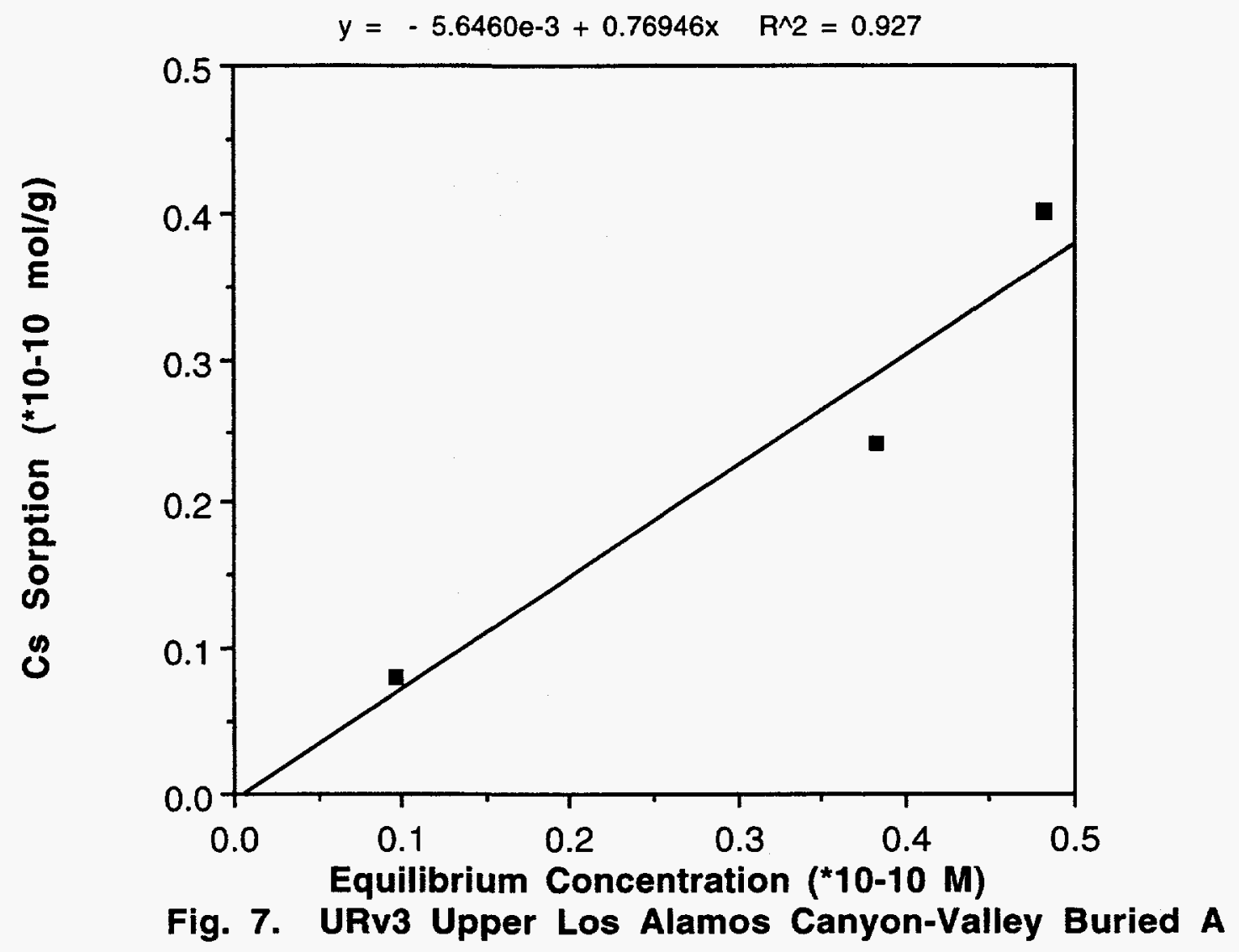


Site.

Sorption isotherms of Cs on soil samples of upper Los Alamos Canyon

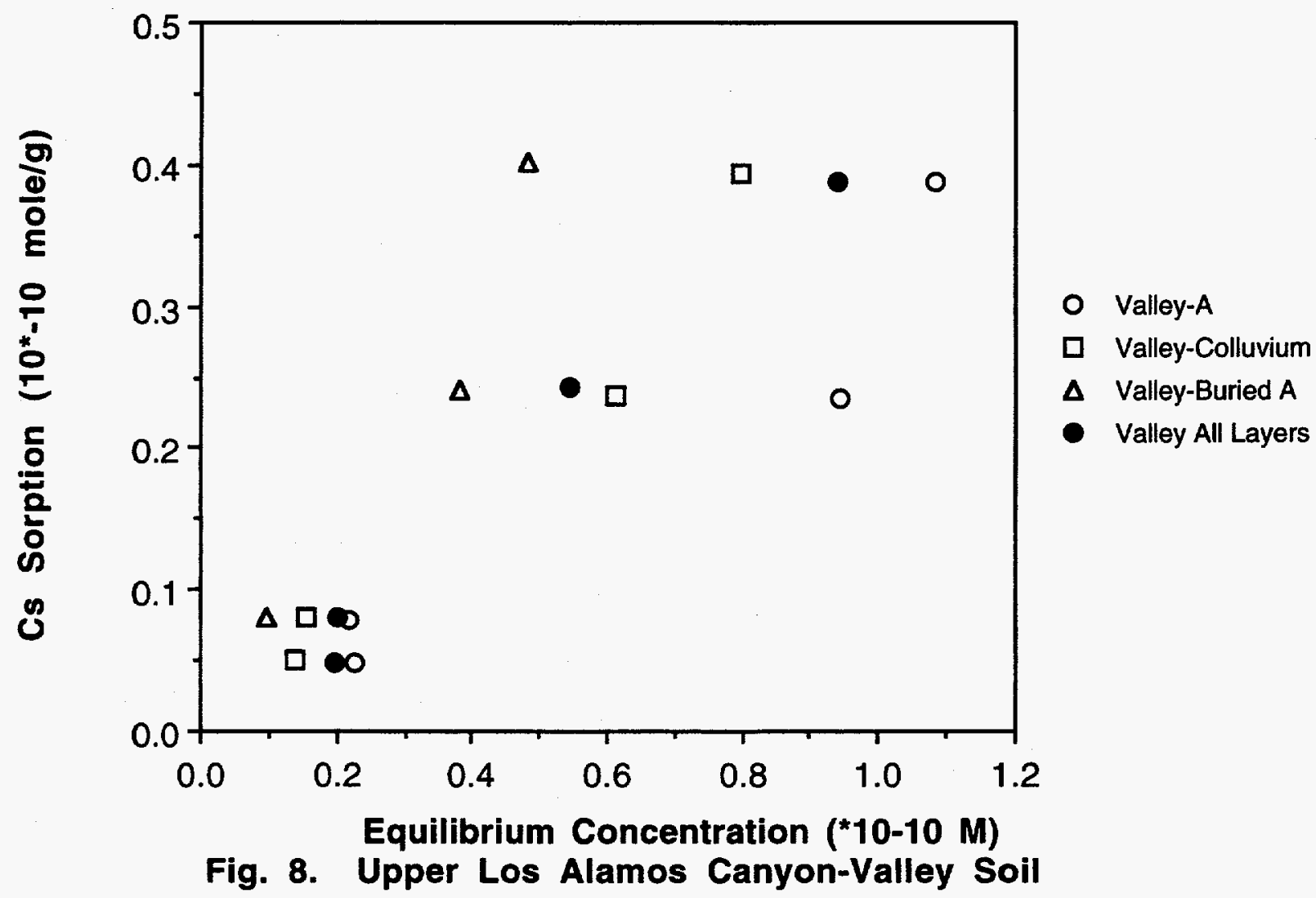


Sorption isotherm of Cs on valley whole soil sample of upper Los Alamos Canyon Site. Cesium sorption coefficient is calculated as 44.3 (in $\mathrm{ml} \mathrm{per} \mathrm{g)} \mathrm{for} \mathrm{this}$ soil sample.

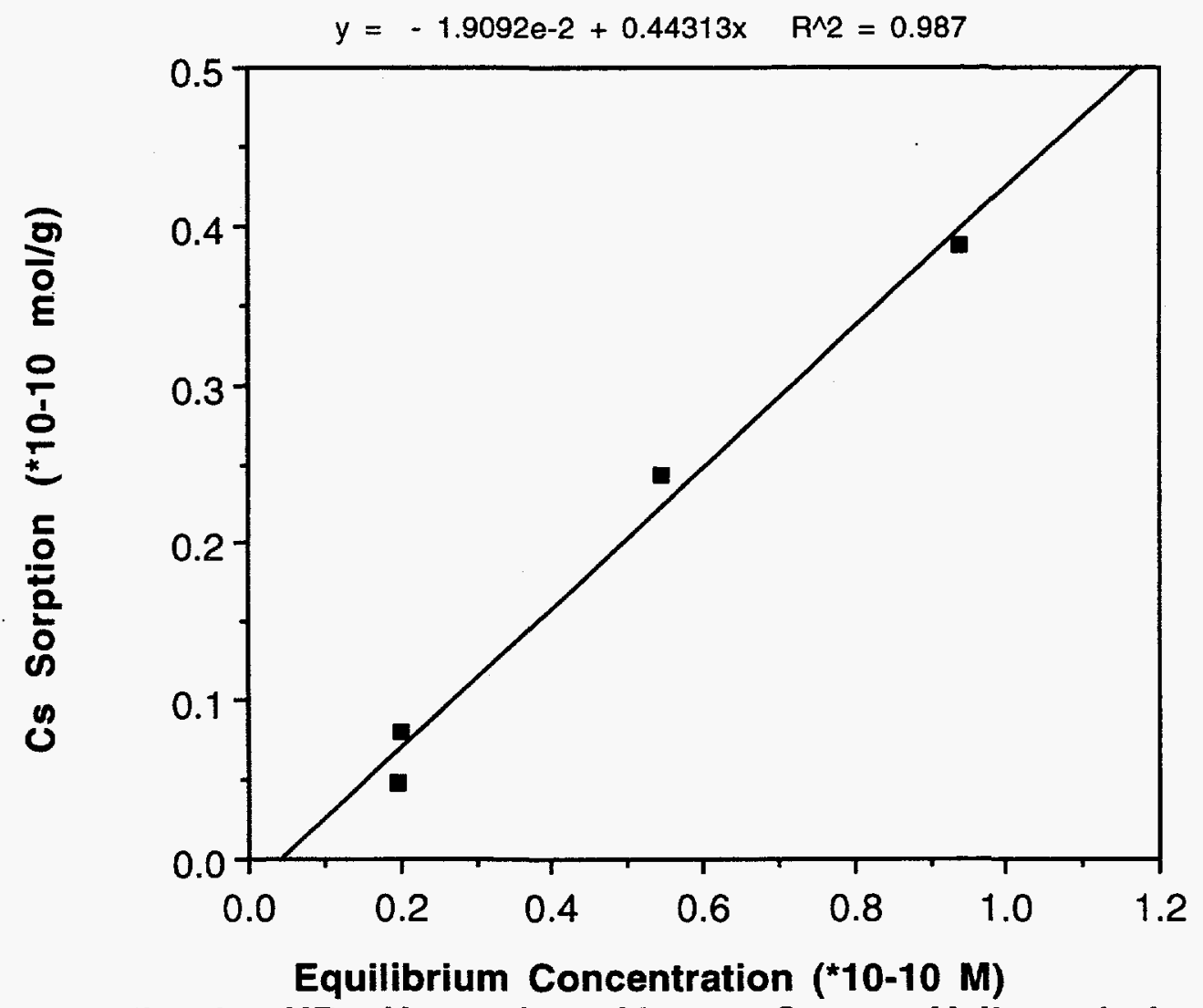

Fig. 9. URv Upper Los Alamos Canyon-Valley whole soil 
Sorption isotherms of Cs on soil sample of upper Los Alamos Canyon Site.

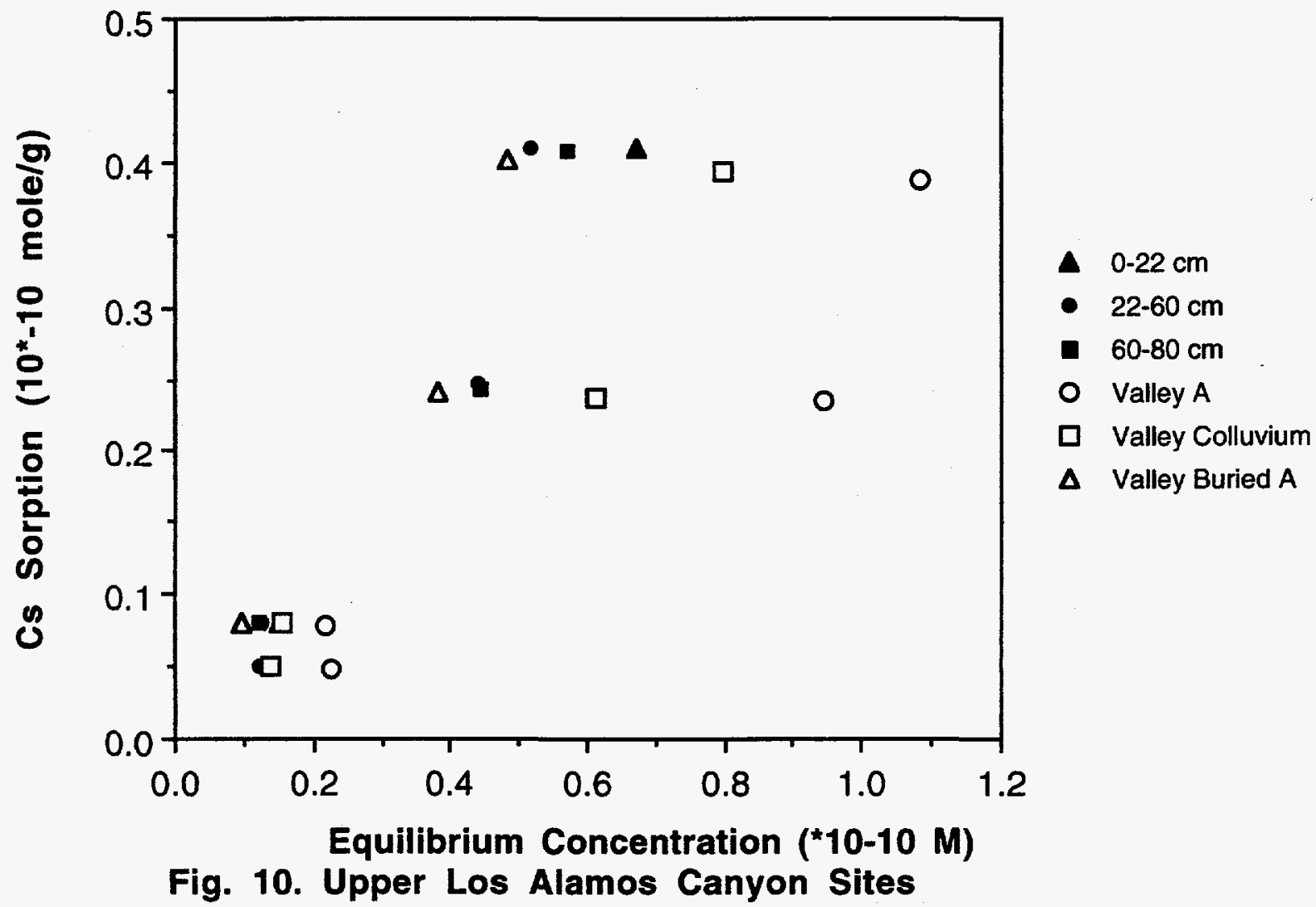


EGEG Sites. Sorption isotherm of Cs on A Layer soil sample of EG\&G Site.

Cesium sorption coefficient is calculated as 99.2 (in $\mathrm{ml} \mathrm{per} \mathrm{g}$ ) for this soil sample.

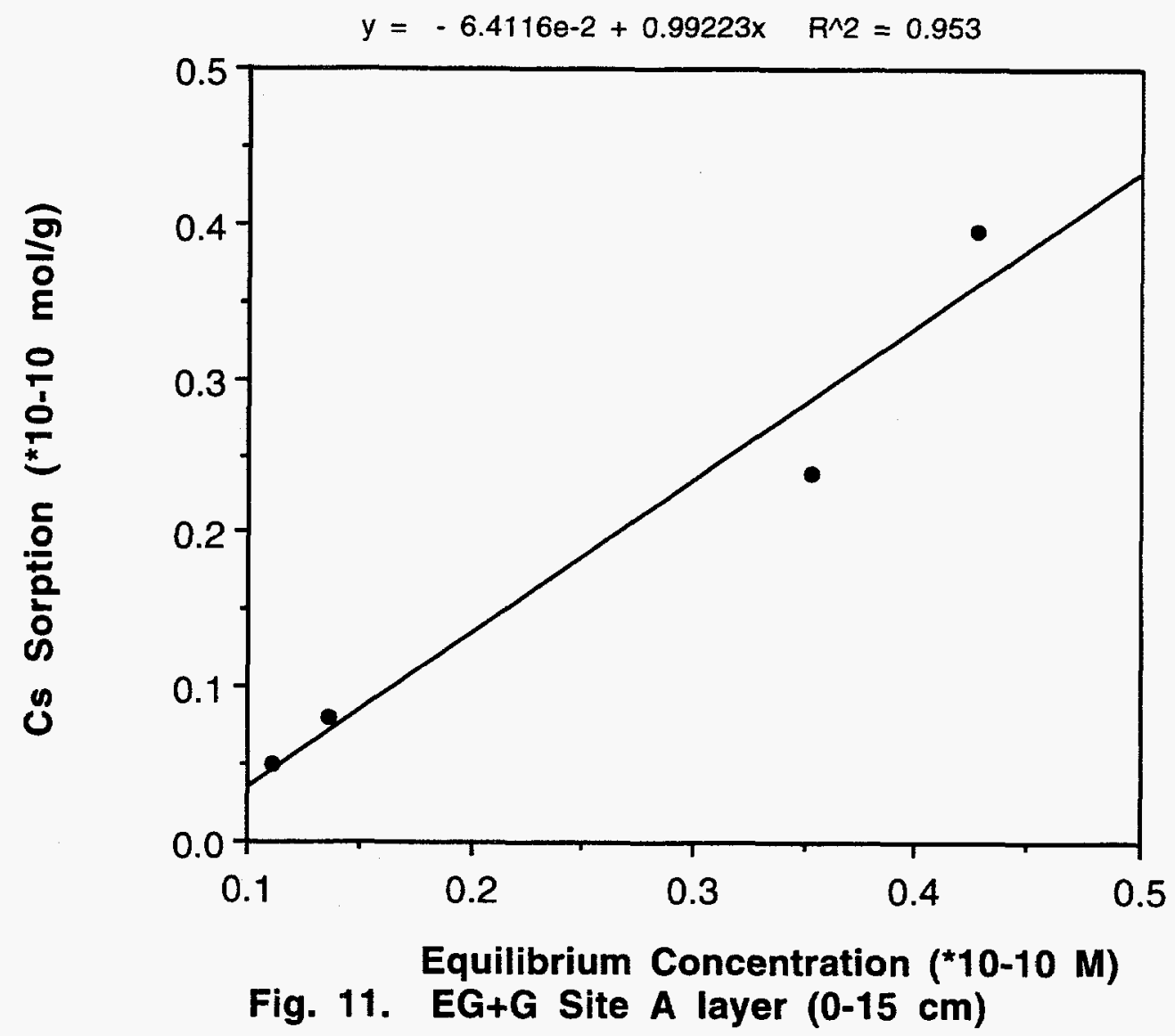


Sorption isotherm of Cs on Bt Layer soil sample of EG\&G Site. Cesium sorption coefficient is calculated as 103.5 (in $\mathrm{ml}$ per $\mathrm{g}$ ) for this soil sample.

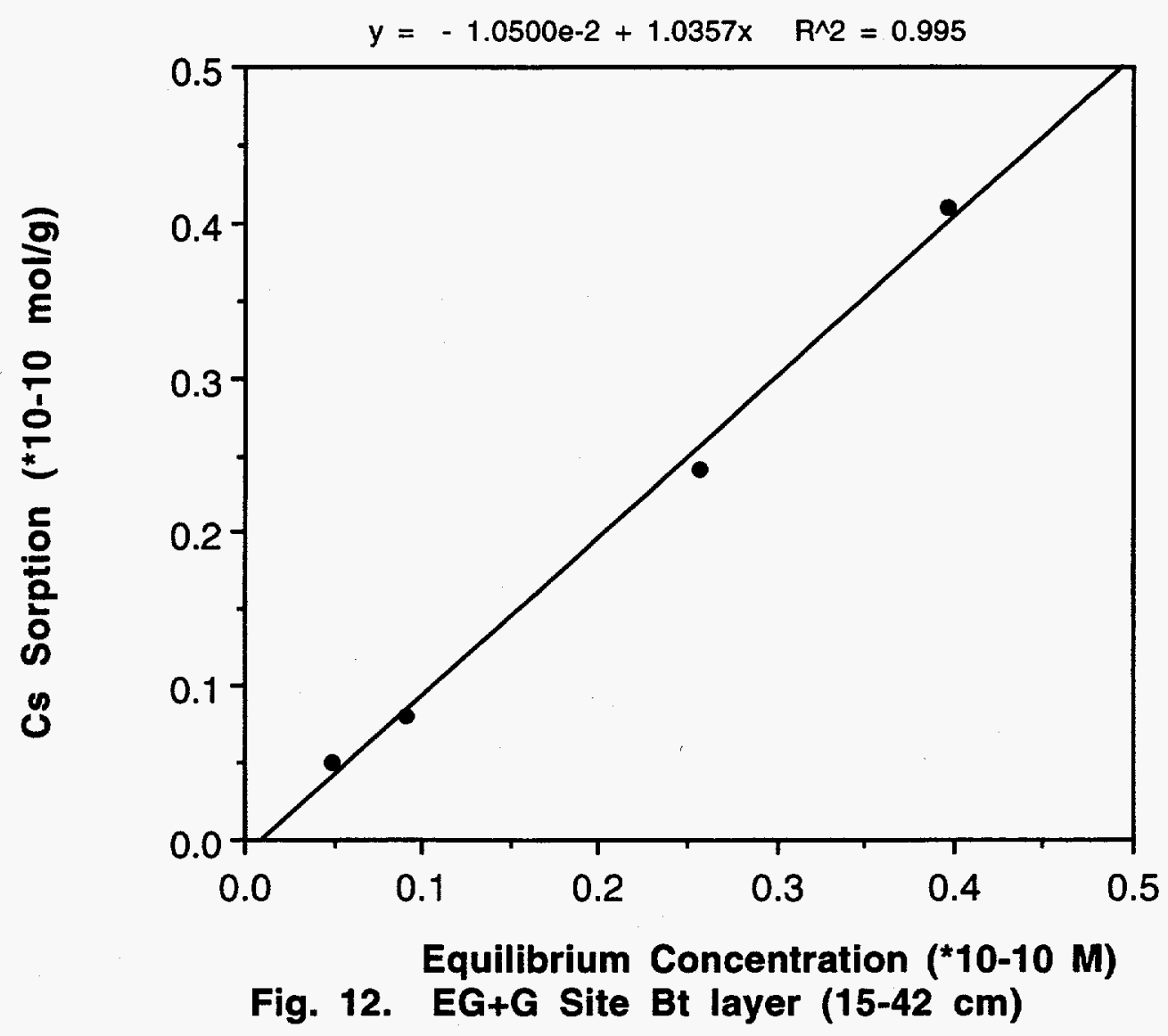


Sorption isotherm of Cs on Bw Layer soil sample of EG\&G Site. Cesium sorption coefficient is calculated as 129.7 (in $\mathrm{ml}$ per $\mathrm{g}$ ) for this soil sample.

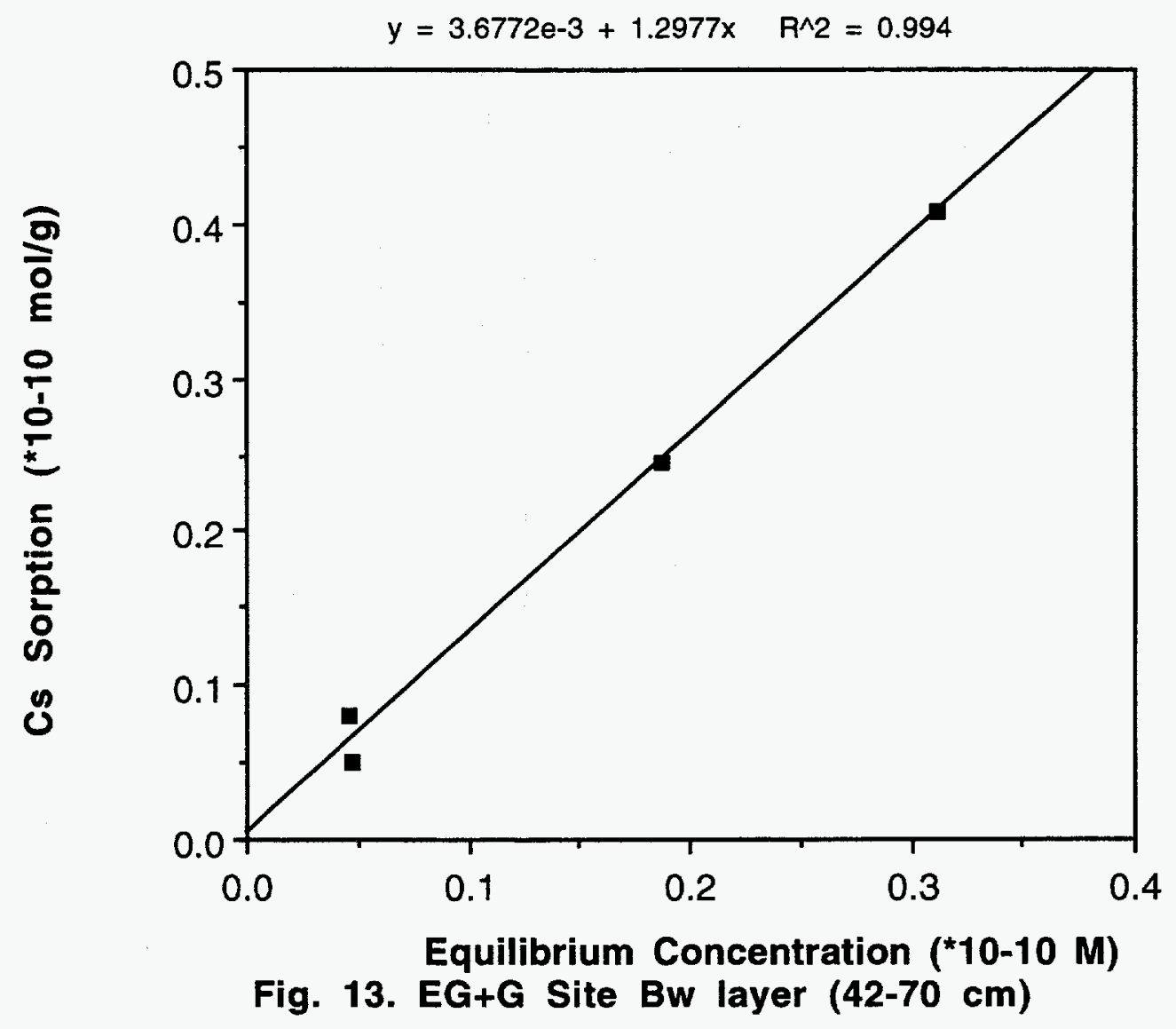


Sorption isotherm of Cs on CB Layer soil sample of EG\&G Site. Cesium sorption coefficient is calculated as 94.8 (in $\mathrm{ml}$ per $\mathrm{g}$ ) for this soil sample.

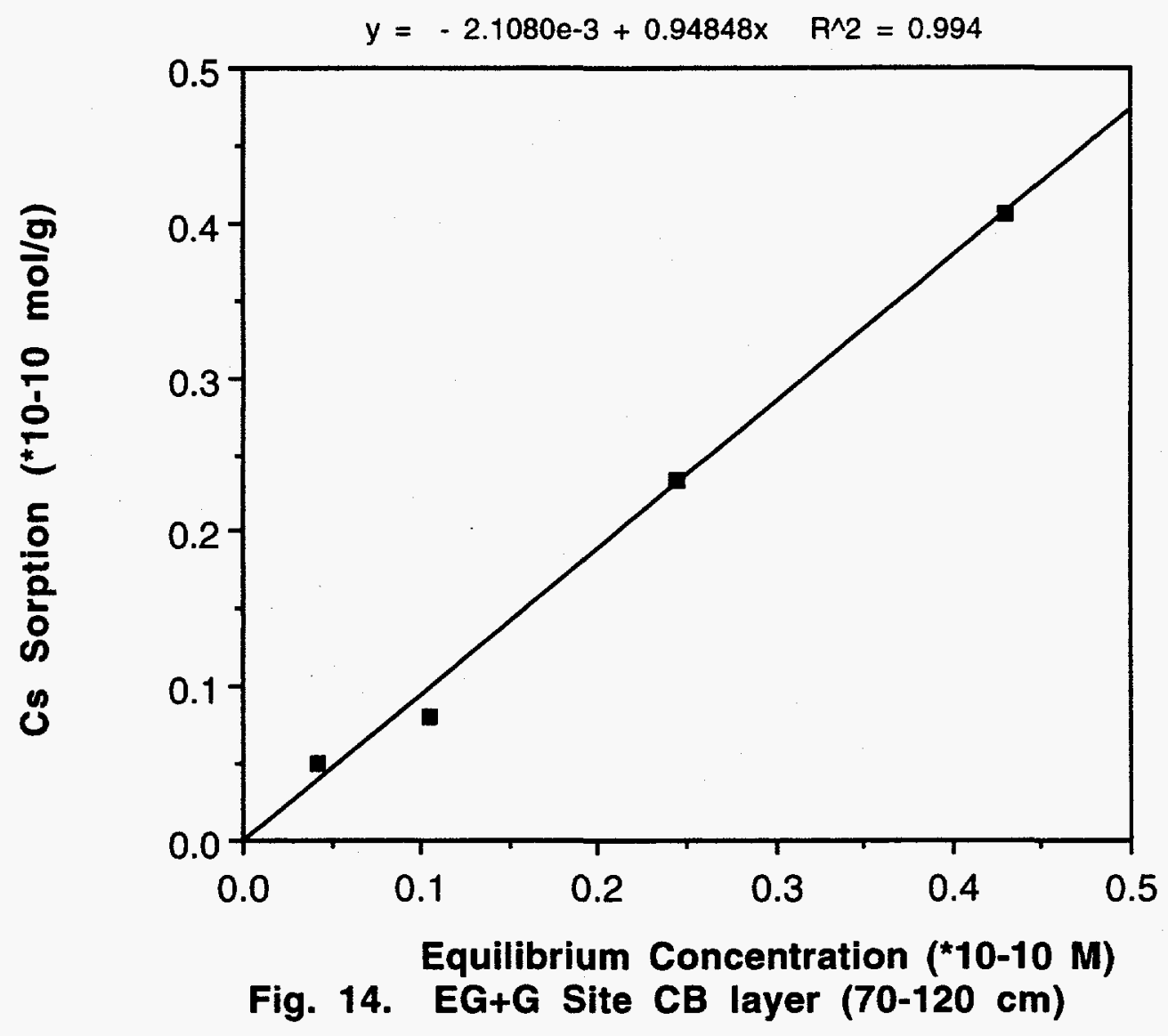


Sorption isotherm of Cs on Bwb Layer soil sample of EG\&G Site. Cesium sorption coefficient is calculated as 191.0 (in $\mathrm{ml}$ per $\mathrm{g}$ ) for this soil sample.

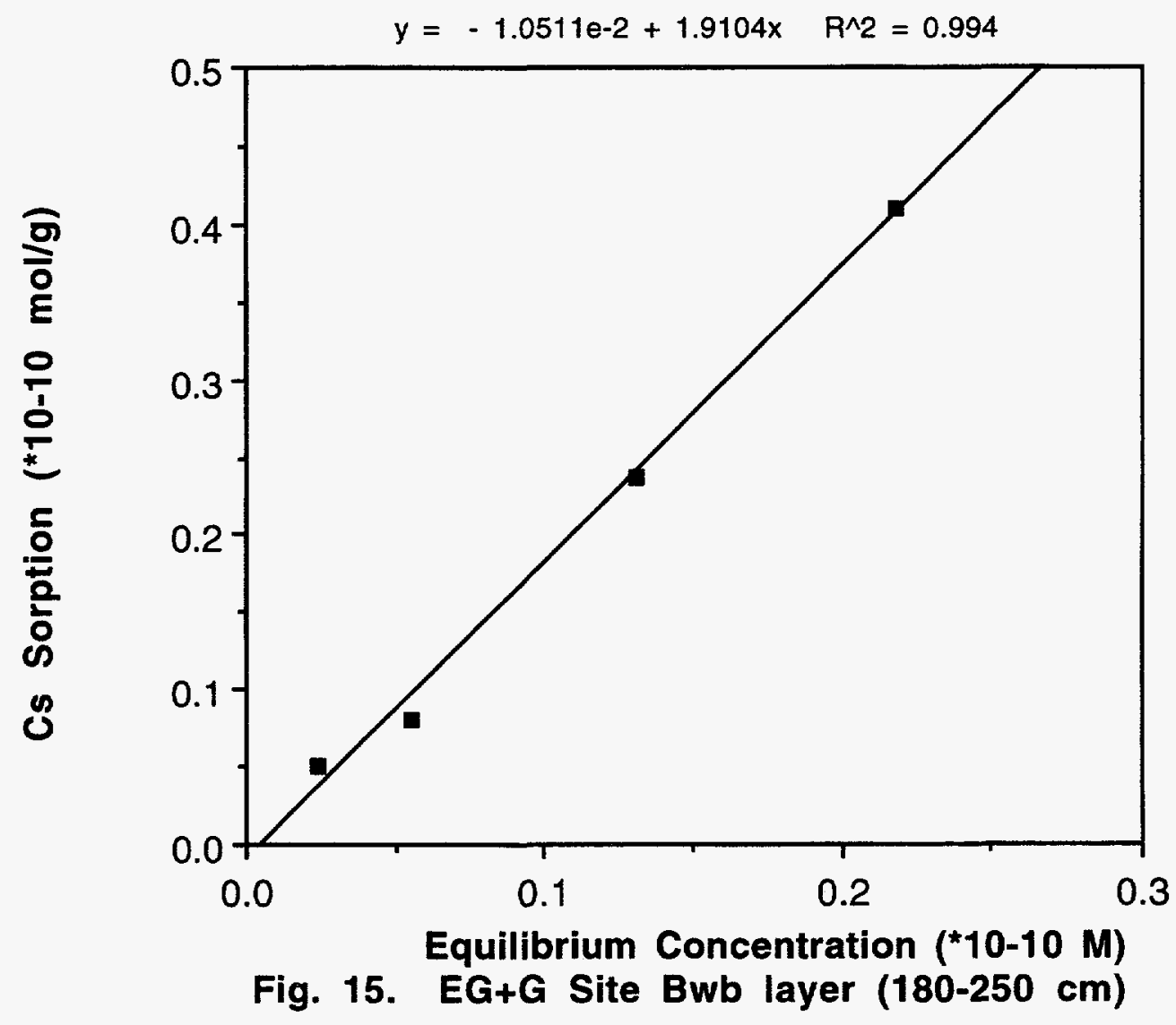


Sorption isotherms of Cs on soil sample of EG\&G Site.

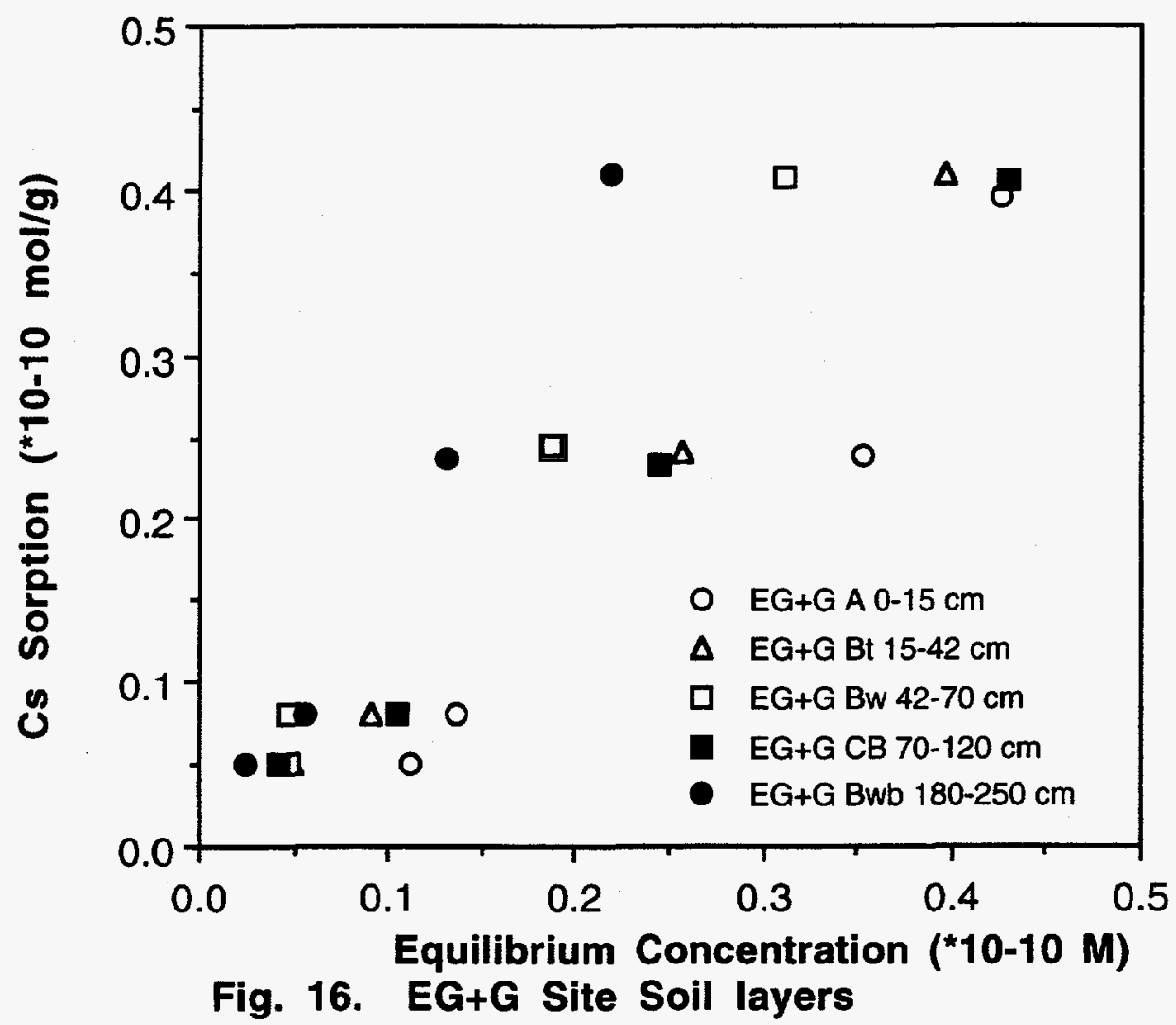


Lower Los Alamos Canyon. Sorption isotherm of Cs on A Layer soil sample of lower Los Alamos Canyon Site. Cesium sorption coefficient is calculated as 37.4 (in $\mathrm{ml}$ per $\mathrm{g}$ ) for this soil sample.

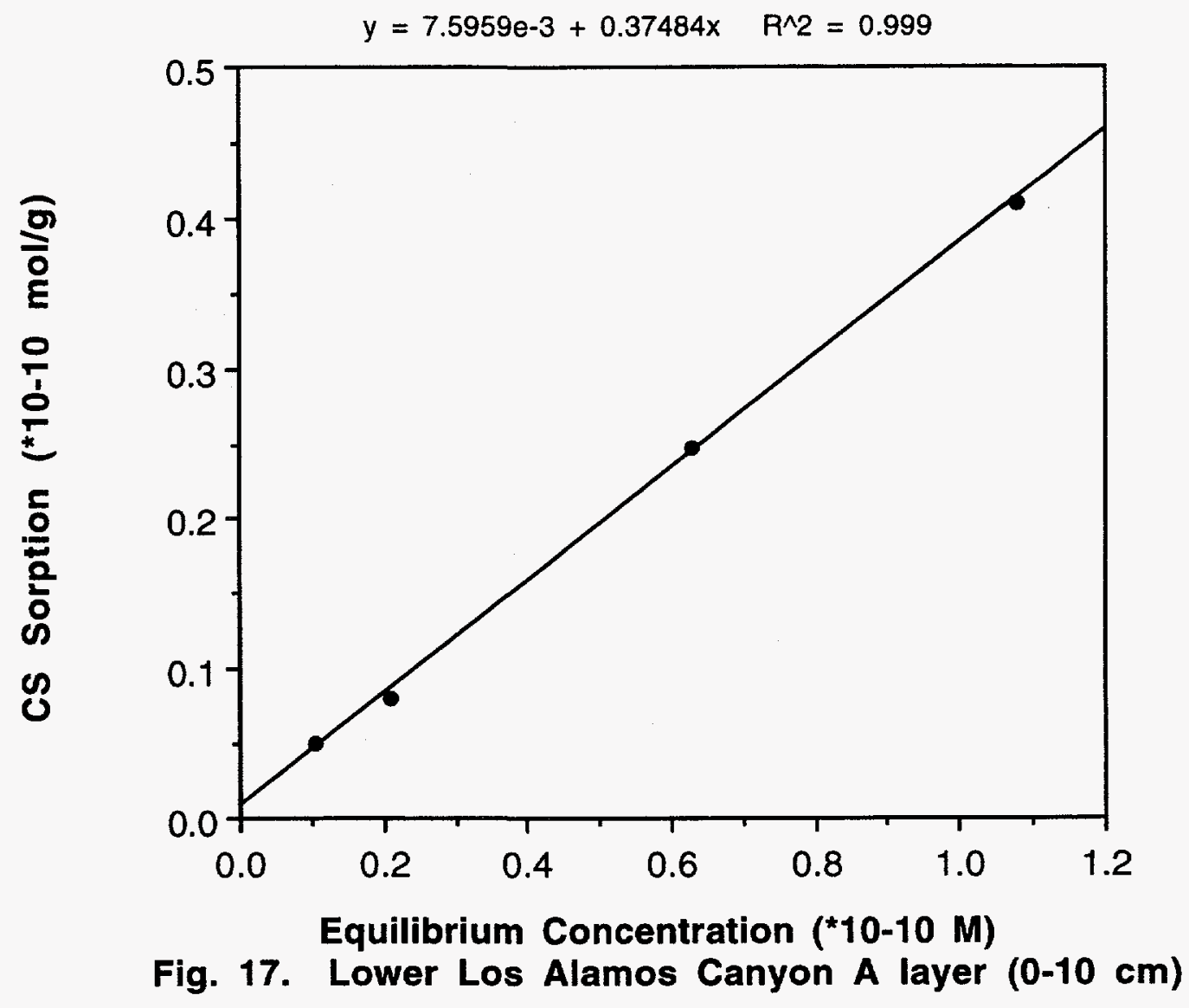


Sorption isotherm of Cs on C Layer soil sample of lower Los Alamos Canyon Site. Cesium sorption coefficient is calculated as 29.3 (in $\mathrm{ml} \mathrm{per} \mathrm{g}$ ) for this soil sample.

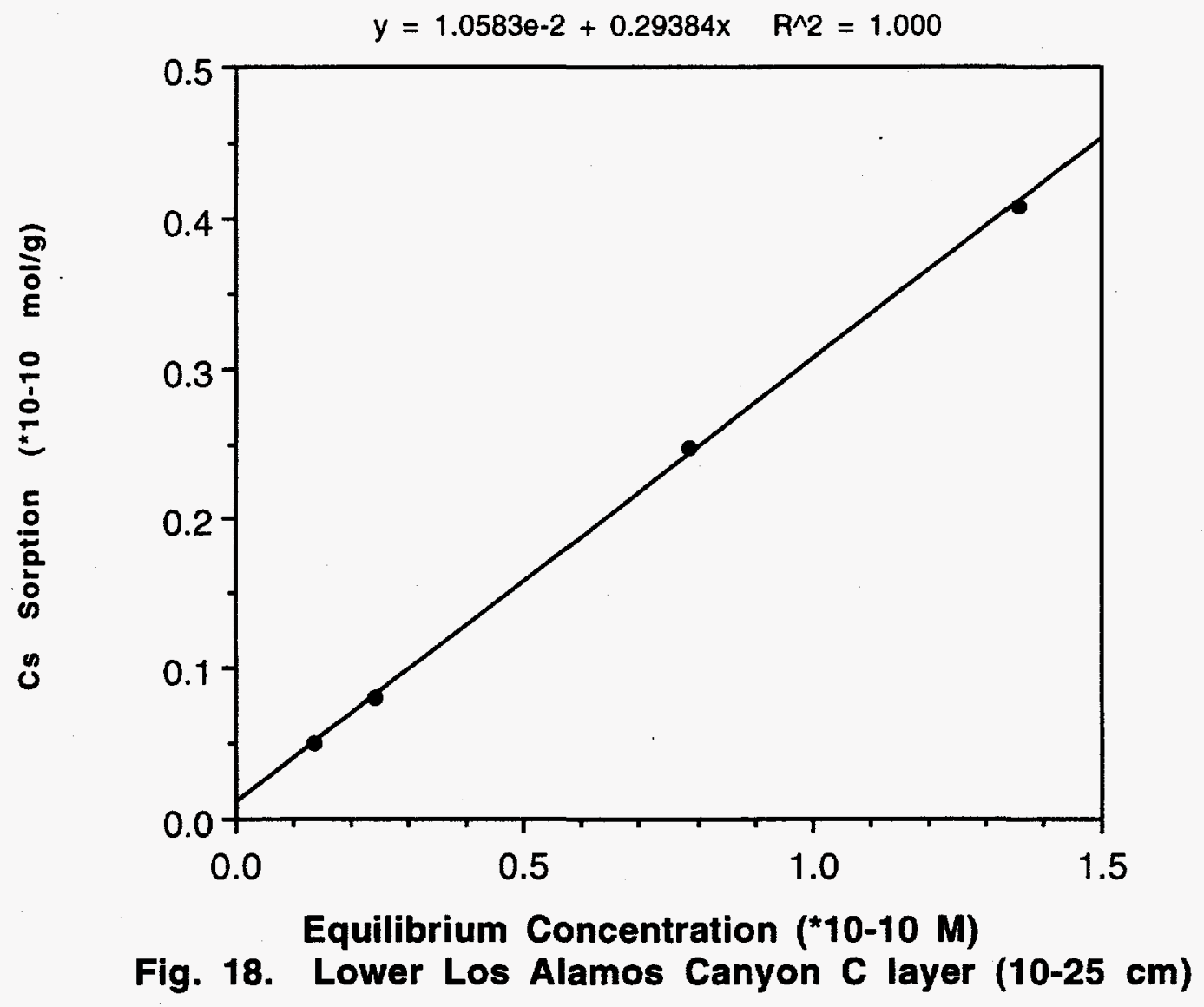


Sorption isotherm of $\mathrm{Cs}$ on whole soil sample of lower Los Alamos Canyon Site. Cesium sorption coefficient is calculated as 33.6 (in $\mathrm{ml} \mathrm{per} \mathrm{g}$ ) for this soil sample.

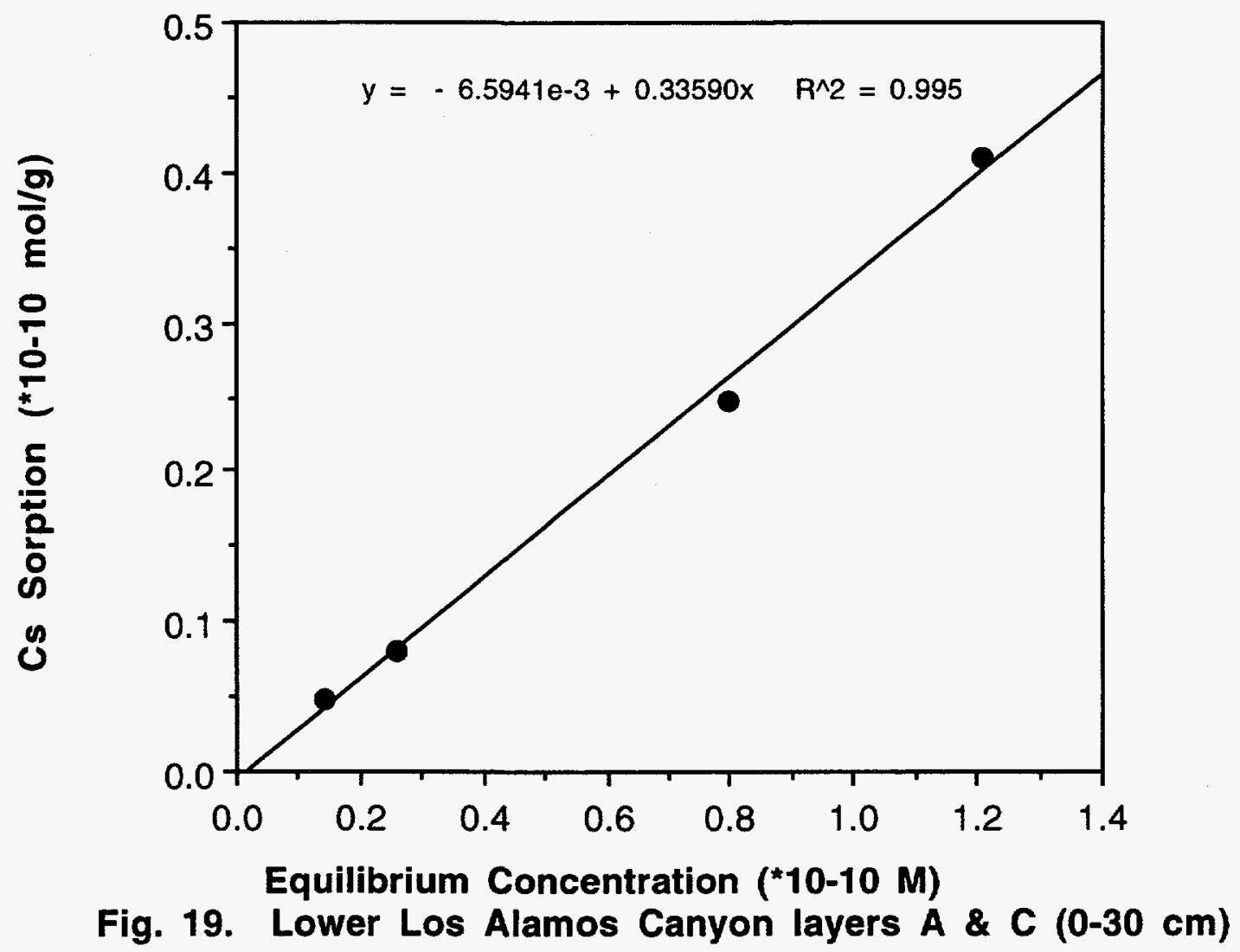


Sorption isotherm of Cs on stream washout soil sample of lower Los Alamos Canyon Site. Cesium sorption coefficient is calculated as 26.5 (in ml per g) for this soil sample.

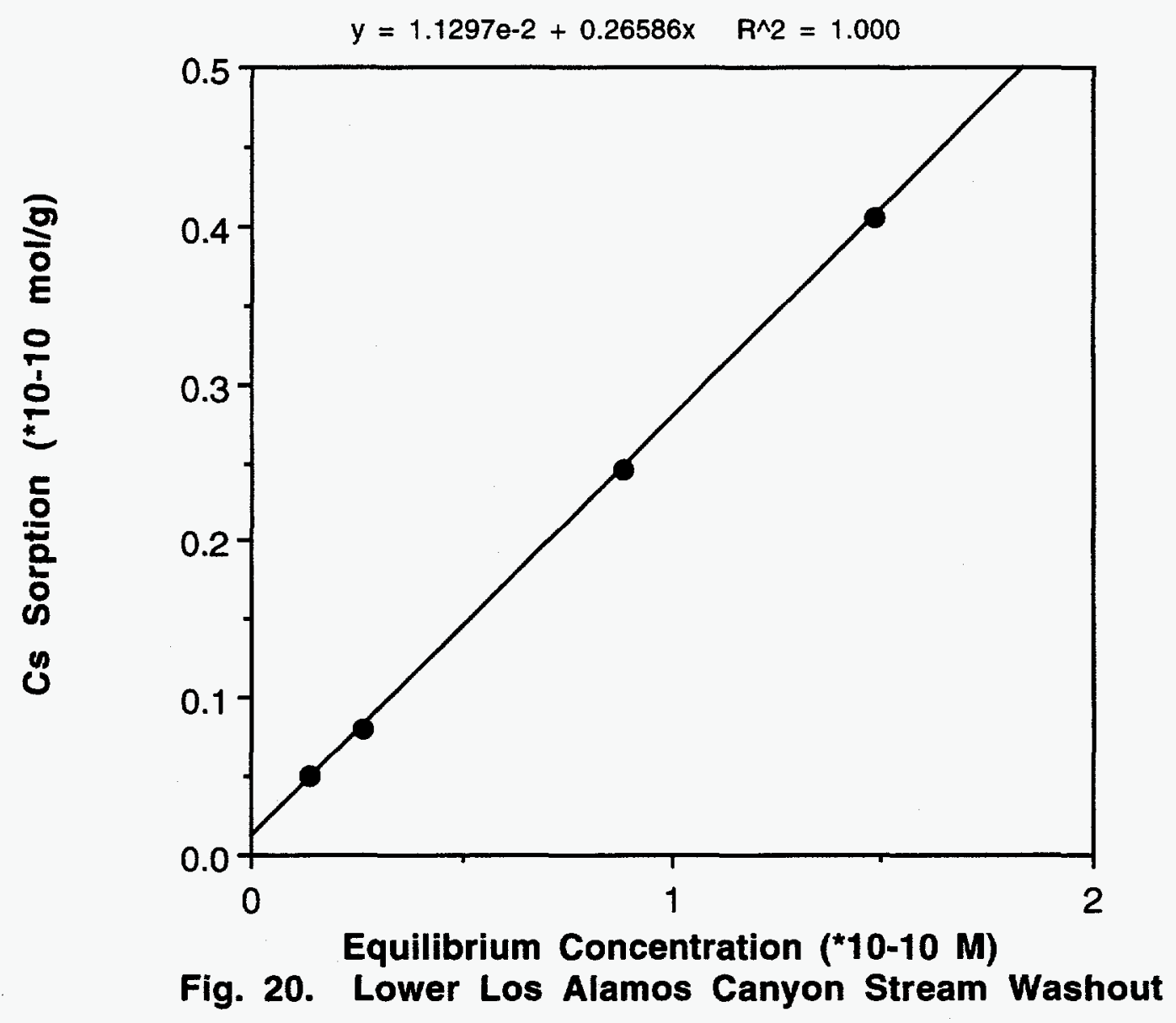


Sorption isotherms of Cs on soil samples of lower Los Alamos Canyon Site.

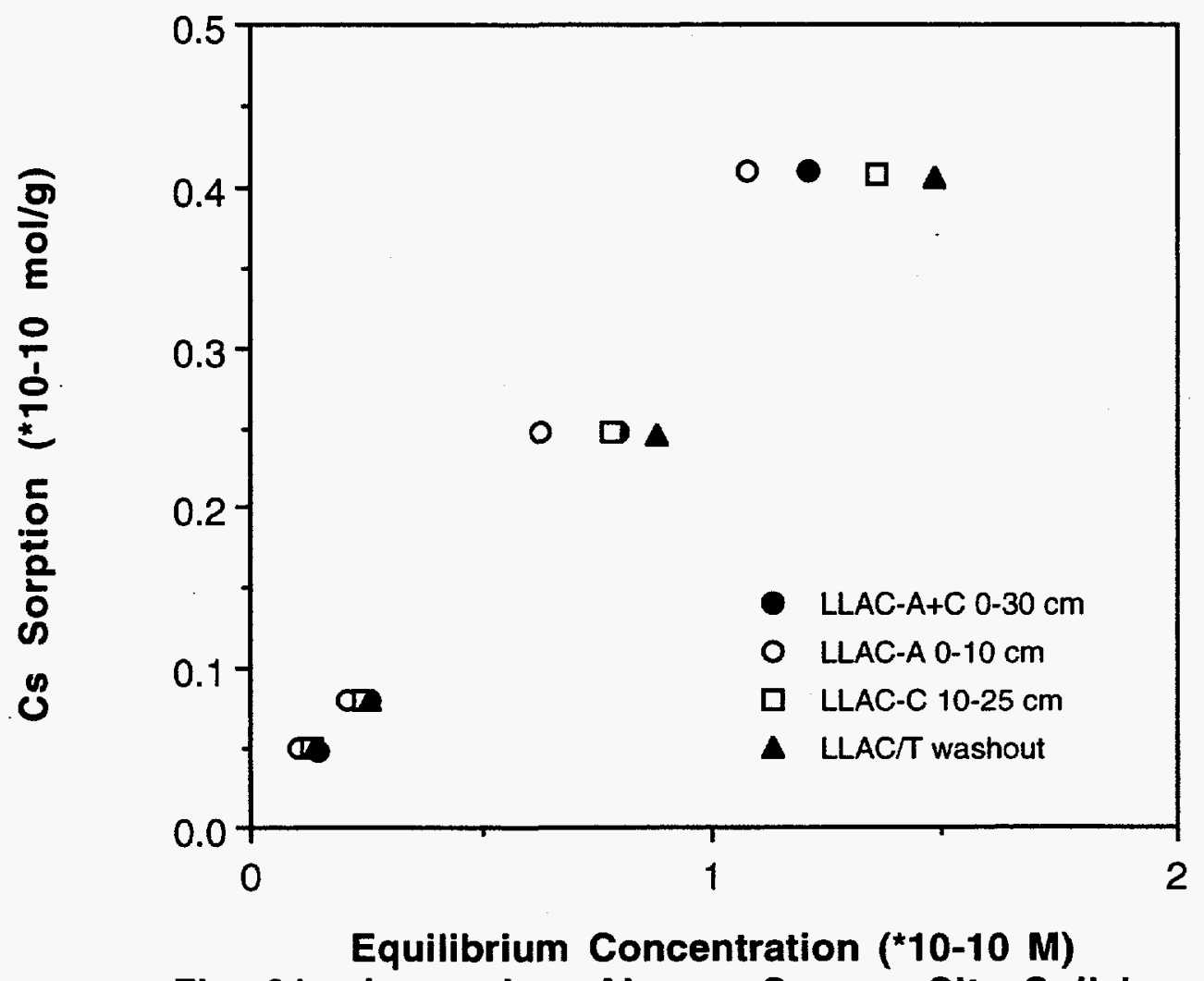

Fig. 21. Lower Los Alamos Canyon Site Soil layers 
Ancho Canyon Site. Sorption isotherm of Cs on A Layer soil sample of Ancho Canyon Site. Cesium sorption coefficient is calculated as 222.7 (in $\mathrm{ml}$ per g) for this soil sample.

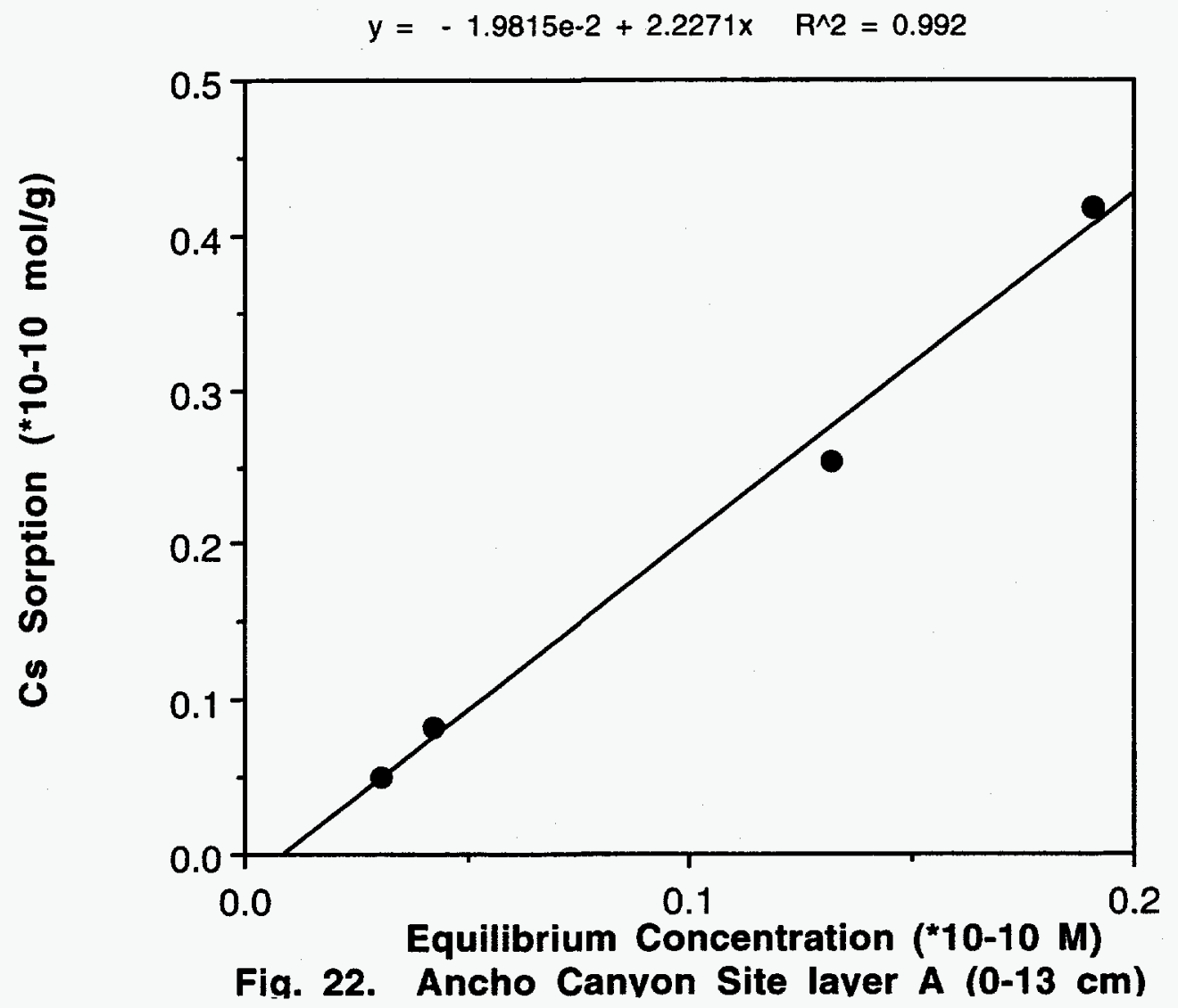


Sorption isotherm of Cs on Bt Layer soil sample of Ancho Canyon Site. Cesium sorption coefficient is calculated as 539.2 (in $\mathrm{ml} \mathrm{per} \mathrm{g}$ ) for this soil sample.

$$
y=2.6467 e-2+5.3921 x \quad R^{\wedge} 2=0.986
$$

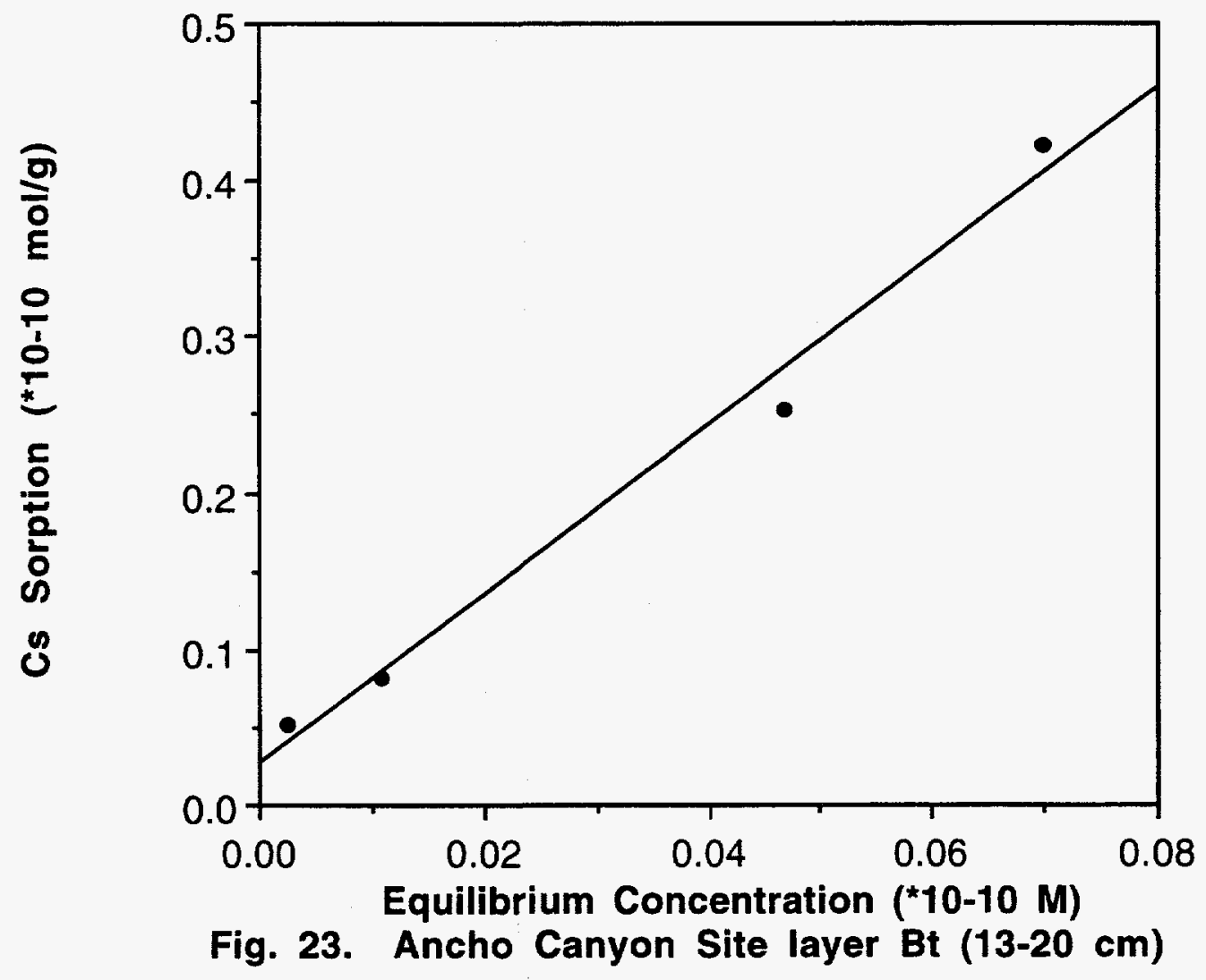


Sorption isotherm of Cs on Bwkb Layer soil sample of Ancho Canyon Site. Cesium sorption coefficient is calculated as 322.8 (in $\mathrm{ml} \mathrm{per} \mathrm{g}$ ) for this soil sample.

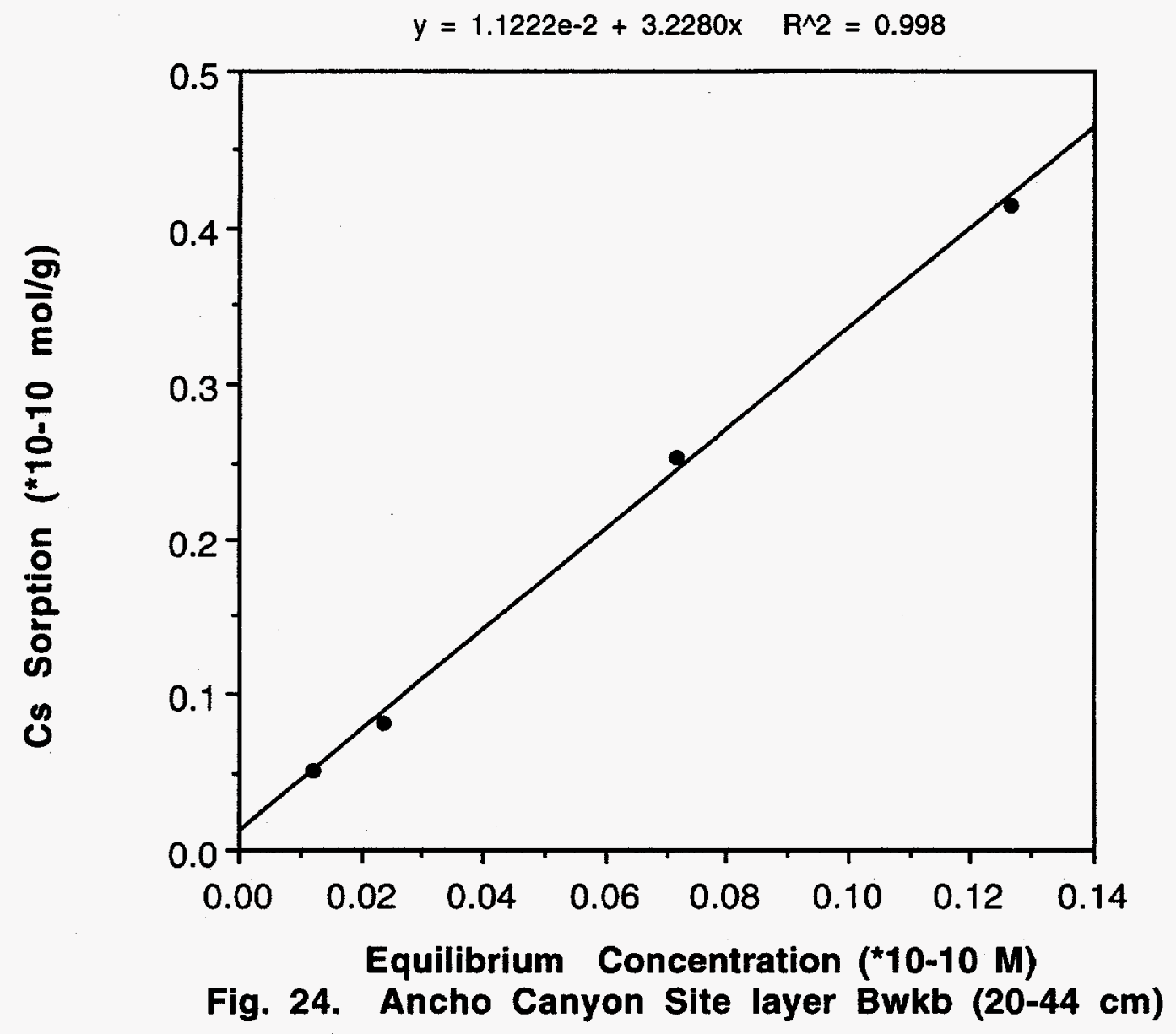


Sorption isotherm of Cs on Btkb Layer soil sample of Ancho Canyon Site. Cesium sorption coefficient is calculated as 498 (in $\mathrm{ml}$ per $\mathrm{g}$ ) for this soil sample.

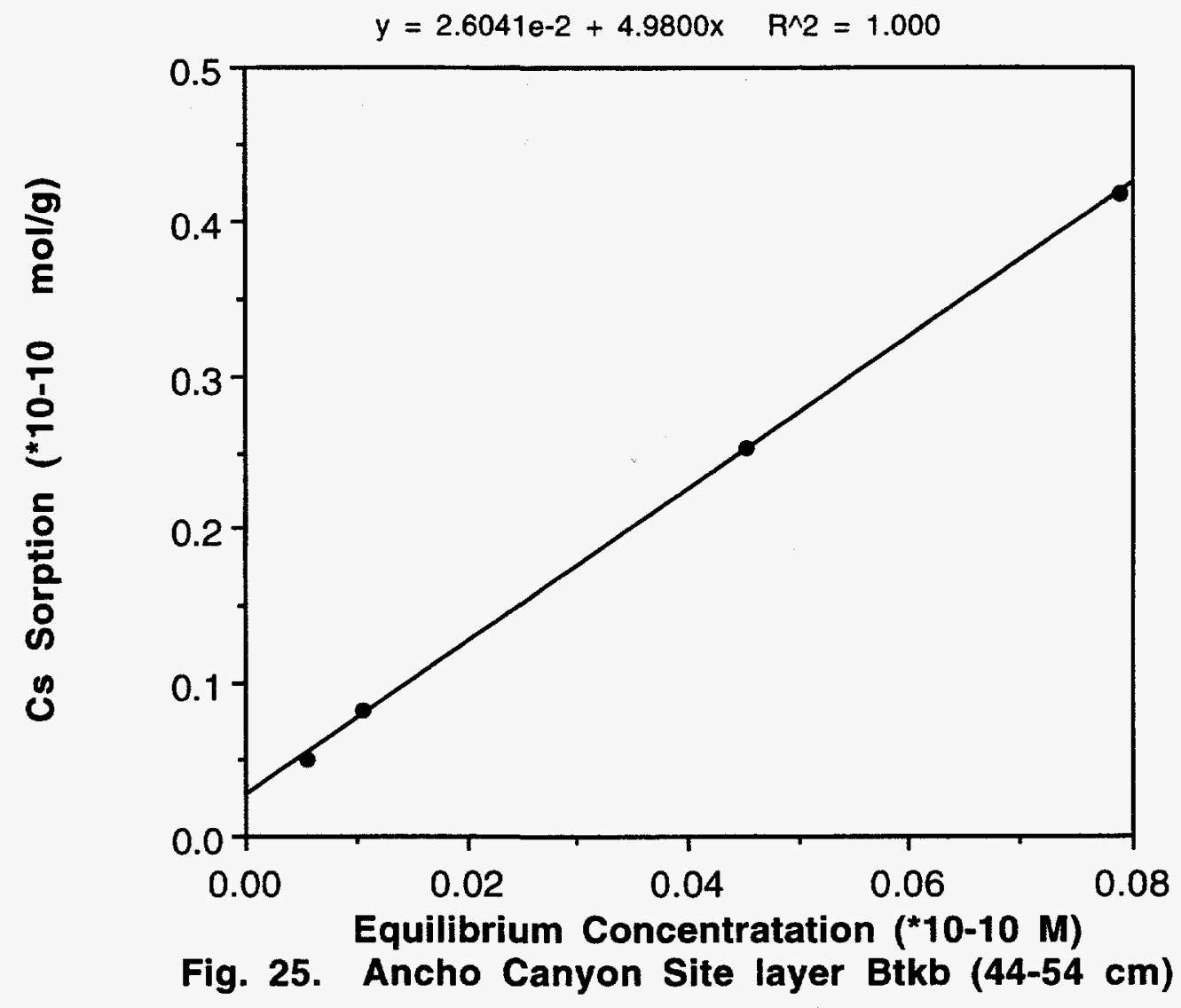


Sorption isotherm of Cs on whole soil sample of Ancho Canyon Site.

Cesium sorption coefficient is calculated as 180.5 (in $\mathrm{ml} \mathrm{per} \mathrm{g}$ ) for this soil sample.

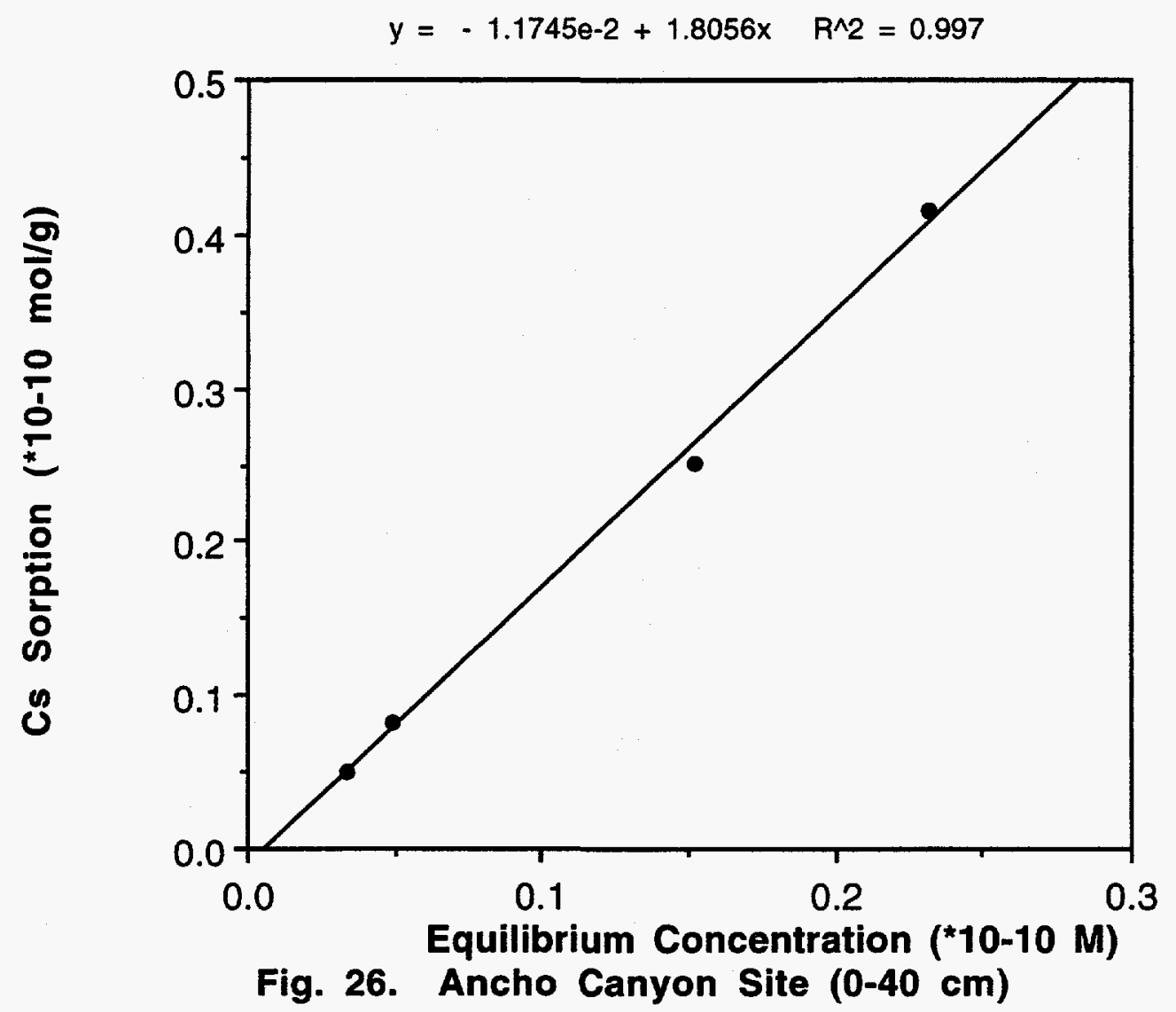


Sorption isotherms of Cs on soil samples of Ancho Canyon Site.

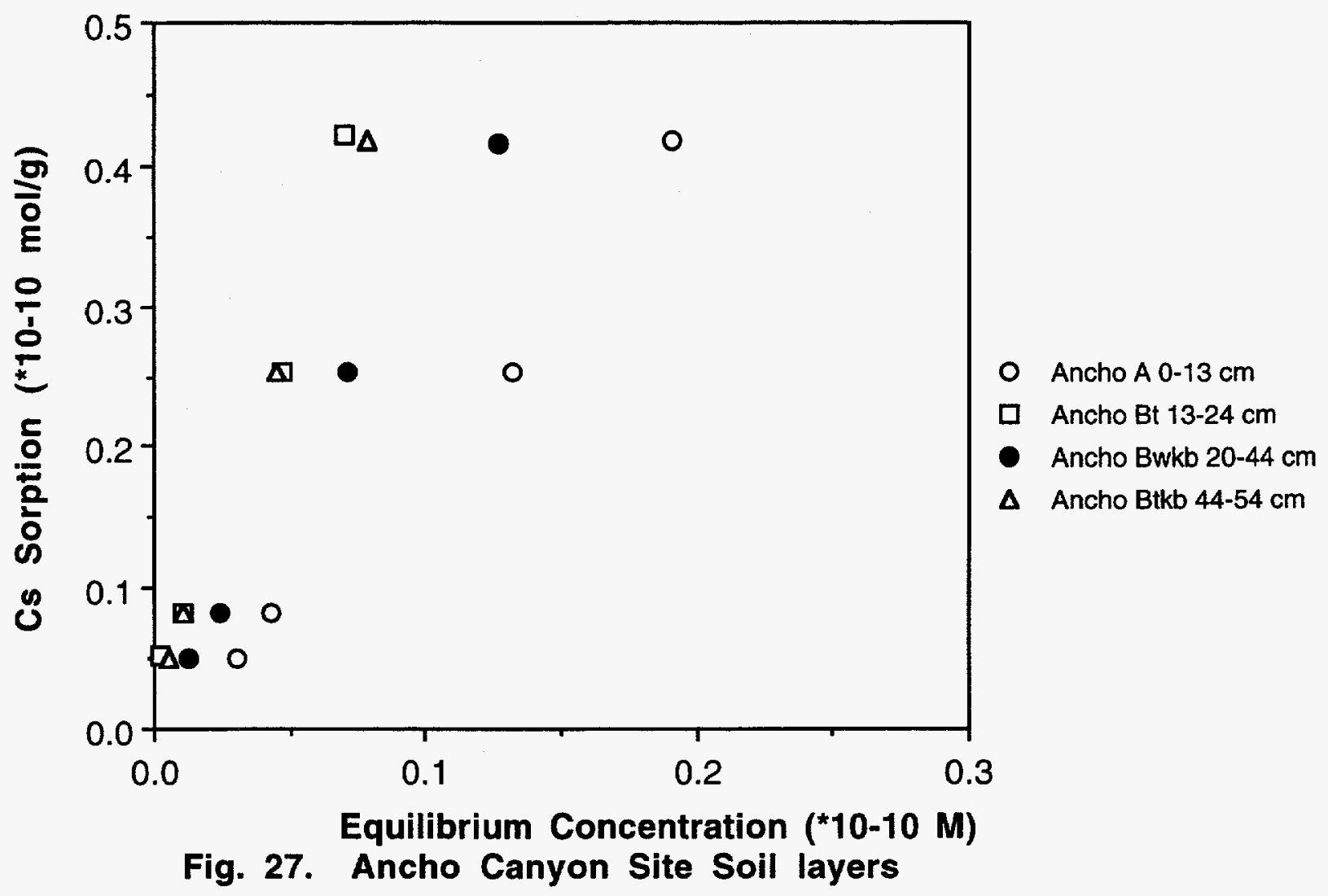




\subsection{Cesium Desorption}

The desorption experiments of Cs-137 were studied using the same samples in the sorption experiment. A $0.01 \mathrm{M} \mathrm{KCl}$ concentration was used to generate the desorption isotherms. The slope of the isotherm is the desorption coefficient (in liter per gram) of cesium in the soil sample. Results were plotted for each horizon of the soil profile. In these figures, the amount of cesium desorption (in mole per gram of soil) onto a given soil sample is plotted as a function of the equilibrium cesium concentration (in mole per liter) of the cesium solution. Final cesium sorption in these desorption experiments was calculated by subtracting the final cesium equilibrium concentration in the desorption study from the initial amount of cesium retention from the cesium sorption study. Percentage of cesium desorption from soil samples was calculated by dividing the amount of cesium desorption to the amount of cesium initially retained in the sorption experiments.

For the desorption results, it was identified that less than $1 \%$ of the presorbed cesium was desorbed from Ancho Canyon soils and most EG\&G soils. About $1-3 \%$ of cesium was found desorbed from upper Los Alamos Canyon soils and about $3-6 \%$ of cesium was found desorbed from lower Los Alamos Canyon soils. Desorption isotherms for all soil samples were reported in the following table.

\section{SOIL SAMPLES}

ULAC-A

ULAC-A

ULAC-A

ULAC-A

ULAC-BA

ULAC-BA

ULAC-BA

ULAC-BA

ULAC-BW

ULAC-Bw

ULAC-BW

ULAC-BW

ULAC-valley-A

ULAC-valley-A

ULAC-valley-A

ULAC-valley-A

ULAC-valley-colluvium

ULAC-valley-colluvium

ULAC-valley-colluvium

ULAC-valley-colluvium

ULAC-valley-buried A

ULAC-valley-buried $A$

ULAC-valley-buried $A$

ULAC-valley-buried $A$
$\% \mathrm{Cs}$ DESORBED

1.14

1.01

0.99

0.96

0.97

0.85

0.81

0.85

1.16

1.29

1.23

1.24

2.33

2.22

2.40

2.18

1.23

1.39

n/a

1.46

1.25

1.24

1.25

1.15
SOIL SAMPLES

Ancho-A

Ancho-A

Ancho-A

Ancho-A

Ancho-Bt

Ancho-Bt

Ancho-Bt

Ancho-Bt

Ancho-Bwkb

Ancho-Bwkb

Ancho-Bwkb

Ancho-Bwkb

Ancho-Btkb

Ancho-Btkb

Ancho-Btkb

Ancho-Btkb

Ancho-Whole Soil

Ancho-Whole Soil

Ancho-Whole Soil

Ancho-Whole Soil
$\%$ Cs

DESORBED

0.84

1.02

0.94

0.93

0.03

0.17

0.20

0.16

0.23

0.21

0.22

0.23

0.14

0.15

0.13

0.14

0.54

0.49

0.36

0.33 
SOIL SAMPLES

ULAC whole soil

ULAC whole soil

ULAC whole soil

ULAC whole soil

LLAC-A

LLAC-A

LLAC-A

LLAC-A

LLAC-C

LLAC-C

LLAC-C

LLAC-C

LLAC-A+C

LLAC-A+C

LLAC-A+C

LLAC-A+C

LLAC Washout

LLAC Washout

LLAC Washout

LLAC Washout
$\% \mathrm{Cs}$

DESORBED

2.33

2.40

2.32

2.13

2.62

2.96

2.95

2.98

1.02

3.13

3.40

3.44

3.19

3.43

3.50

3.21

5.31

5.42

6.04

6.02
SOIL SAMPLES

EG\&G-A

EG\&G-A

EG\&G-A

EG\&G-A

EG\&G-Bt

EG\&G-Bt

EG\&G-Bt

EG\&G-Bt

EG\&G-Bw

EG\&G-Bw

EG\&G-Bw

EG\&G-Bw

EG\&G-CB

EG\&G-CB

EG\&G-CB

EG\&G-CB

$E G+G$ Bwb

$E G+G$ Bwb

$E G+G$ Bwb

$E G+G$ Bwb
$\%$ Cs

DESORBED

1.41

1.39

1.35

1.21

0.84

0.90

0.96

0.84

0.58

0.65

0.75

0.67

0.82

0.74

0.74

0.77

0.45

0.38

0.39

0.39 
Upper Los Alamos Canyon Site. Desorption isotherm of Cs on A layer soil sample of Upper Los Alamos Canyon Site.

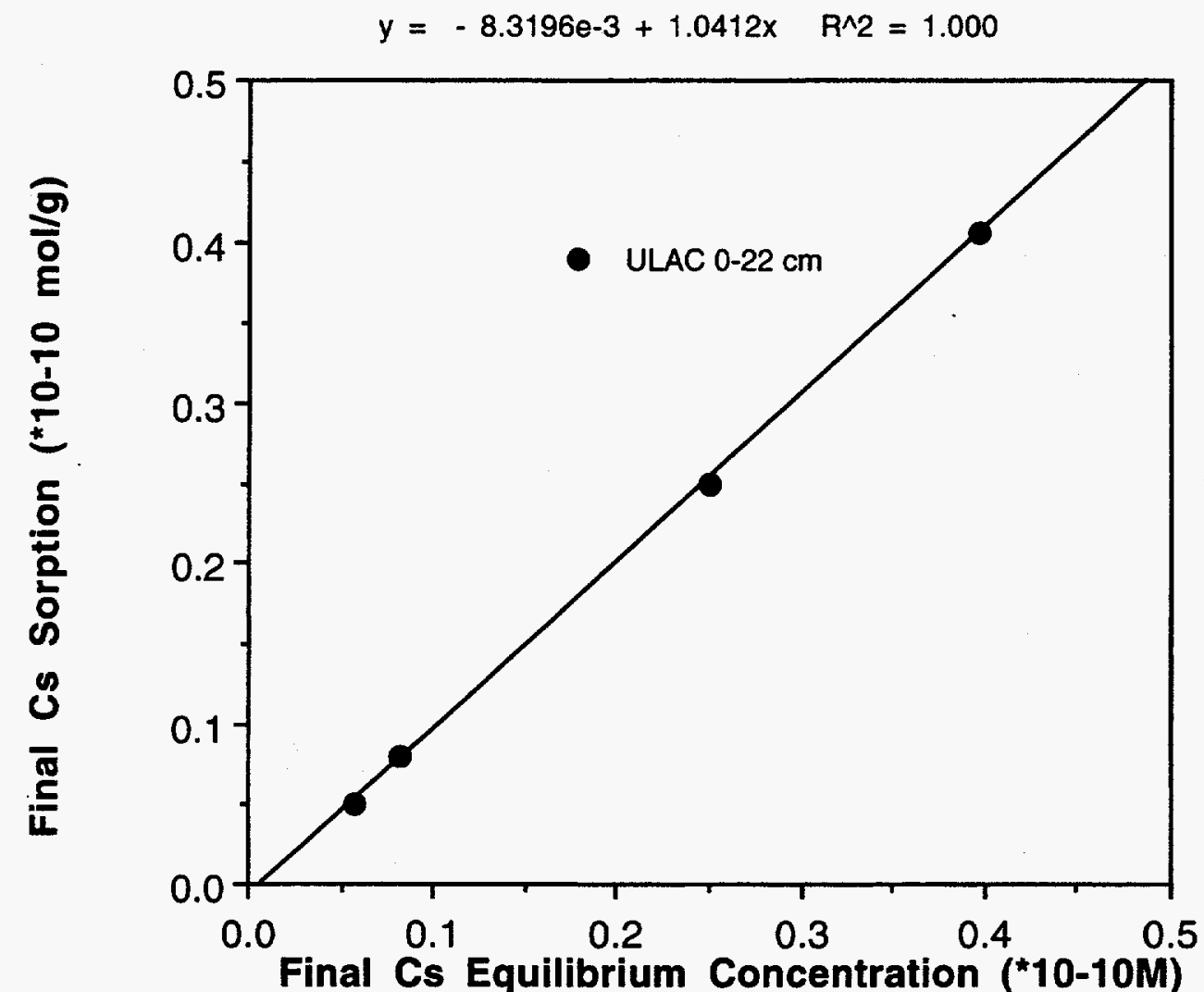

Fig. 28. Upper Los Alamos Canyon A Layer $(0-22 \mathrm{~cm})$ Cs Desorption Exp. 
Desorption isotherm of Cs on BA layer soil sample of Upper Los Alamos Canyon Site.

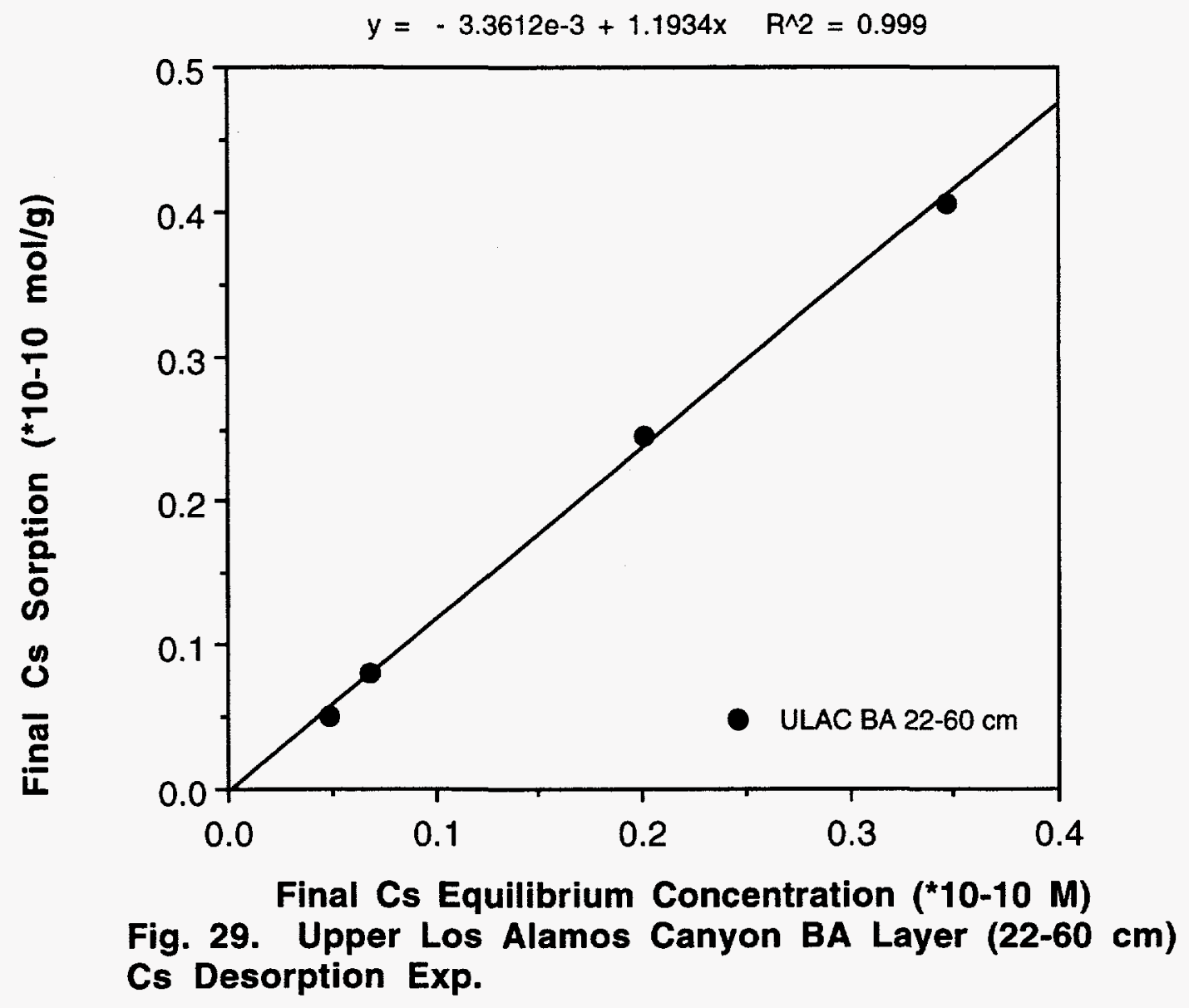


Desorption isotherm of Cs on Bw layer soil sample of Upper Los Alamos Canyon Site.

$$
y=4.9879 e-4+0.79683 x \quad R^{\wedge} 2=1.000
$$

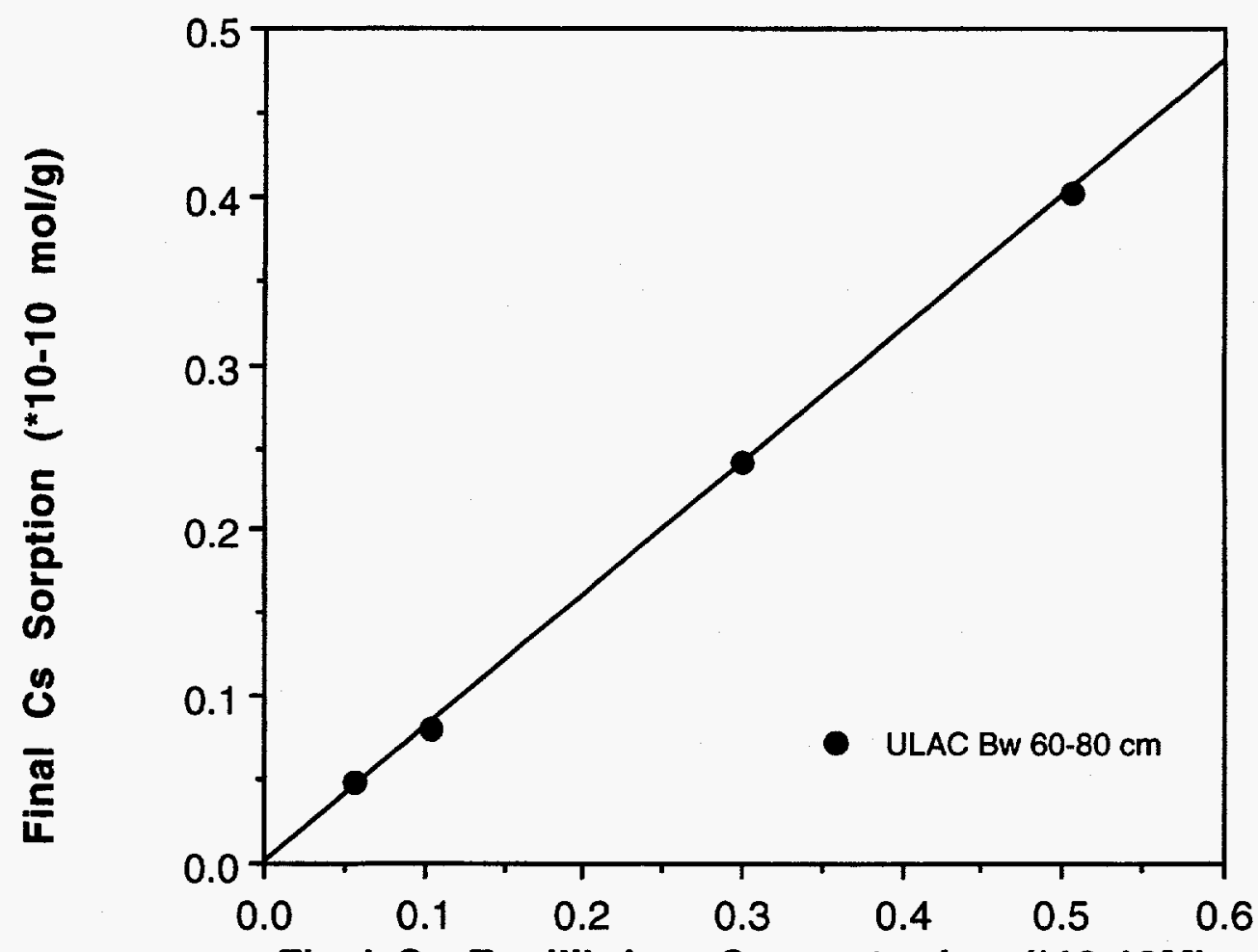

Final Cs Equilibrium Concentration ( $* 10-10 \mathrm{M})$

Fig. 30. Upper Los Alamos Canyon Bw Layer $(60-80 \mathrm{~cm})$ Cs Desorption Exp. 

Site.

Desorption isotherms of Cs on soil samples of Upper Los Alamos Canyon

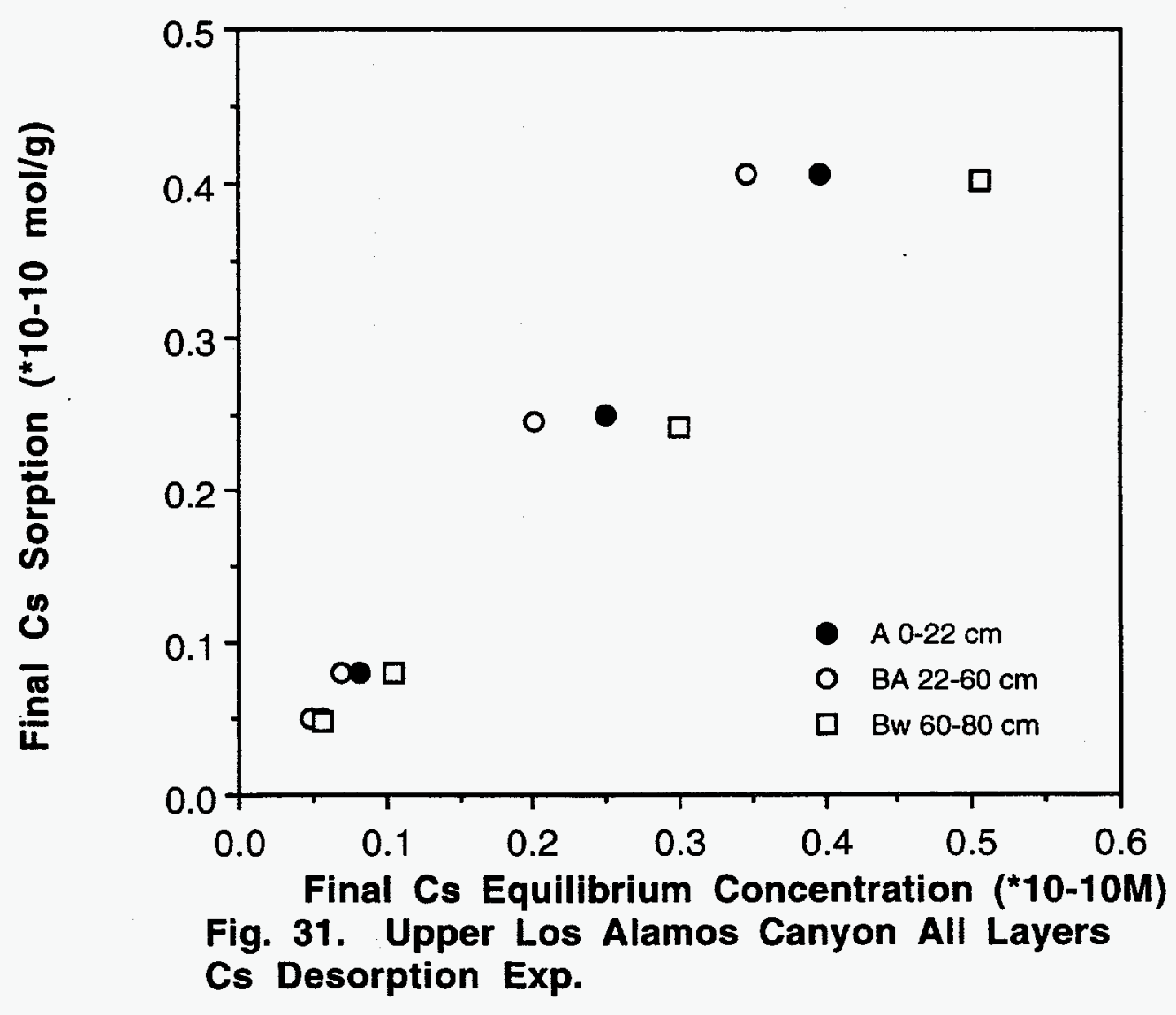


Desorption isotherm of Cs on valley A layer soil sample of Upper Los Alamos Canyon Site.

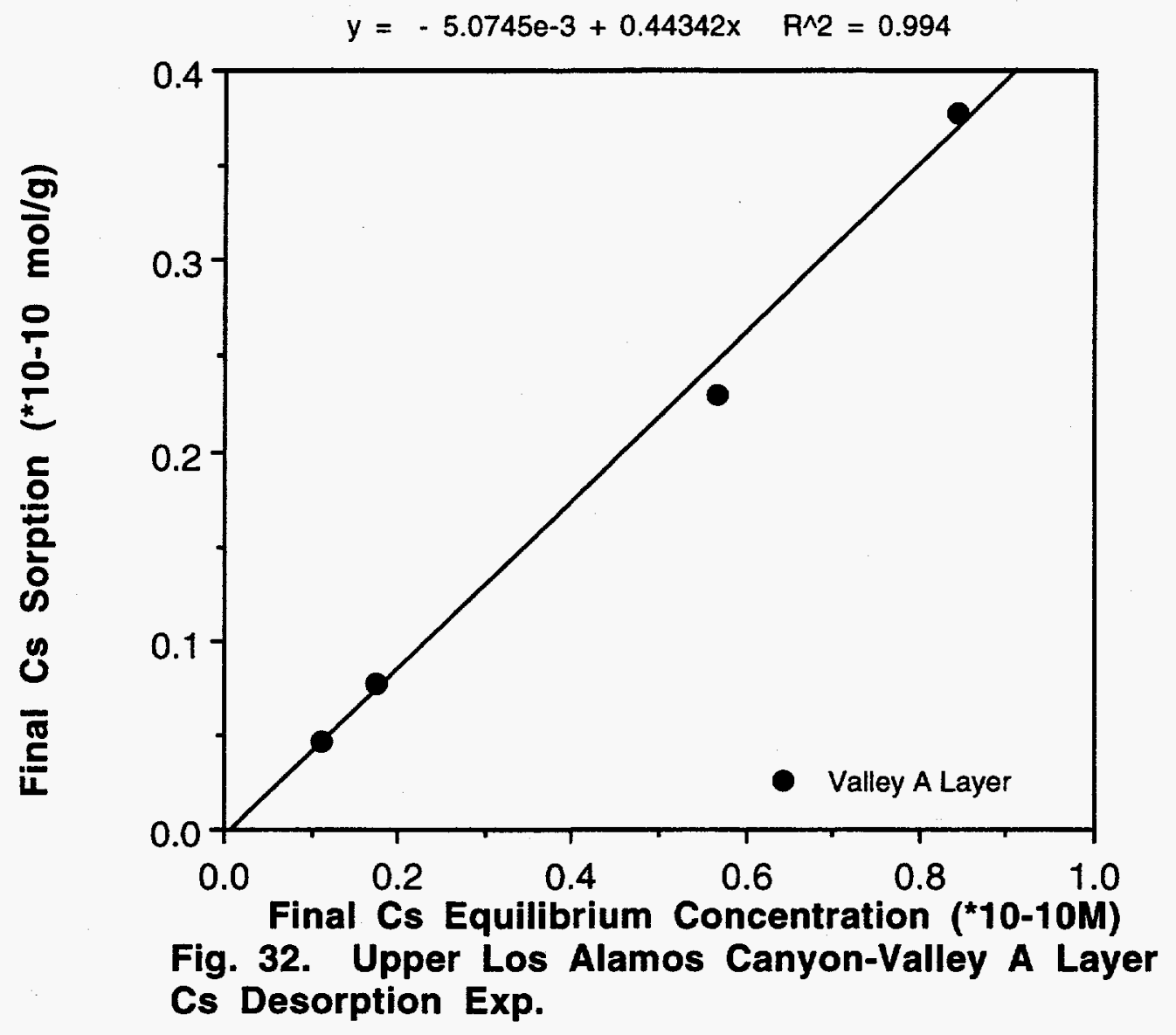


Desorption isotherm of Cs on valley colluvium soil sample of Upper Los Alamos Canyon Site.

$$
y=7.2413 e-3+0.66425 x \quad R^{\wedge} 2=1.000
$$

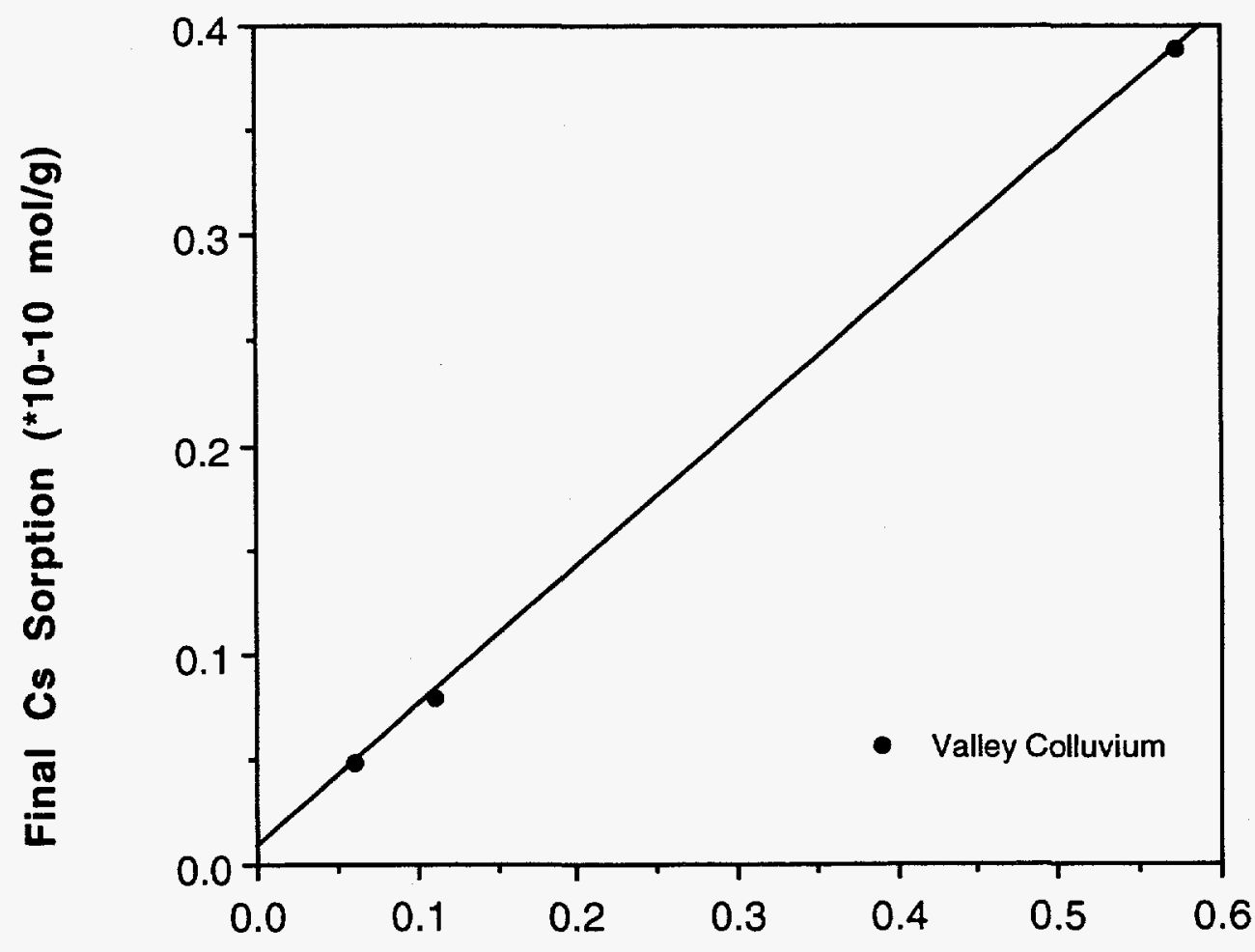

Final Cs Equilibrium Concentration ( $\left.{ }^{*} 10-10 \mathrm{M}\right)$ Fig. 33. Upper Los Alamos Canyon-Valley Colluvium Cs Desorption Exp. 
Desorption isotherm of Cs on valley buried soil sample of Upper Los Alamos Canyon Site.

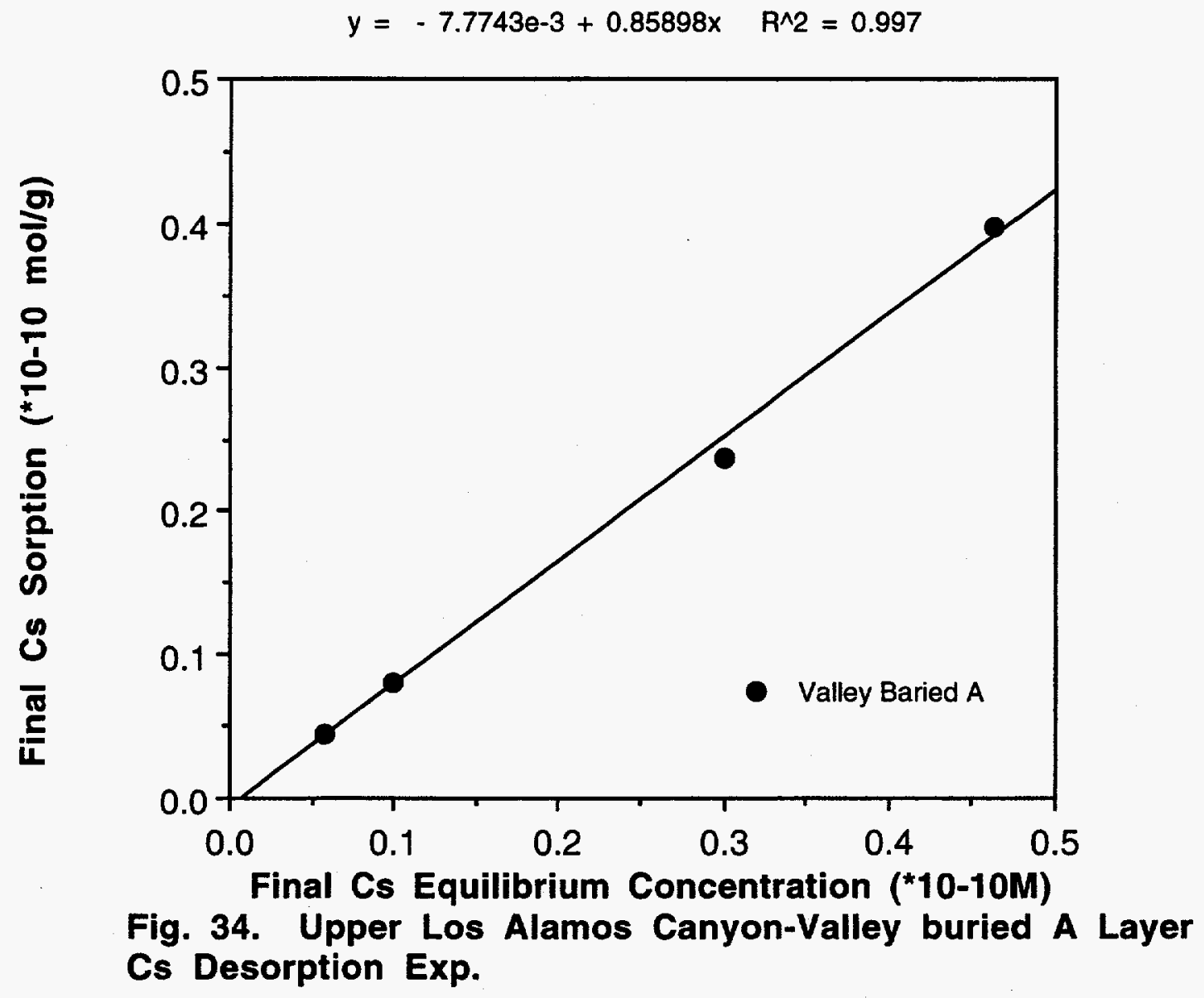


Desorption isotherm of Cs on valley whole soil sample of Upper Los Alamos Canyon Site.

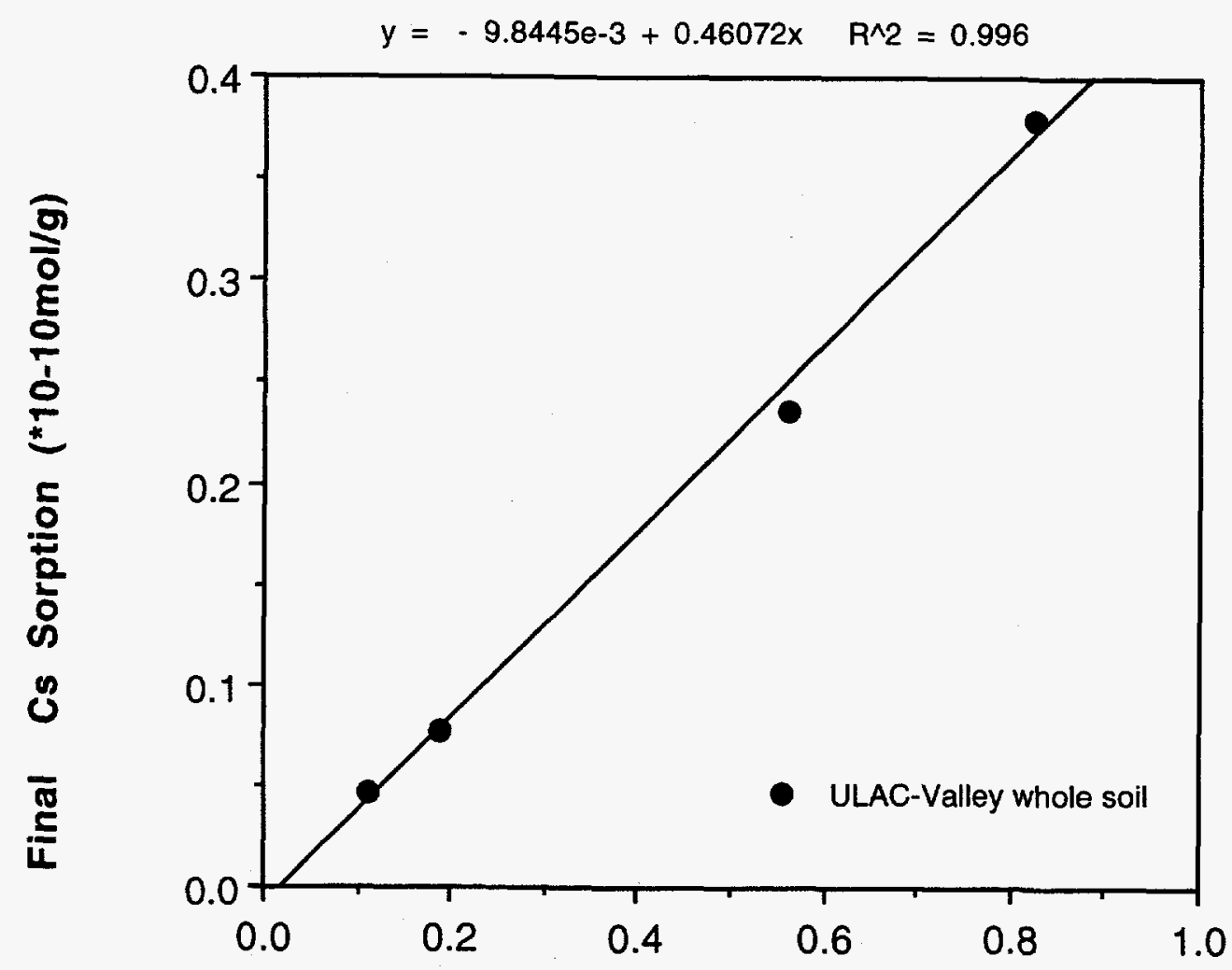

Final Cs Equilibrium Concentration ( $\left.{ }^{*} 10-10 \mathrm{M}\right)$ Fig. 35. Upper Los Alamos Canyon-Valley Whole Soil Cs Desorption Exp. 
Desorption isotherms of Cs on valley soil samples of Upper Los Alamos Canyon Site.

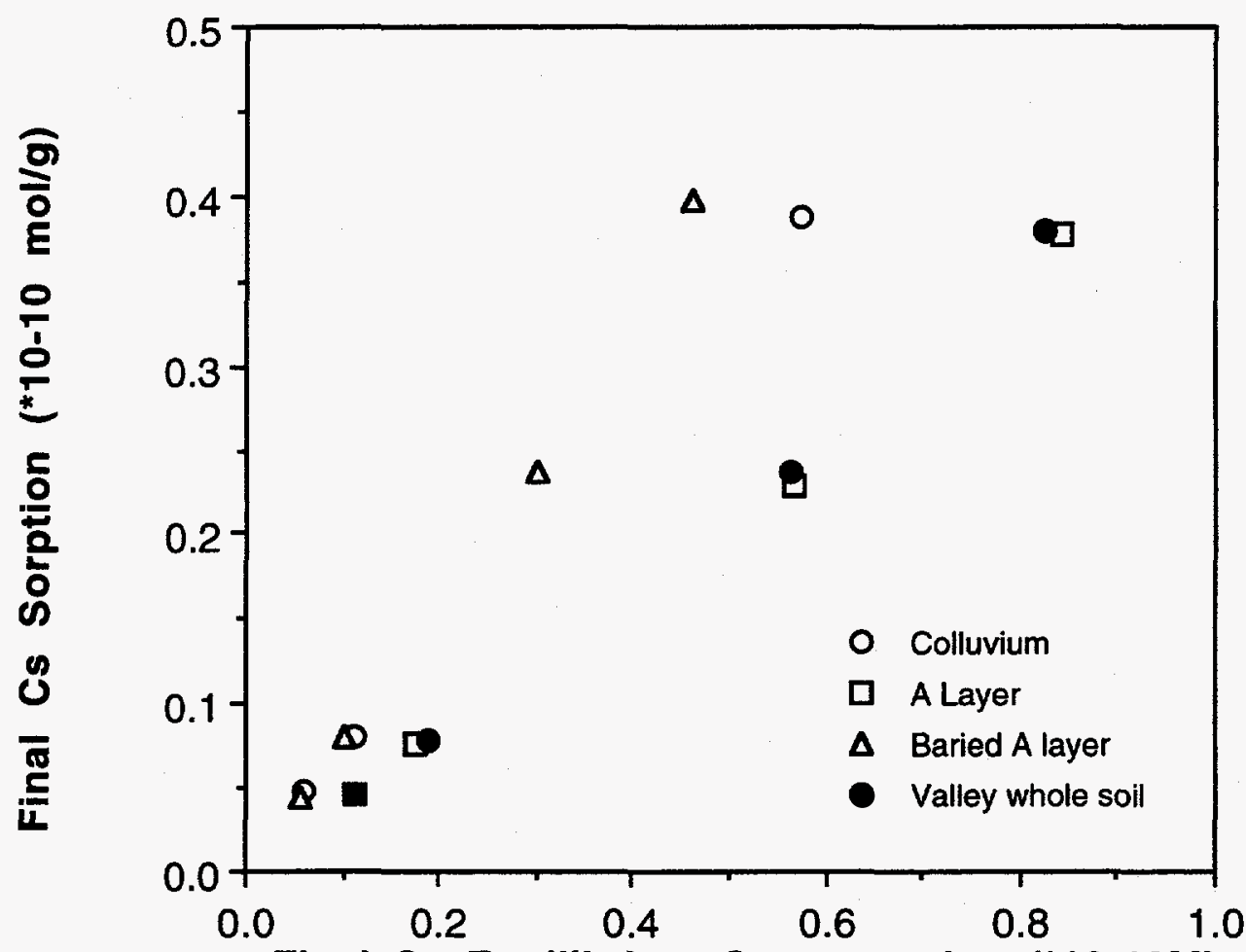

Final Cs Equilibrium Concentration ( ${ }^{*} 10-10 \mathrm{M}$ )

Fig. 36. Upper Los Alamos Canyon-Valley Soil Layers Cs Desorption Exp. 
Site.

Desorption isotherms of Cs on soil sample of Upper Los Alamos Canyon

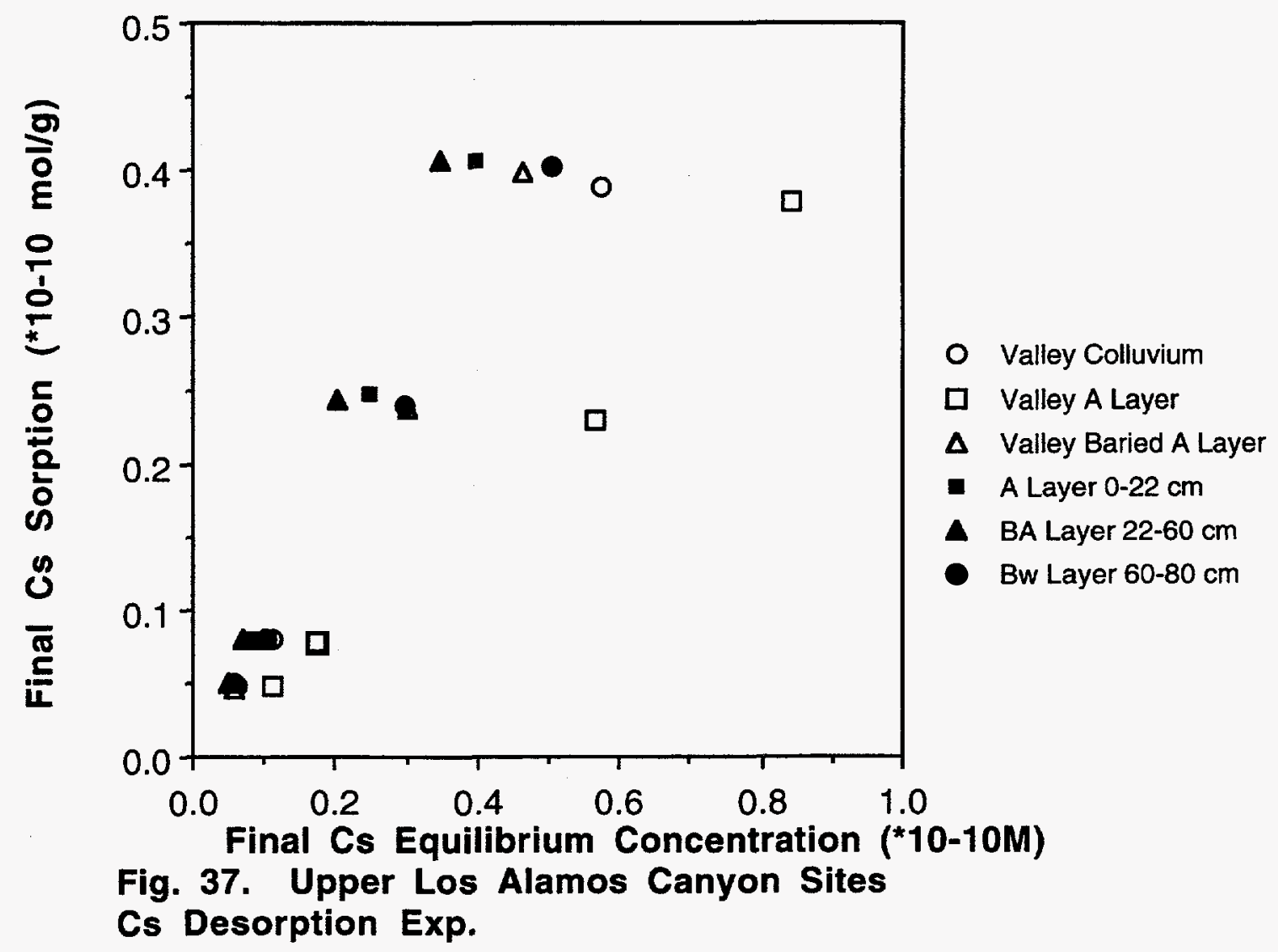


EGEG Site. Desorption isotherm of Cs on A layer soil sample of EG\&G Site.

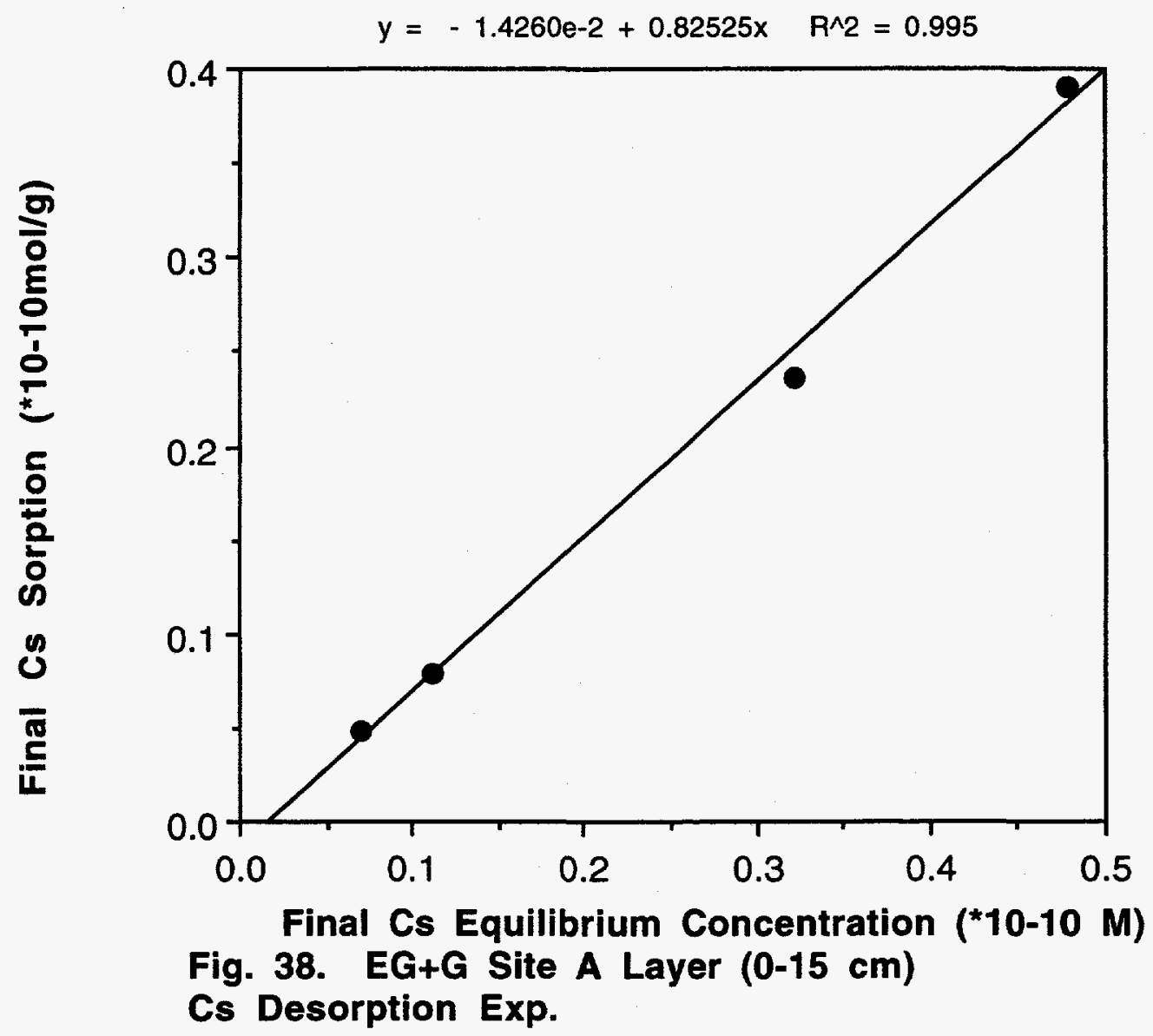


Desorption isotherm of Cs on Bt layer soil sample of EG\&G Site.

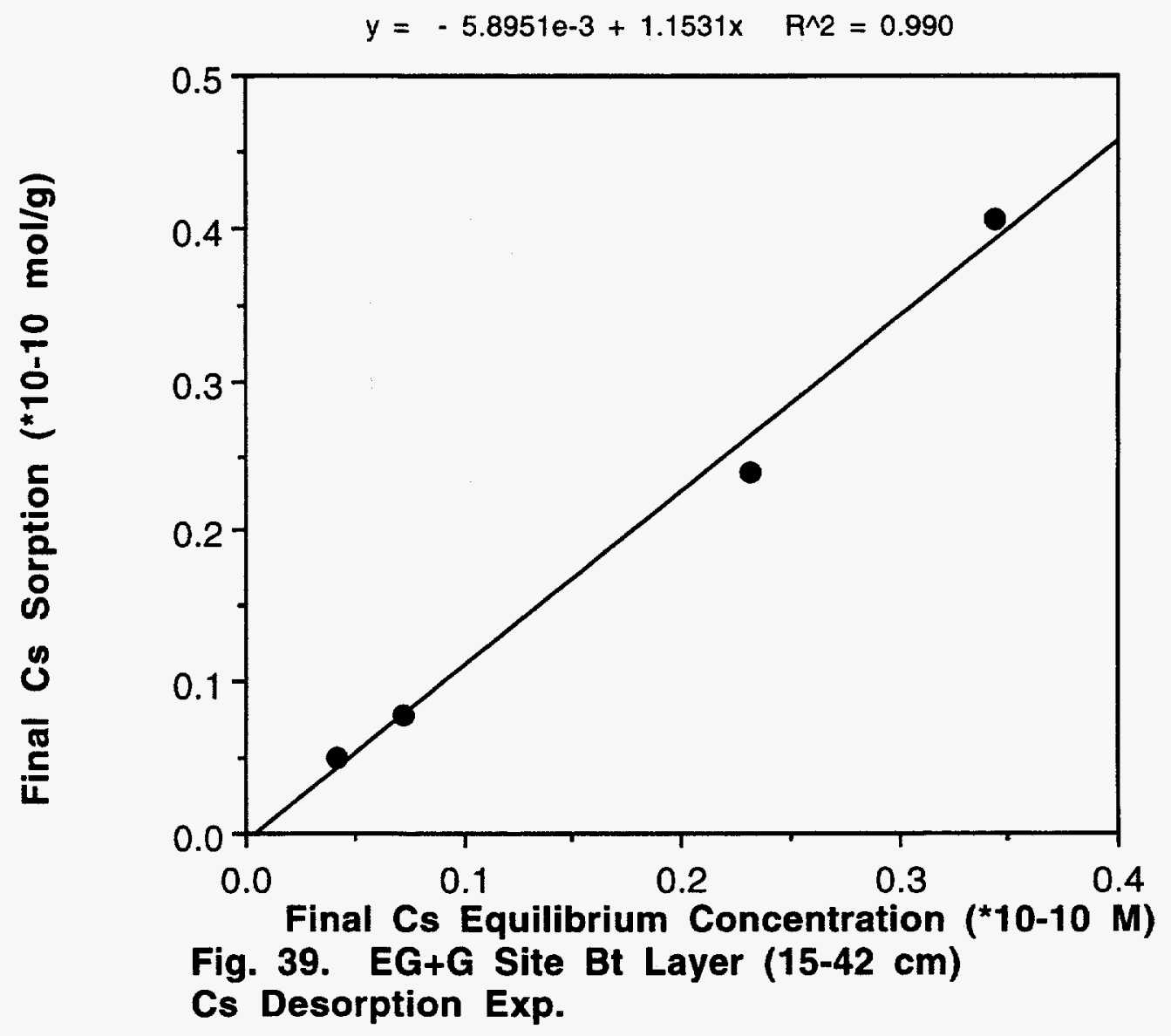


Desorption isotherm of Cs on Bw layer soil sample of EG\&G Site.

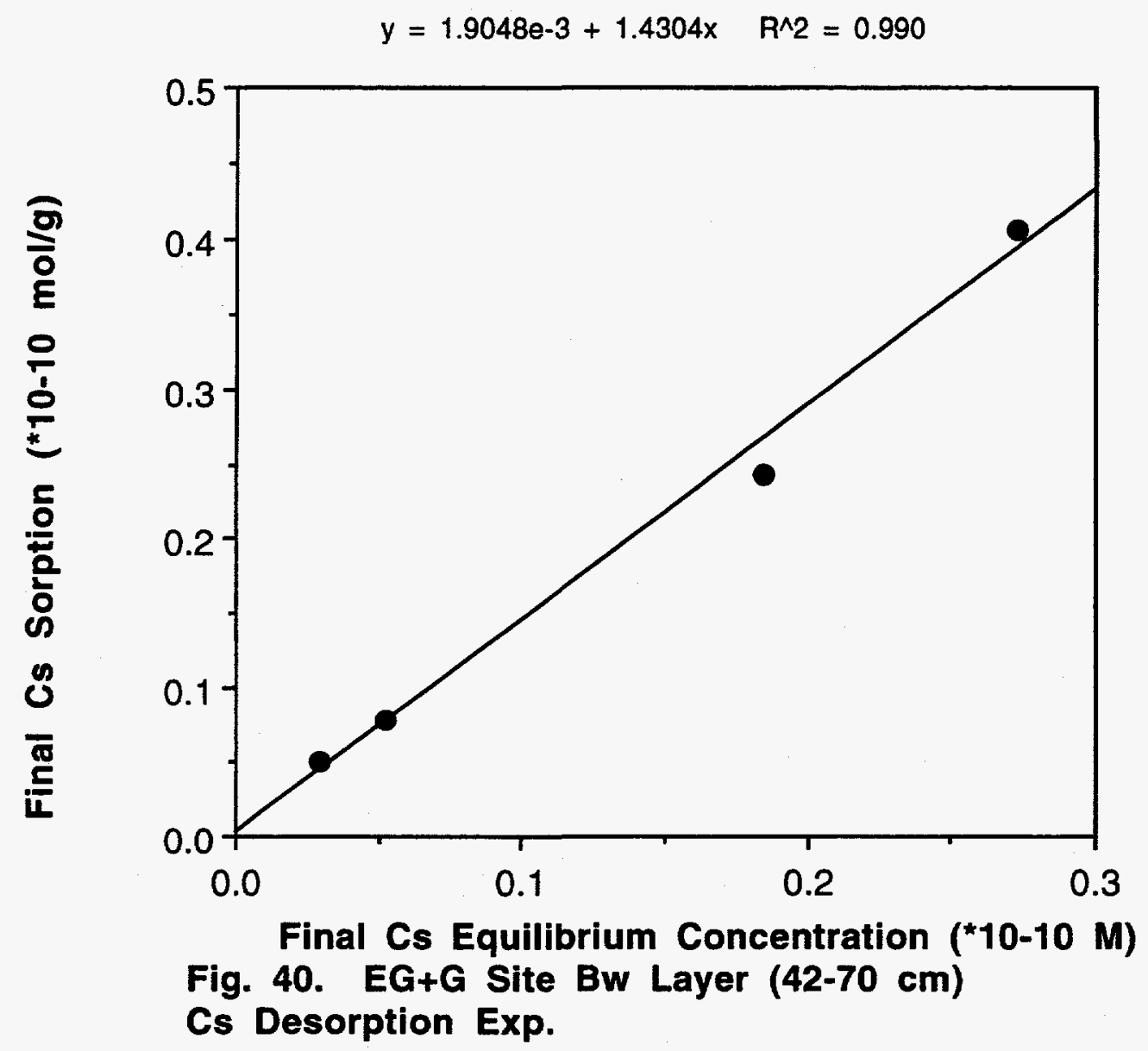


Desorption isotherm of Cs on CB layer soil sample of EG\&G Site.

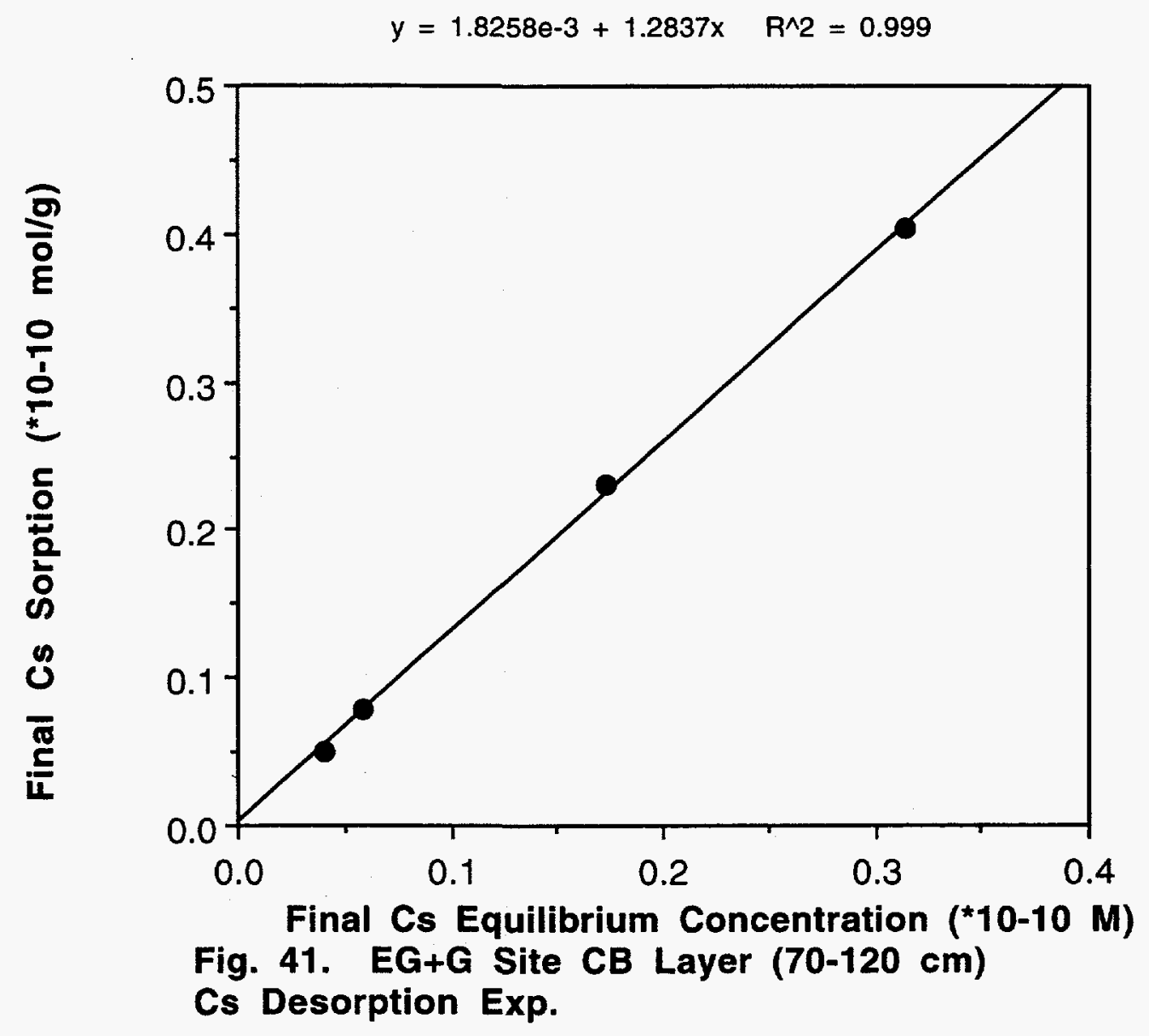


Desorption isotherm of Cs on Bwb layer soil sample of EG\&G Site.

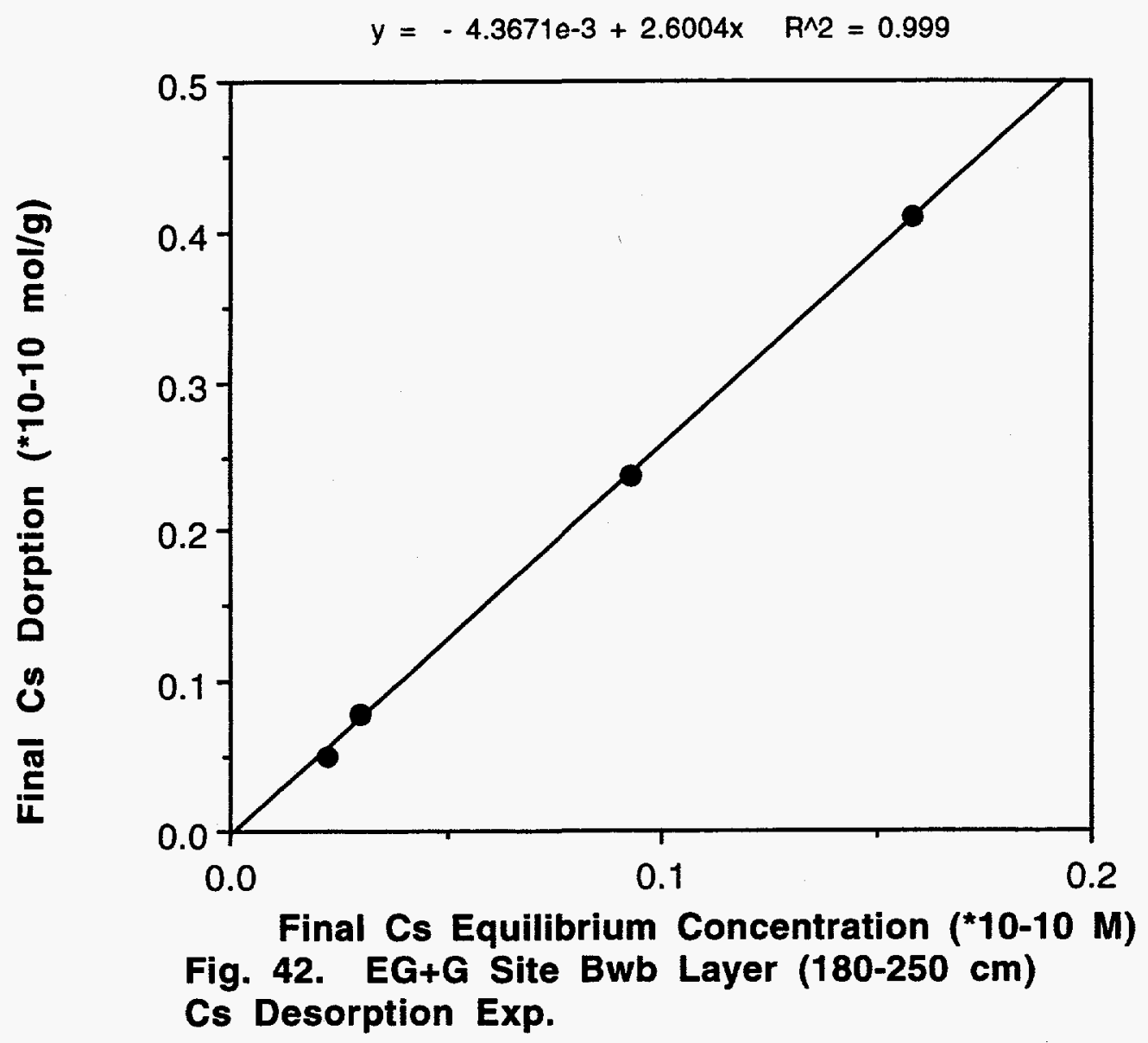


Desorption isotherm of Cs on soil samples of EG\&G Site.

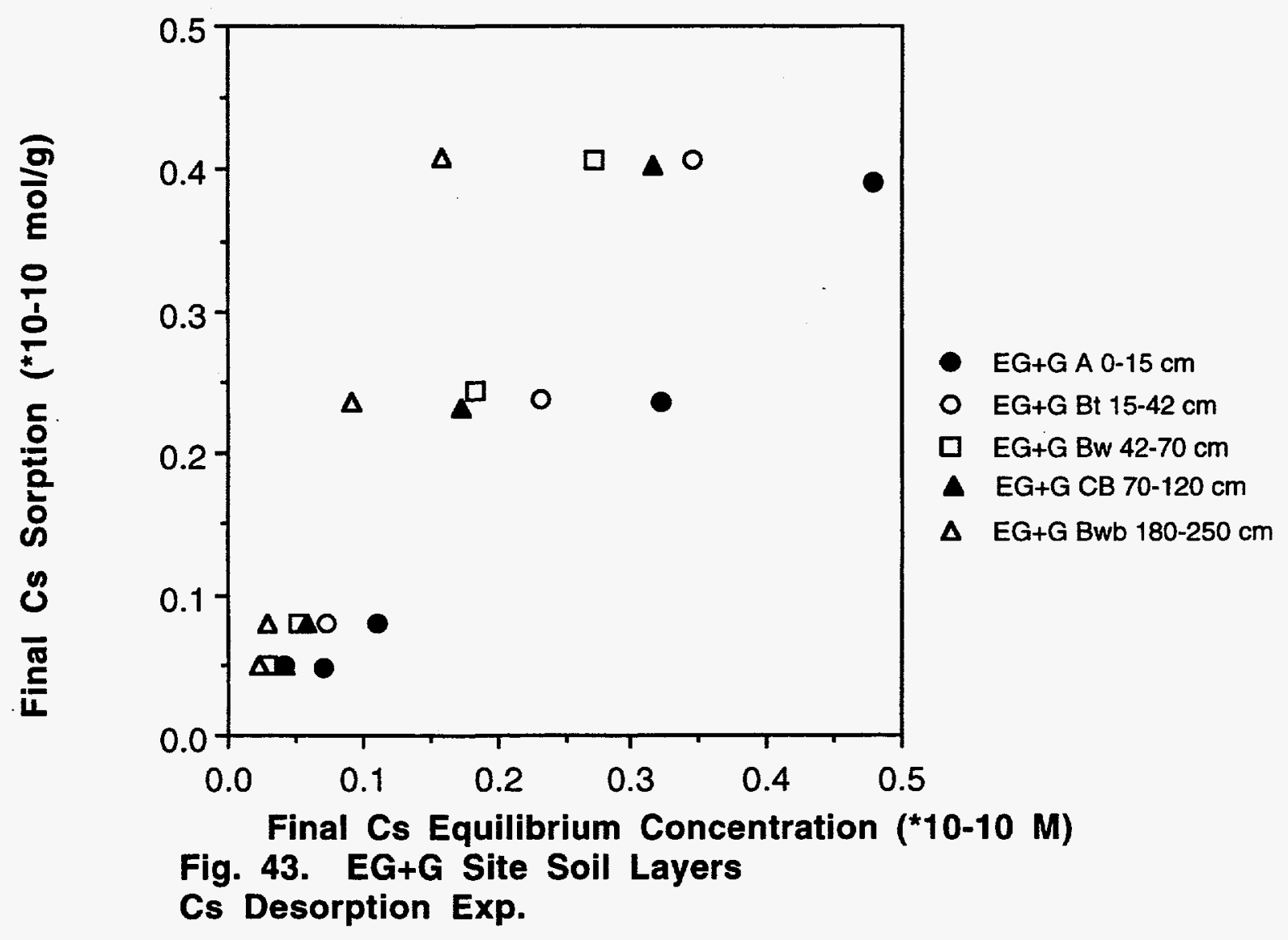


Lower Los Alamos Canyon Site. Desorption isotherm of Cs on A Layer soil sample of Lower Los Alamos Canyon Site.

$$
y=4.2205 e-3+0.32291 x \quad R^{\wedge} 2=1.000
$$

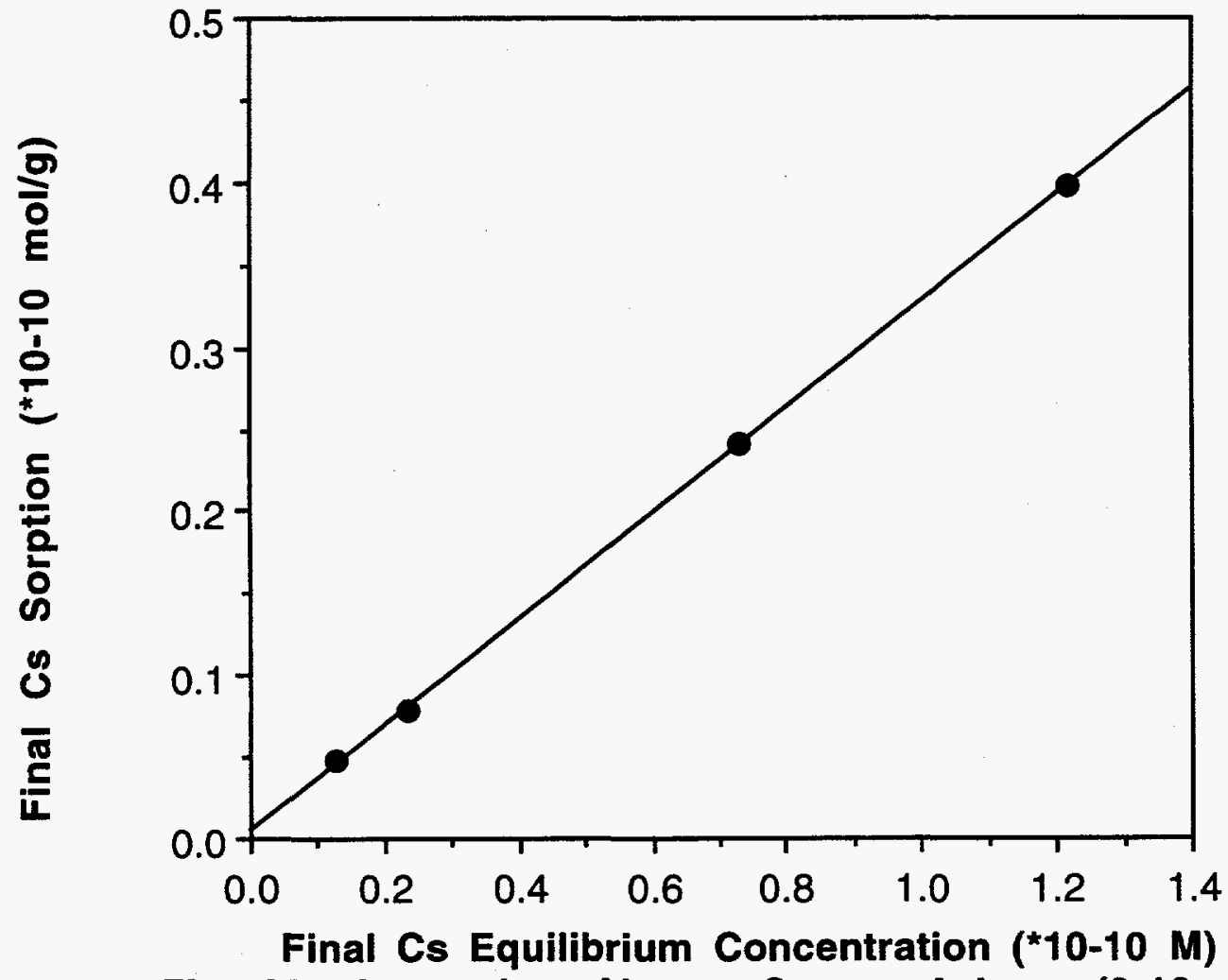

Fig. 44. Lower Los Alamos Canyon-A layer $(0-10 \mathrm{~cm})$ Cs Desorption Exp. 
Desorption isotherm of Cs on C Layer soil sample of Lower Los Alamos Canyon Site.

$$
y=2.4045 e-2+0.26105 x \quad R^{\wedge} 2=0.996
$$

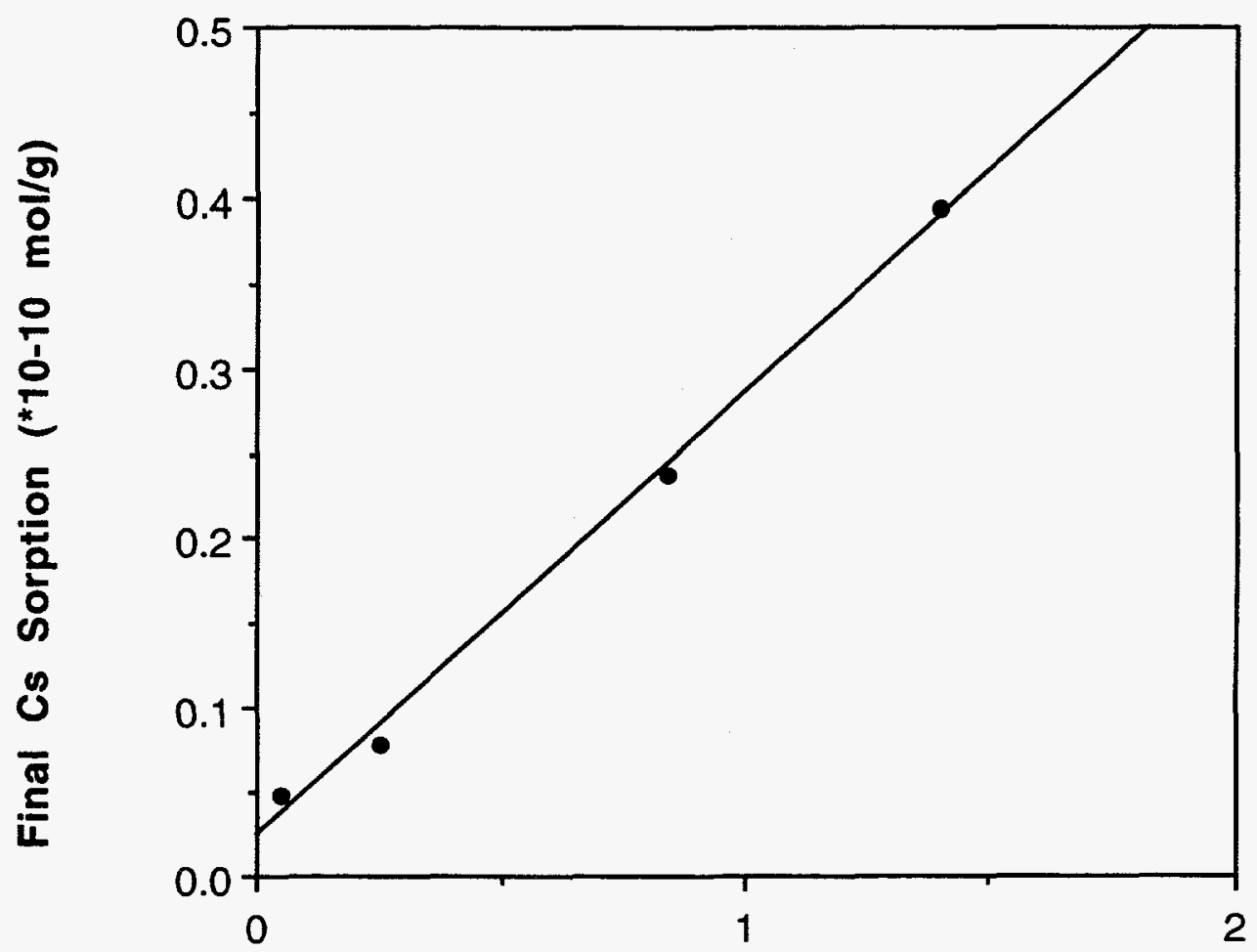

Final Cs Equilibrium Concentration ( $* 10-10 \mathrm{M}$ )

Fig. 45. Lower Los Alamos Canyon-C layer $(10-25 \mathrm{~cm})$ Cs Desorption Exp. 
Desorption isotherm of Cs on whole soil sample of Lower Los Alamos Canyon Soil.

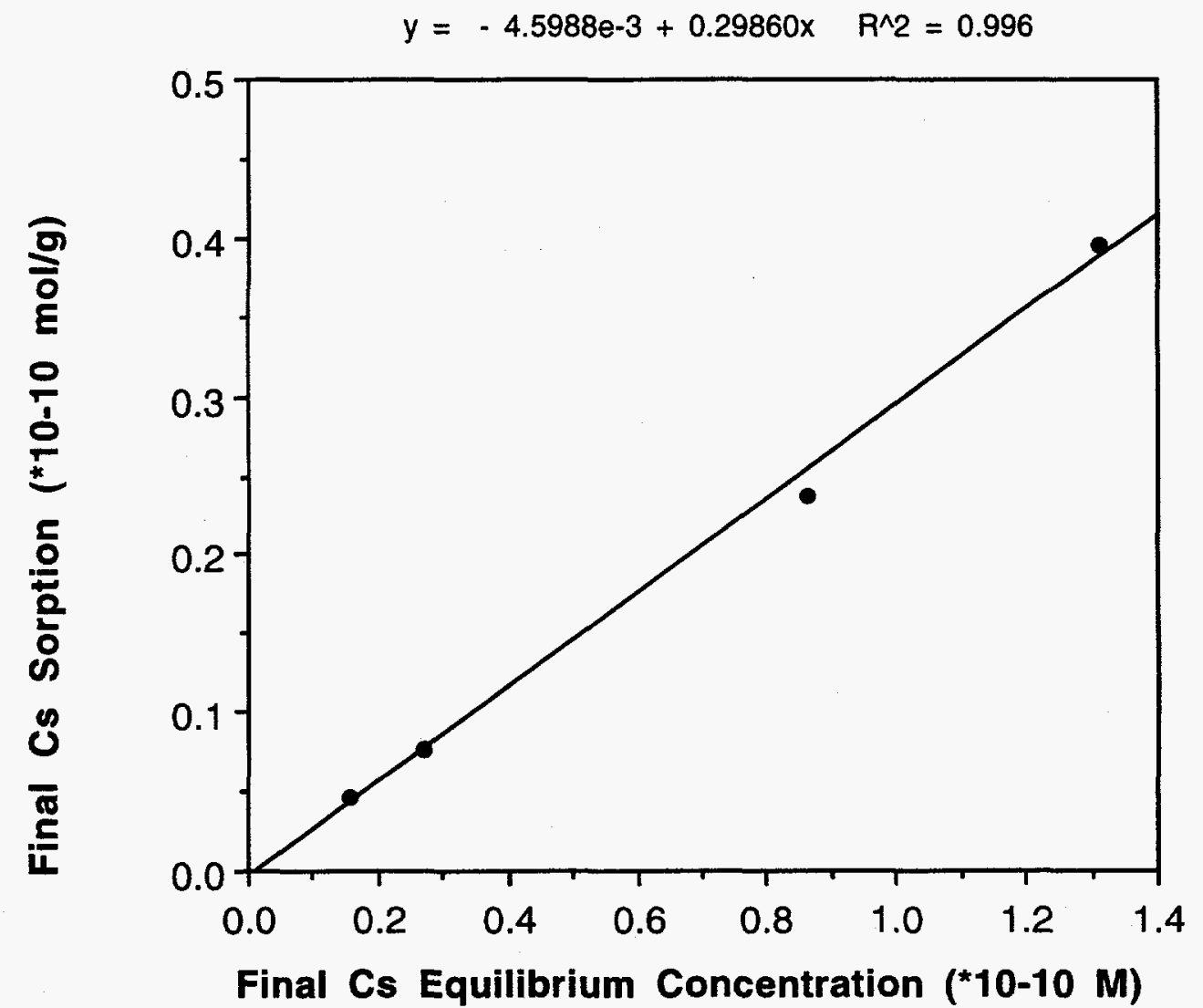

Fig. 46. Lower Los Alamos Canyon-whole soil $(0-30 \mathrm{~cm})$ Cs Desorption Exp. 
Desorption isotherm of Cs on stream washout sample of Lower Los Alamos Canyon Soil.

$$
y=7.3513 e-3+0.15299 x \quad R^{\wedge 2}=1.000
$$

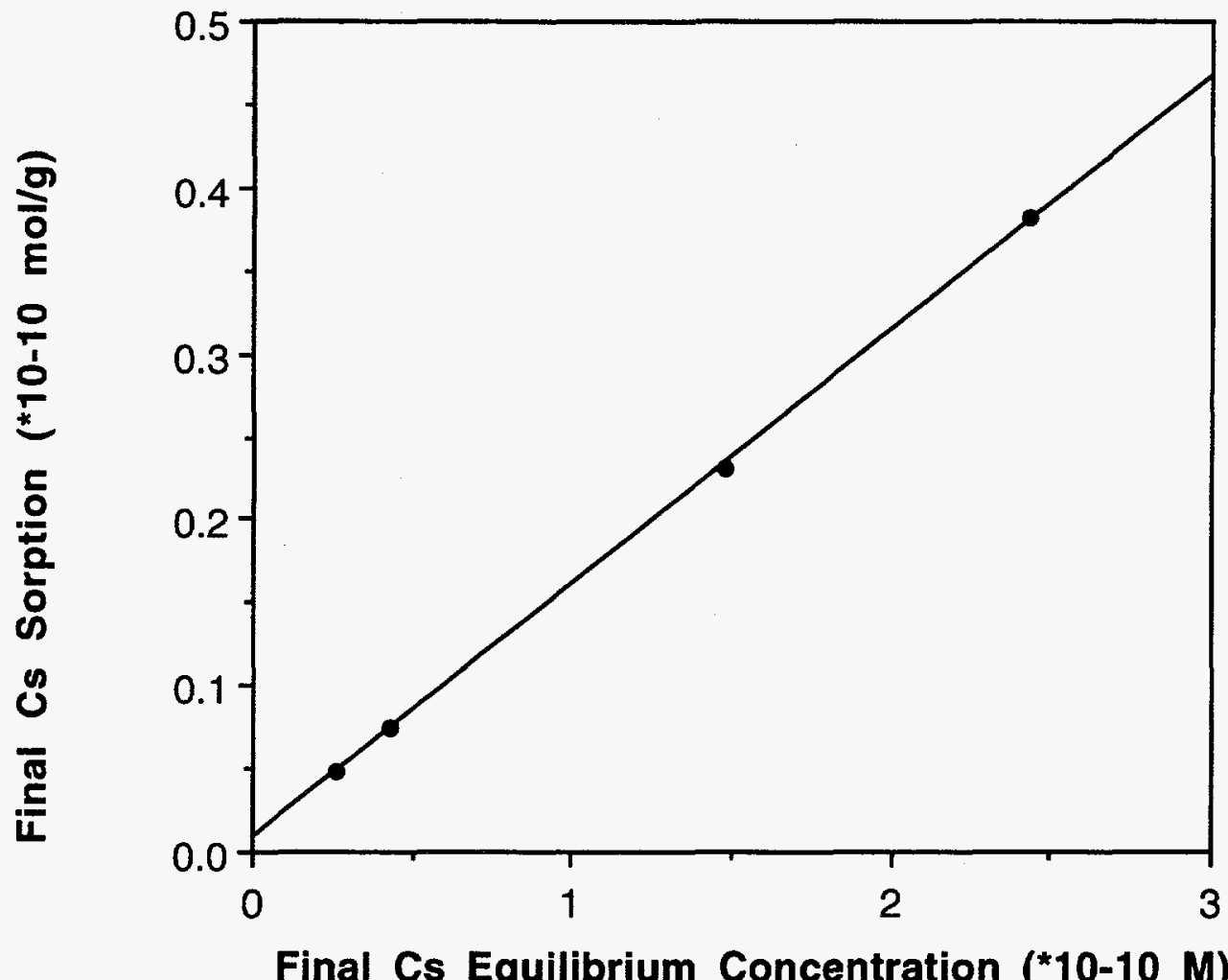

Fig. 47. Lower Los Alamos Canyon-Stream Washout Cs Desorption Exp. 
Desorption isotherms of Cs on Lower Los Alamos Canyon Soil. The highest desorption of Cs was found in stream washout sample.

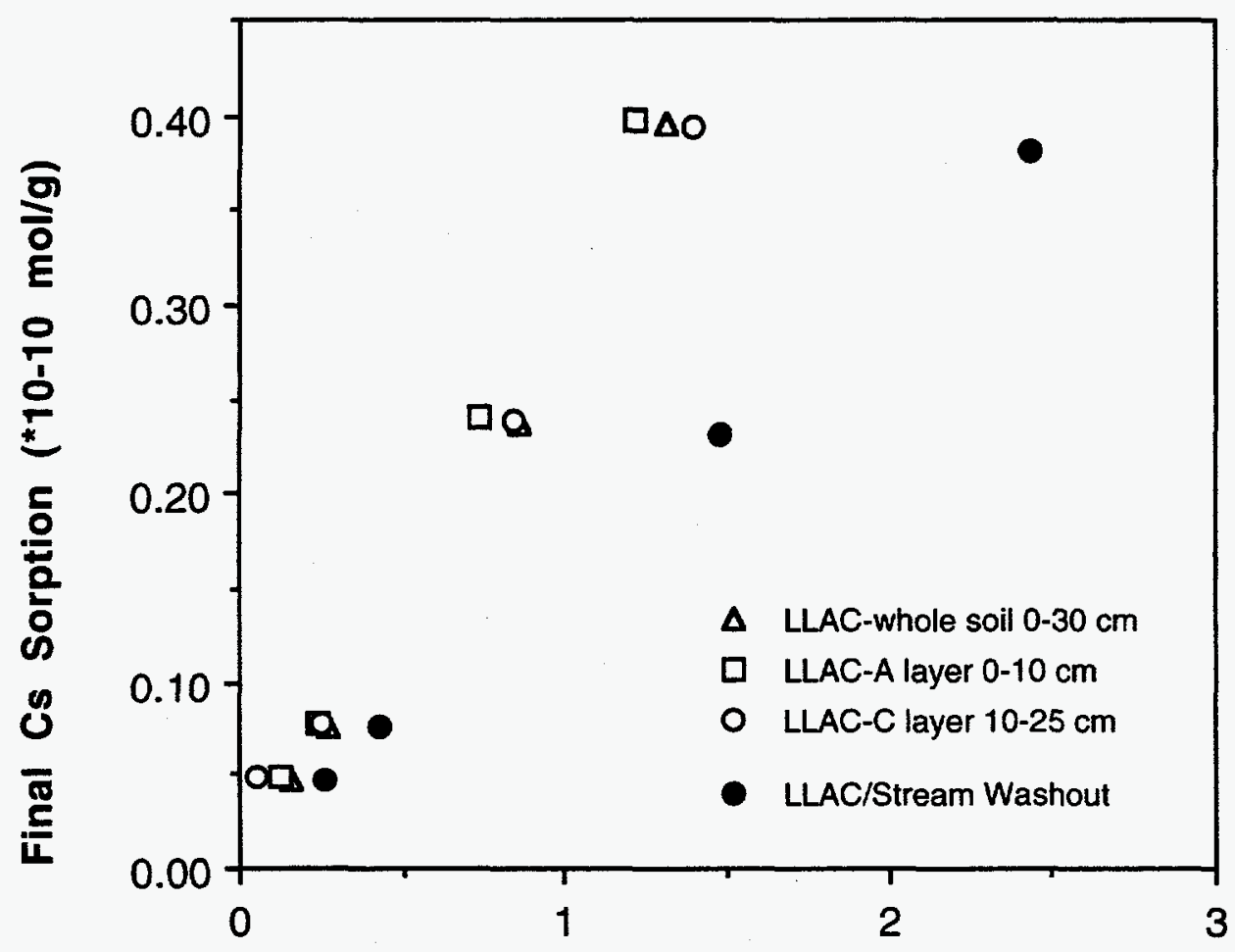

Final Cs Equilibrium Concentration ( ${ }^{*} 10-10 \mathrm{M}$ ) Fig. 48. Lower Los Alamos Canyon-Site Soil Layers Cs Desorption Exp. 
Ancho Canyon Site. Desorption isotherm of Cs on A layer of Ancho Soil.

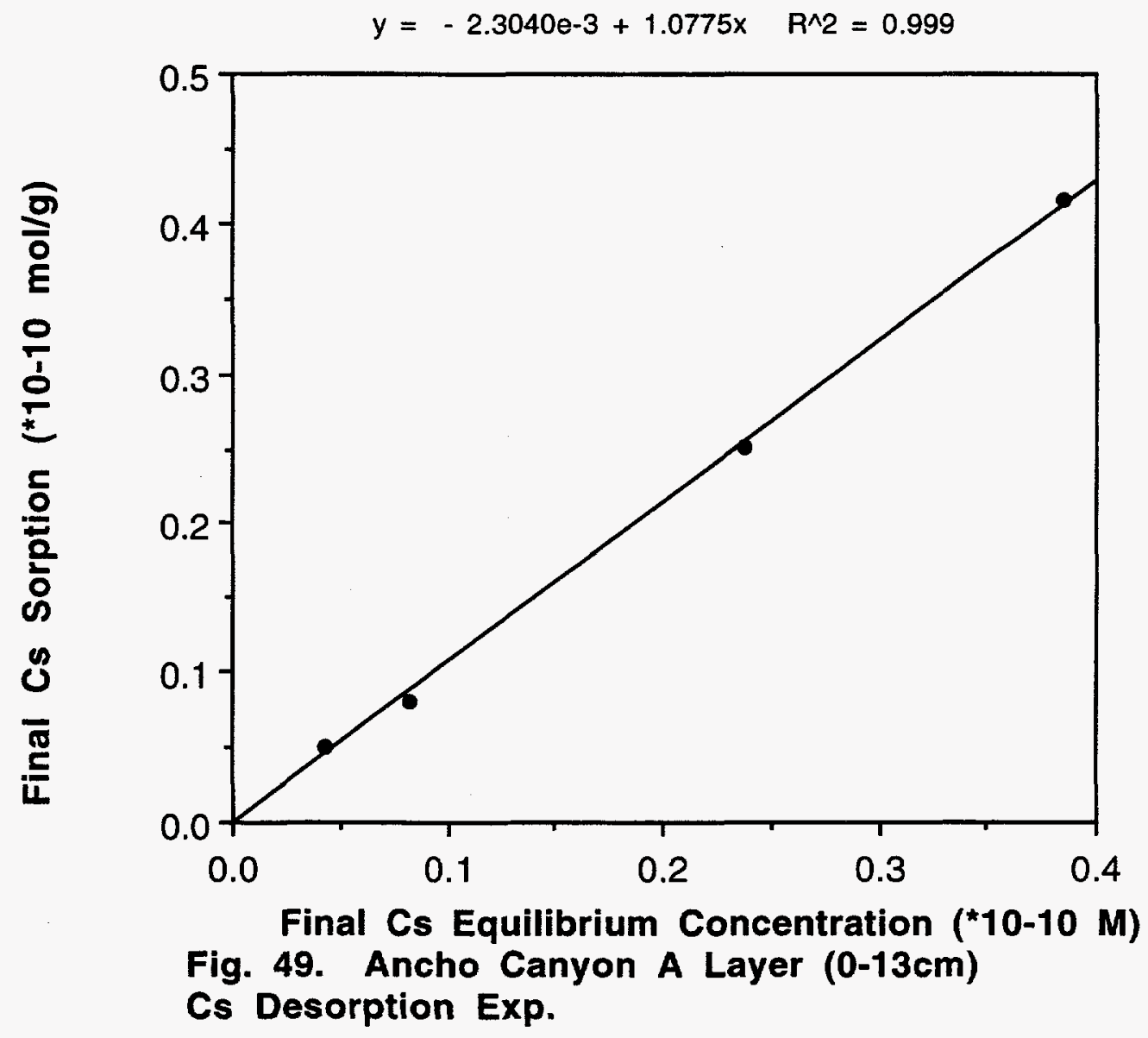


Desorption isotherm of Cs on Bt layer of Ancho Soil.

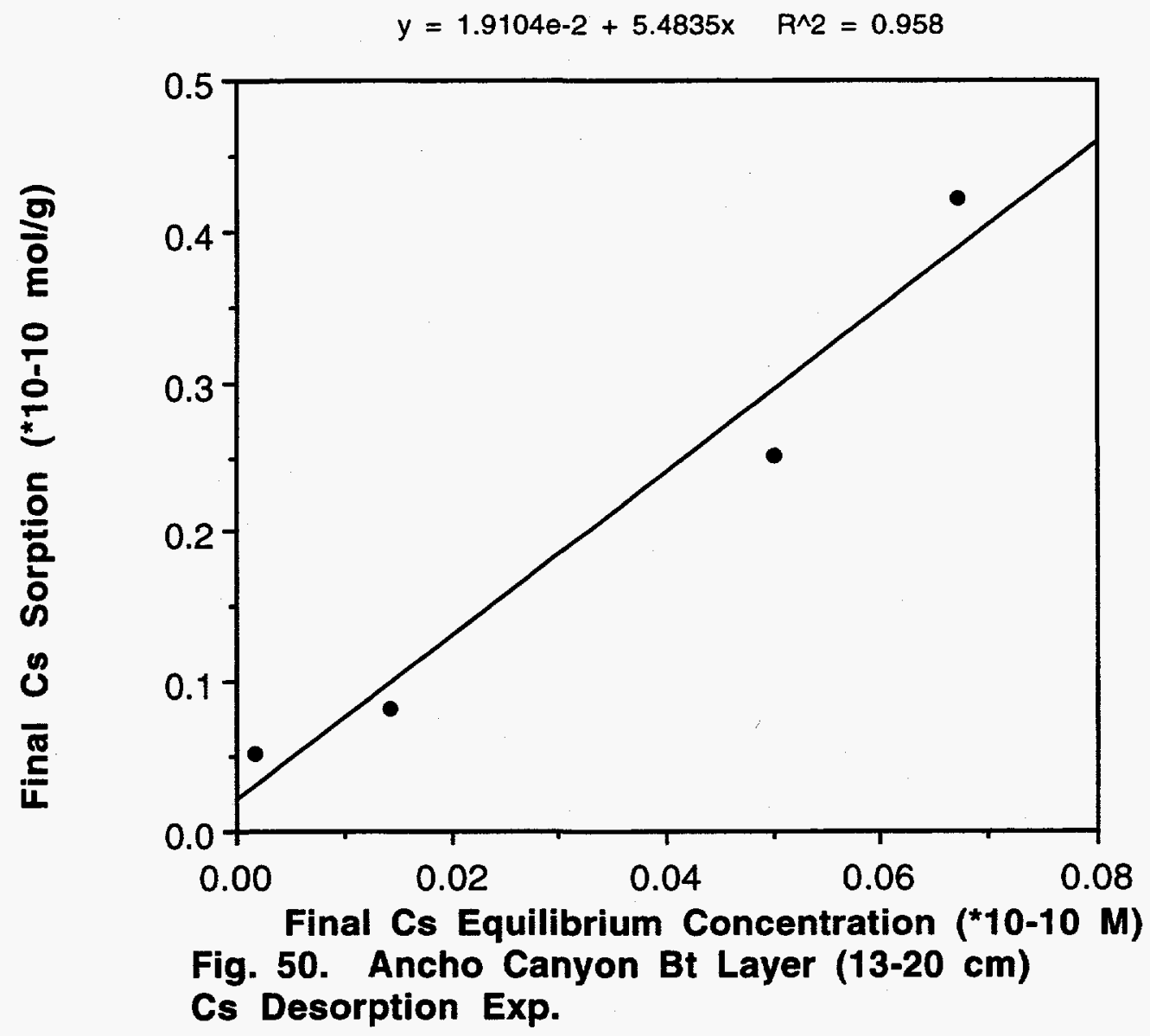


Desorption isotherm of Cs on Bwkb layer of Ancho Soil.

$$
y=3.1110 e-3+4.4012 x \quad R^{\wedge} 2=1.000
$$

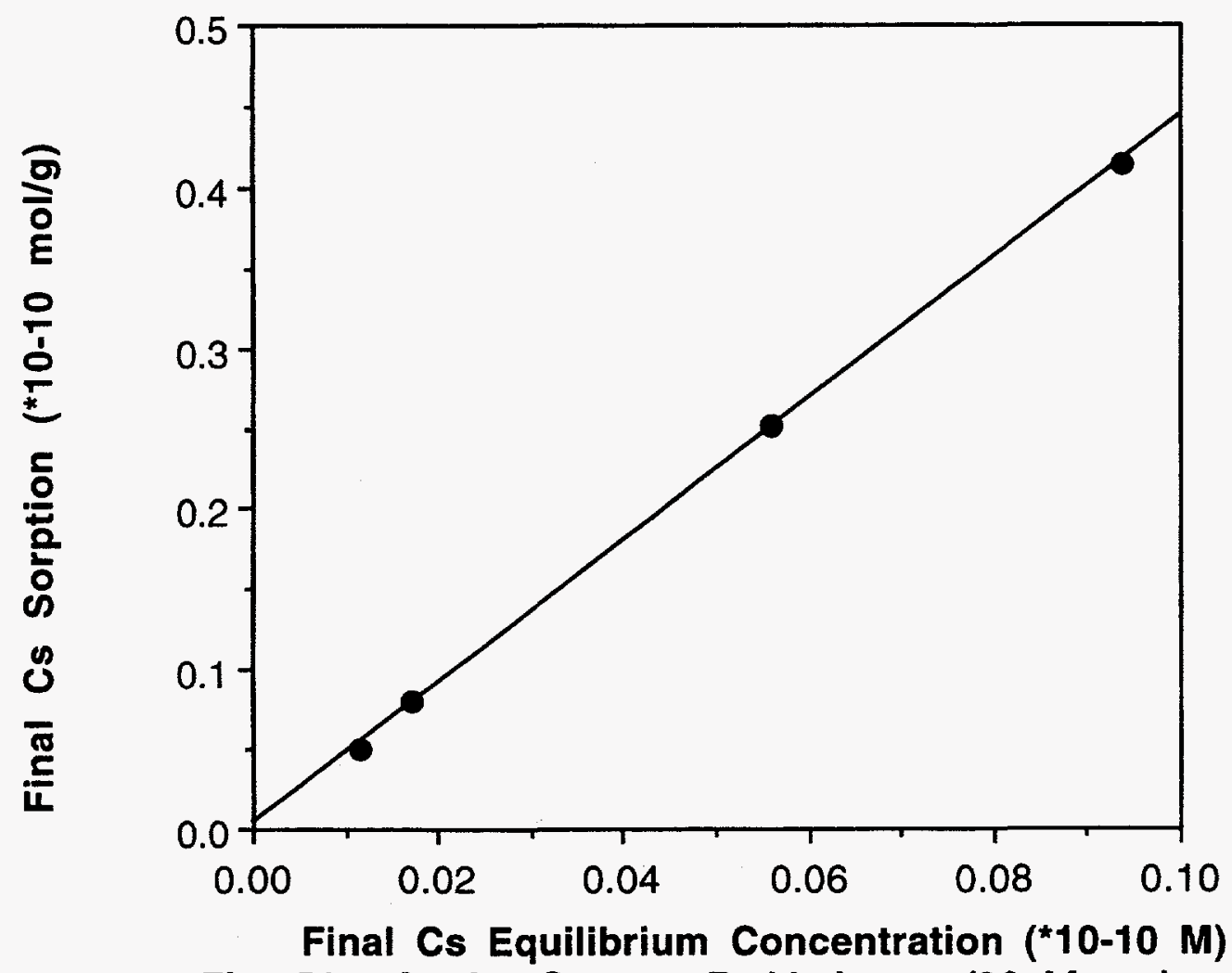

Fig. 51. Ancho Canyon Bwkb Layer $(20-44 \mathrm{~cm})$ Cs Desorption Exp. 
Desorption isotherm of Cs on Btkb layer of Ancho Soil.

$$
y=-4.0696 e-3+7.3557 x \quad R^{\wedge} 2=0.999
$$

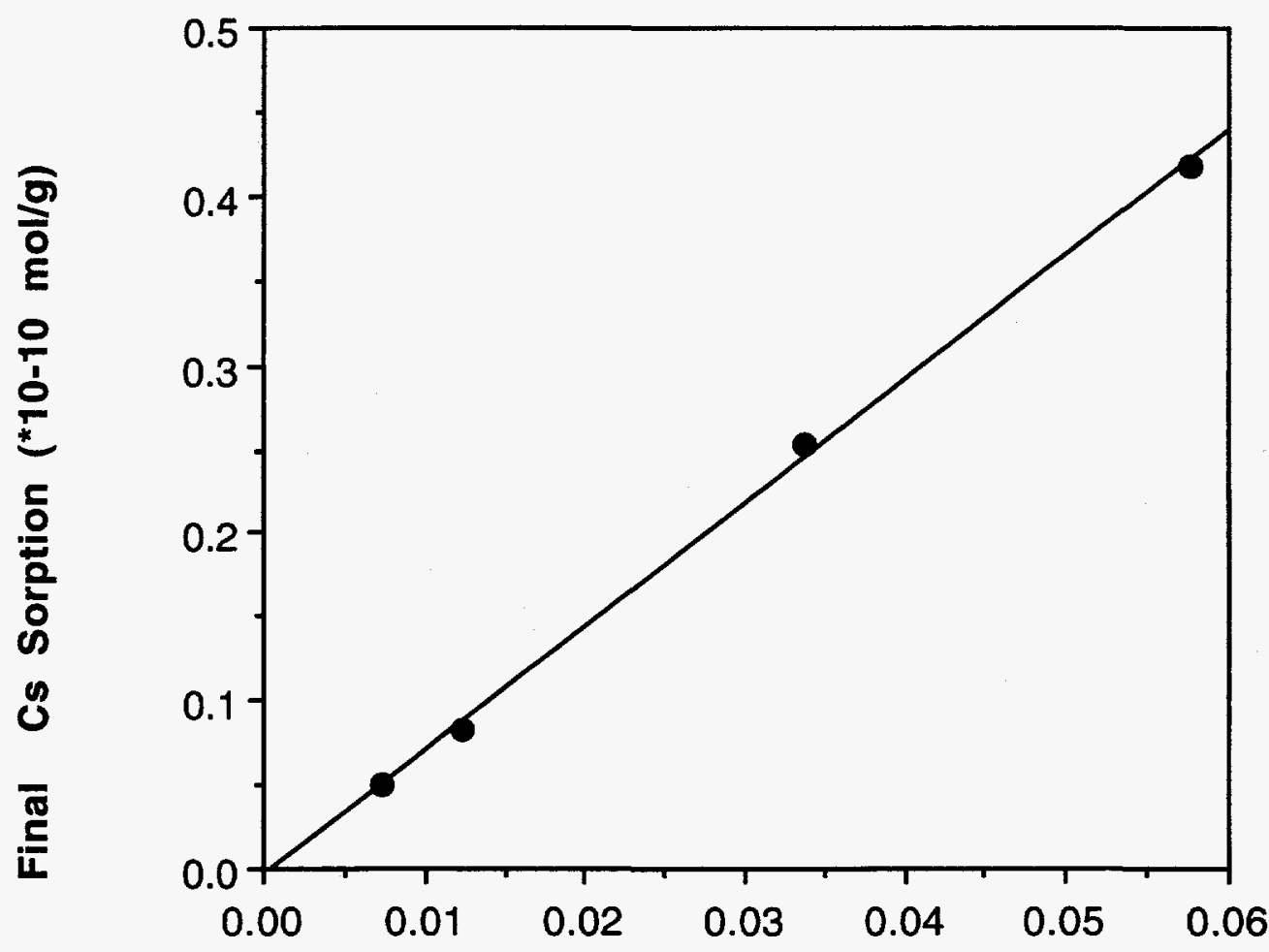

Final Cs Equilibrium Concentration ( ${ }^{*} 10-10 \mathrm{M}$ )

Fig. 52. Ancho Canyon Btkb Layer $(44-54 \mathrm{~cm})$

Cs Desorption Exp. 
Desorption isotherm of Cs on whole soil of Ancho site.

$$
y=-4.4710 e-2+3.3068 x \quad R^{\wedge} 2=0.999
$$

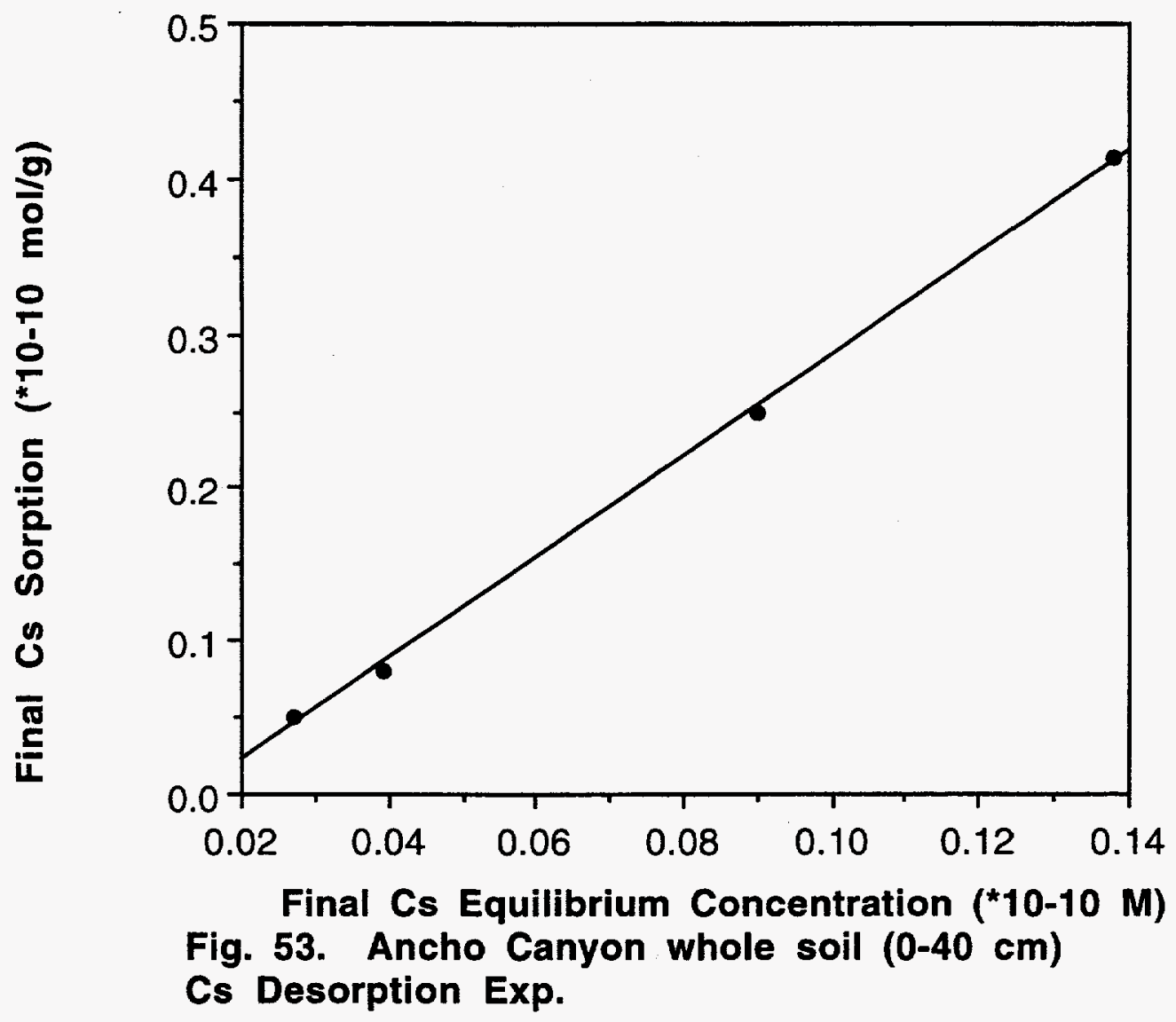


Desorption isotherms of Cs on Ancho Soil. Similar amount of Cs desorbed from $\mathrm{Bt}, \mathrm{Bwkb}$ and $\mathrm{Btkb}$ layers. The amount of $\mathrm{Cs}$ desorption is higher in $\mathrm{A}$ layer than all other layers.

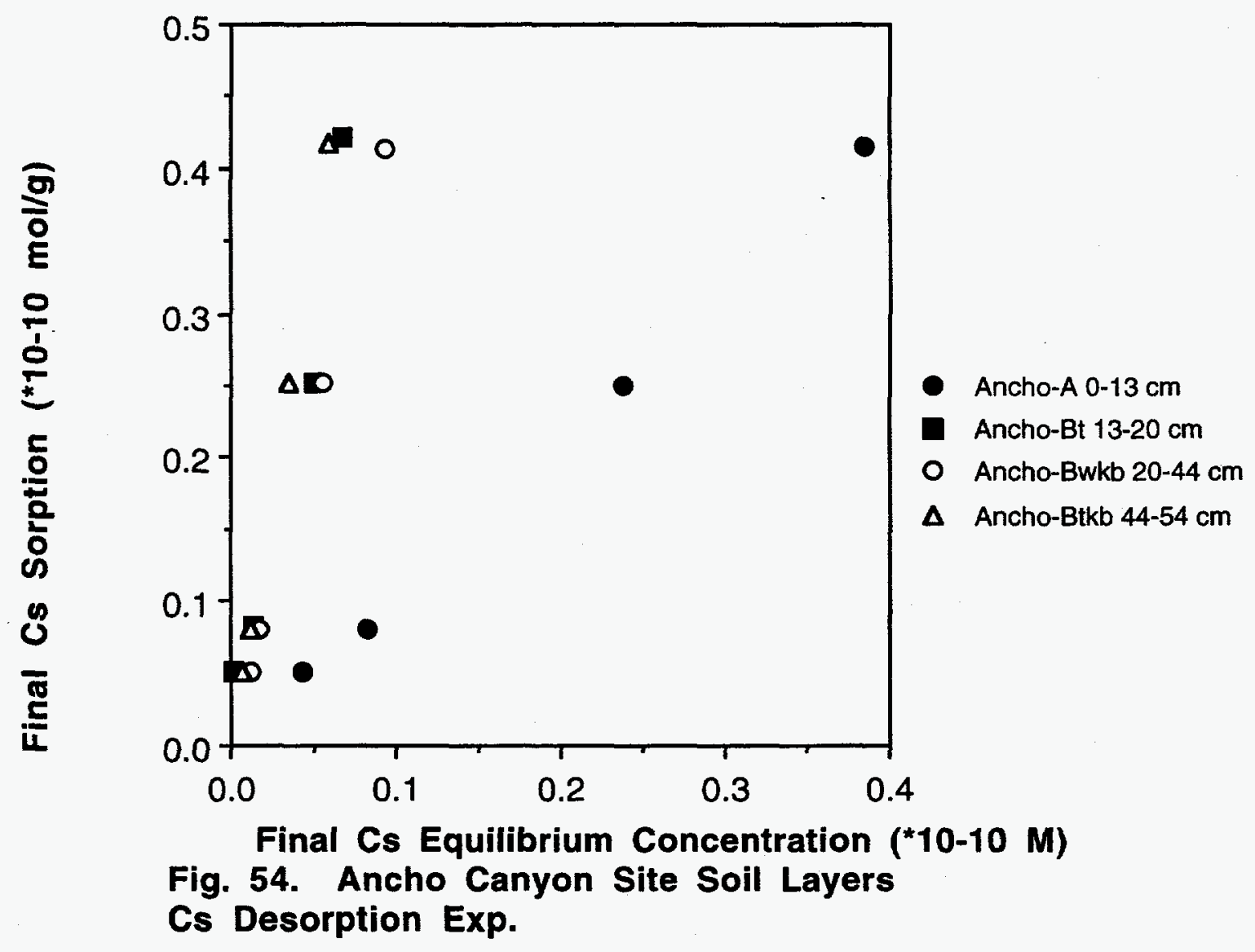




\section{REFERENCES}

Longmire, P., C. Duffy, and S. Reneau. "Preliminary Background Elemental Concentrations in Bandelier Tuff and Selected Soil Series." LA-ER-0958, Los Alamos National Laboratory, 1993.

Longmire, P., Reneau, S., Watt, P., Gardner, J., and C. Duffy. "Geomorphology, Pedogenesis, and Geochemistry of Background Tuff and Selected Soil Profiles" in preparation. Los Alamos National Laboratory.

\section{ACKNOWLEDGMENT}

Funding for this work was provided by Operable Unit 1098 (TA-2/TA-41), Environmental Restoration Program, Los Alamos National Laboratory. The authors would like to thank Jerry Boak and Allyn Pratt for their support of this study. 